\title{
Redução de dimensionalidade em series temporais
}

\author{
Andre Rodrigo Sanches \\ DISSERTAÇÃO APRESENTADA \\ $\mathrm{AO}$ \\ INSTITUTO DE MATEMÁTICA E ESTATÍSTICA \\ DA \\ UNIVERSIDADE DE SÃO PAULO \\ PARA OBTENÇÃO DO GRAU DE MESTRE \\ EM \\ CIÊNCIA DA COMPUTAÇÃO \\ Área de Concentração : Ciência da Computação \\ Orientadora: Profa. Dra. Nina S. T. Hirata
}

- São Paulo, Agosto de 2006 - 


\section{Resumo}

O armazenamento de dados sequenciais (como as séries temporais, por exemplo) em bases de dados trouxe à tona a necessidade de desenvolvimento de técnicas eficientes de indexação e busca e também de técnicas eficazes de mineração de dados.

Devido ao tamanho das seqüencias, as séries temporais são em geral reduzidas em tamanho, principalmente para indexação e busca. Para a redução do tamanho das séries são utilizados diferentes algoritmos de redução de dimensionalidade.

Os efeitos de diferentes tipos de redução são bastante investigados na literatura da área com respeito aos aspectos quantitativos tais como tempo de processamento, quantidade de memória requerida e número de acesso a páginas do disco. No entanto, não se observam muitos estudos que avaliam os efeitos sob o ponto de vista qualitativo.

Neste trabalho propomos a uso de critérios objetivos para avaliar de que forma os resultados de atividades tais como busca por similaridade e cálculo de aglomerados (clustering) são afetados do ponto de vista qualitativo pelos diferentes algoritmos de redução de dimensionalidade.

Foram implementados quatro algoritmos de redução de dimensionalidade na plataforma R. Em busca por similaridade foi avaliado o desempenho dos algoritmos na categoria de buscas conhecida por "vizinhos mais próximos" e em aglomeração foram utilizados dois algoritmos de aglomeração. As avaliaçōes foram realizadas em conjuntos de dados provenientes de uma central de atendimento. 


\section{Agradecimentos}

Agradeço a Deus, a meus pais Valdir e Neuza, a minha namorada Vivianne e a minha irmã Simone pelo grande apoio, compreensão, amor e carinho que ofereceram durante esta jornada. Também contei com a compreensão de minhas duas sobrinhas Laura e Letícia, tios e avós, que não tiveram um familiar tão presente em alguns momentos.

Sou eternamente grato aos professores Nina Hirata e João Eduardo Ferreira (IMEUSP) pela dedicação empenhada e pela compreensão de algumas dificuldades pessoais e profissionais que enfrentei, bem como o conhecimento que eles me passaram ao longo do mestrado.

Obrigado à Direct Talk Comércio de Tecnologia LTDA (www.directtalk.com.br) pelo tempo e recursos computacionais cedidos bem como apoio a este trabalho. Um grande abraço ao diretor Alexandre Bernardoni (alexandre@directtalk.com.br), ao coordenador Charlie Nakagawa (charlie@directtalk.com.br) e a todos meus amigos da empresa.

Meus agradecimentos também ao pessoal da lista de discussão de amigos do IMEUSP (email-da-galera@yahoogrupos.com.br) pelo apoio nos momentos de dúvidas e desespero tanto em conteúdo como em comandos do $\mathrm{IAT}_{\mathrm{E} X}$.

Sou grato pelo apoio dos meus amigos e professores da Faculdade Sumaré, em especial ao coordenador José Oscar Machado Alexandre, que soube compreenderme nos momentos difíceis nas aulas que ministrei ao longo destes últimos dois anos.

Agradeço aos professores Eamonn Keogh (eamonn@cs.ucr.edu), Richard J. Povinelli (Richard.Povinelli@Marquette.edu), Brian Ripley (ripley@stats.ox.ac.uk) e Marina Meilă (mmp@stat.washington.edu) pelo apoio e dúvidas solucionadas durante o trabalho. Agradeço ao Alexandre Nardi pelo material e apresentação do ambiente de mineração de dados do MS SQL Server 2005.

E por fim gostaria de felicitar as crianças e voluntários do projeto Teu Sonho Meu Sonho (www.teusonhomeusonho . org.br) que sempre inspiraram a realização e término deste trabalho. 


\section{Conteúdo}

\section{Introdução}

1.1 Motivações. . . . . . . . . . . . . . . . . . . . . . 1

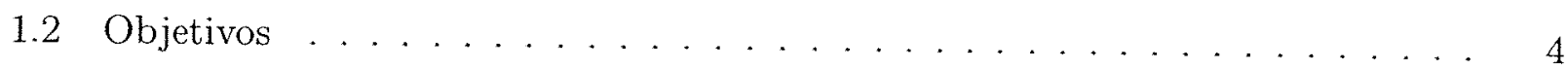

1.3 Contribuições deste trabalho . . . . . . . . . . . . . . . 4

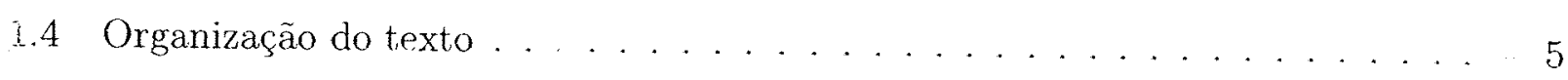

2 Séries temporais

2.1 Representação de séries temporais . . . . . . . . . . . . . . . 7

2.1.1 Representações contínuas em domínio temporal ........... . 8

2.1.2 Representações em outros domínios . . . . . . . . . . . . . . . . 9

2.1.3 Representações discretas . . . . . . . . . . . . . . . . . . . . 10

2.2 Similaridade entre séries temporais . . . . . . . . . . . . . 11

2.2 .1 Tipos de busca por similaridade . . . . . . . . . . . . . . 12

3 Algoritmos de redução de dimensionalidade $\quad 15$

3.1 DFT - Transformada discreta de Fourier . . . . . . . . . . . . . 16

3.2 DWT - Transformada discreta de ondaletas . . . . . . . . . . . 17

3.3 PIP - Pontos perceptualmente importantes . . . . . . . . . . . . . 20

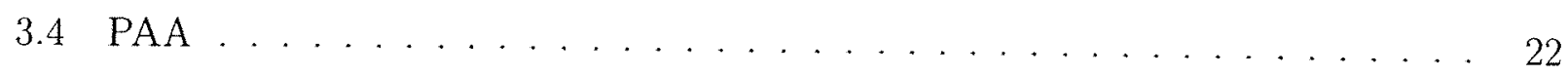

3.5 Outros algoritmos . . . . . . . . . . . . . . . . . 23 
4.1 No contexto de busca por similaridade . . . . . . . . . . . . 27

4.1 .1 Índice de Manutenção de Proximidade . . . . . . . . . . . . . . 28

4.2 No contexto de cálculo de aglomerados . . . . . . . . . . . . . . . . . . 29

4.2 .1 Comparação de aglomerações . . . . . . . . . . . . . . 30

4.2.2 Índice de Permanência em Aglomerados . . . . . . . . . . . . . . 31

4.2 .3 Índice de Variação de Informação . . . . . . . . . . . . . . . . 35

$5 \quad$ Resultados experimentais $\quad 37$

5.1 Centrais de Atendimento . . . . . . . . . . . . . . . 37

5.2 Massa de Dados . . . . . . . . . . . . . . . . . . . . . . 38

5.3 o Sistema R . . . . . . . . . . . . . . . . . 40

5.4 Descrição dos resultados de IMP . . . . . . . . . . . . . . . . 40

5.5 Descrição dos resultados de IPA . . . . . . . . . . . . . . . . 43

5.6 Descrição dos resultados de IPA . . . . . . . . . . . . . . . . 46

$\begin{array}{lll}6 & \text { Conclusão } & 50\end{array}$

A Algoritmos de aglomeração $\quad 52$

A.1 PAM . . . . . . . . . . . . . . . . . 53

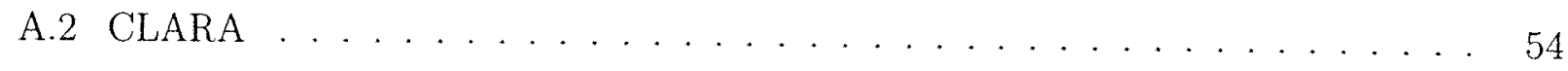

$\begin{array}{ll}\text { B Implementação } & 57\end{array}$

$\begin{array}{ll}\text { Bibliografia } & 64\end{array}$

$\begin{array}{ll}\text { Índice Remissivo } & 66\end{array}$

$\begin{array}{lc}\text { Biografia do autor } & 66\end{array}$ 


\section{Lista de Figuras}

1.1 Pirâmide Dado / Informação / Conhecimento . . . . . . . . . . . . . . 2

2.1 Representação gráfica de uma série temporal . . . . . . . . . . . . . 7

3.1 Transformada discreta de Fourier e coeficientes. . . . . . . . . . . . 17

3.2 Série original e reconstituída com DFT . . . . . . . . . . . . 17

3.3 Transformada discreta de ondaletas . . . . . . . . . . . . . . . . . . 19

3.4 Diferentes famílias de ondaletas . . . . . . . . . . . . . 20

3.5 Série original e reconstituída com DWT . . . . . . . . . . . . 20

3.6 Identificação de 7 PIPs . . . . . . . . . . . . . . . . . . . . 21

3.7 Identificação de 5 PIPs - passo $1 \ldots \ldots \ldots$. . . . . . . . . . . . . 21

3.8 Ordenação de 10 PIPs identificados - passo $2 \ldots \ldots \ldots \ldots . \ldots \ldots 22$

3.9 Série original e reconstituída com PIP . . . . . . . . . . . . . . 22

3.10 Exemplo de redução de dimensionalidade por PAA . . . . . . . . . . . . 23

3.11 PAA - combinação de segmentos . . . . . . . . . . . . . . . 23

3.12 Série original e reconstituída com PAA . . . . . . . . . . . 23

3.13 Alguns algoritmos de redução de dimensionalidade . . . . . . . . . . . 25

4.1 Representação de 21 séries em duas dimensões . . . . . . . . . . . . . . . . 32

4.2 Aglomeração das 21 séries em 3 aglomerados . . . . . . . . . . . . . . . 32

4.3 Representação de 21 séries reduzidas em duas dimensões . . . . . . . . . . . 32

4.4 Aglomeração das 21 séries reduzidas em 3 aglomerados . . . . . . . . . . . 32

4.521 séries reduzidas em 6 aglomerados de dois processos de aglomeração . . . . 32 
5.1 Características do conjunto de 600 séries

$5.2 \quad$ IMP de 100 séries temporais para $N=4 \ldots \ldots \ldots \ldots . \ldots \ldots$. . . . . . 41

5.3 Desvio padrão do IMP de 100 séries temporais para $N=4 \ldots \ldots \ldots . \ldots 4$

5.4 IMP de 197 séries temporais para $N=4 \ldots \ldots \ldots \ldots \ldots$. . . . . . . 41

5.5 Desvio padrão do IMP de 197 séries temporais para $N=4 \ldots \ldots \ldots 41$

5.6 IMP de 600 séries temporais para $N=4 \ldots \ldots \ldots \ldots \ldots$. . . . . . . 41

5.7 Desvio padrão do IMP de 600 séries temporais para $N=4 \ldots \ldots \ldots$. . . 42

5.8 IMP de 100 séries temporais para DFT . . . . . . . . . . . . . . . . 43

5.9 Desvio padrão do IMP de 100 séries temporais para DFT . . . . . . . . . . 43

5.10 Desvio padrão do IMP de 197 séries temporais para PIP . . . . . . . . . . 43

5.11 IPA de 100 séries temporais: algoritmos e número de aglomerados . . . . . . 44

5.12 IPA de 197 séries temporais: algoritmos e número de aglomerados . . . . . . 44

5.13 IPA de 600 séries temporais: algoritmos e número de aglomerados . . . . . . 45

5.14 IPA de 100 séries temporais: algoritmos e número de pontos . . . . . . . . 45

5.15 IPA de 197 séries temporais: algoritmos e número de pontos . . . . . . . . 45

5.16 IPA de 600 séries temporais: algoritmos e número de pontos . . . . . . . . . 46

5.17 IVI de 100 séries temporais: algoritmos e número de aglomerados . . . . . . 47

5.18 IVI de 197 séries temporais: algoritmos e número de aglomerados . . . . . . 47

5.19 IVI de 600 séries temporais: algoritmos e número de aglomerados . . . . . . 47

5.20 IVI de 100 séries temporais: algoritmos e número de reduções . . . . . . . . 47

5.21 IVI de 197 séries temporais: algoritmos e número de reduções . . . . . . . . 48

5.22 IVI de 600 séries temporais: algoritmos e número de reduções . . . . . . . . . 48

A.1 Representação visual do algoritmo PAM . . . . . . . . . . . . . . 54

A.2 Representação visual do algoritmo CLARA . . . . . . . . . . . . . 55

A.3 Silhueta de 4 agrupamentos utilizando CLARA . . . . . . . . . 56 


\section{Lista de Tabelas}

4.1 Combinações dos aglomerados e IPA . . . . . . . . . . . . . . 33

4.2 Matriz de confusão para 21 séries . . . . . . . . . . . . . . 36

4.3 Matriz de informação mútua para 21 séries . . . . . . . . . . . . . 36

5.1 Conjunto de dados de 600 séries . . . . . . . . . . . . . . . . . 39

5.2 IMP: Relação IMP de PIP/IMP de OUTROS algoritmos para $N=4 \ldots . . .42$

5.3 IMP: Relação IMP de PIP/IMP de OUTROS algoritmos para $N=16 \ldots . .42$

5.4 IPA médio de todos os algoritmos e massas de dados . . . . . . . . . . . 45

5.5 IPA médio por algoritmo de aglomeração . . . . . . . . . . . . . . 46

5.6 IVI médio de todos os algoritmos de redução e massas de dados . . . . . . . . 48

5.7 IVI médio por algoritmo de aglomeração . . . . . . . . . . . . . . . . . . . 49 


\section{Capítulo 1}

\section{Introdução}

\subsection{Motivações}

Hoje em dia a produção de dados como resultado do armazenamento de transações tornouse uma tarefa simples e rotineira e tem gerado enormes volumes de dados. Os sistemas transacionais armazenam todas as transações de um cliente, seu histórico, vendas de uma empresa, os mais diferentes dados sobre produtos, fornecedores, clientes, empregados, etc. Além disso, avanços em aquisição de dados, desde um simples leitor de código de barras até sistemas de sensoriamento remoto, geram mais e mais dados. A cada dia, mais operações corriqueiras são automatizadas, e a cada nova transação como compras com cartão de crédito, operações bancárias e terminais de venda, novos registros correspondentes são armazenados. Estes dados estão em um nível de granularidade muito pequeno, dificultando uma visão mais generalizada. Além disso, muitos dos bancos de dados atuais contém um volume tal de registros que inviabiliza a possibilidade de análise humana.

O dado é a estrutura fundamental sobre a qual um sistema de informação atua. A informação pode ser vista como uma representação ordenada e enxuta dos dados resultantes de uma consulta que permite a visualização e interpretação dos mesmos. O conhecimento provém da interpretação, geralmente pessoal, das informações apresentadas pelo sistema de banco de dados. Inteligência é o bom uso do conhecimento adquirido. A pirâmide do conhecimento, representada na figura 1.1 demonstra que a quantidade de dados existente em um sistema é muito grande. Já o montante de informação é reduzido devido a dados errôneos ou sem expressão (importância). Menor ainda é a quantidade de conhecimento que pode ser extraído desta informação através de técnicas de descoberta de conhecimento. 


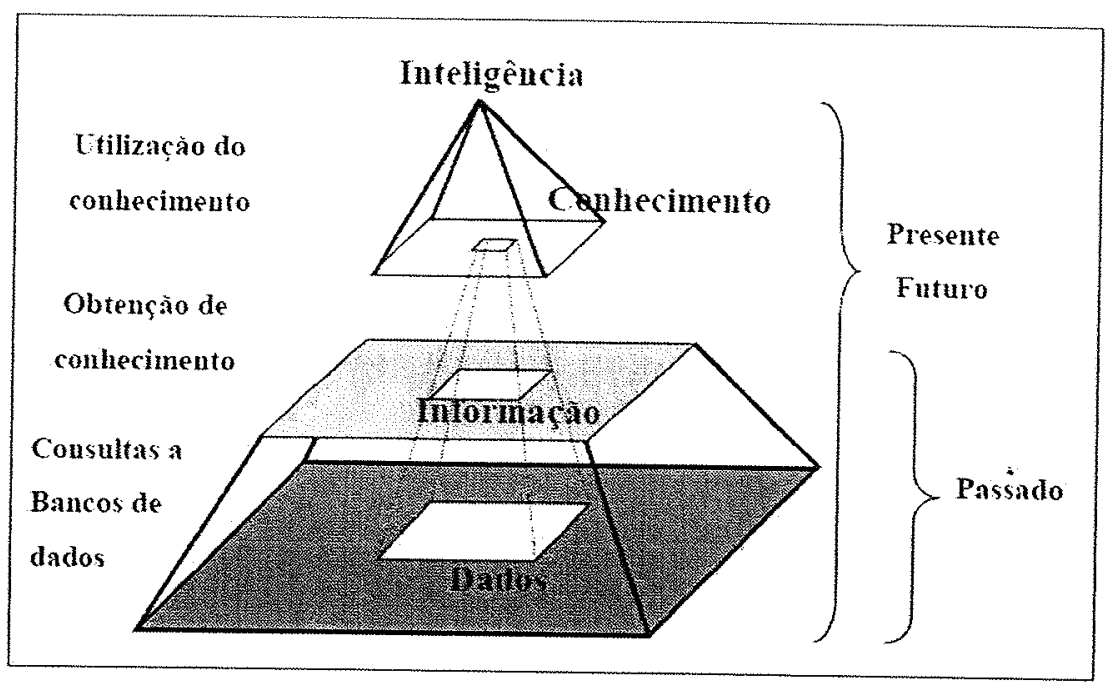

Figura 1.1: Pirâmide Dado / Informação / Conhecimento

Os sistemas analíticos visam facilitar a análise por parte de pessoas que necessitam de tomadas de decisão. Visam também integrar sistemas e consolidar informações, facilitando a análise, pois os dados no ambiente analítico são consolidados, sumarizados ou sintetizados, constituindo informações de granularidade maior em relação aos ambientes transacionais.

Os sistemas analíticos, porém, ainda são incapazes de obter conhecimento, ou fazem isso a um preço muito alto e com alta interação do usuário já que é necessária a interpretação pessoal dos dados, constituindo um processo lento, caro e altamente subjetivo.

A busca por informações em uma base de dados é realizada utilizando-se sofisticadas técnicas de análise daqueles dados a fim de encontrar padrões e regularidades nos mesmos: é a descoberta de informação "oculta" nestes dados. A esse processo dá-se o nome de Descoberta de Conhecimento em Banco de Dados (Knowledge Discovery in Database - KDD).

Um passo particular do KDD é aquele denominado de mineração de dados (data mining), que consiste na aplicação de algoritmos específicos para a extração de padrões a partir das bases de dados, constituindo parte do processo de aquisição de conhecimento. Diversos algoritmos de mineração existem e cada um possui uma particularidade e aplicação.

Atualmente, muitos dos dados cadastrados nas bases de dados são variantes no tempo. Por exemplo, o número de determinado produto vendido diariamente em uma loja, o número de carros que passam por um pedágio a cada minuto, o desempenho diário das açōes de uma certa companhia na bolsa de valores nos últimos 12 meses, o número de atendimentos por hora em uma central de atendimento, etc, são variáveis que tomam valores que podem variar de uma unidade de tempo (minuto, hora, dia, mês, ano, etc) para outra. Esses dados 
podem ser, portanto, representados por uma seqüência ordenada de valores na qual cada valor corresponde ao valor observado da variável num determinado instante. Essas variáveis que possuem uma dimensão tempo são conhecidas por séries temporais (time series). A análise de séries temporais tem-se tornado um dos grandes desafios na área de mineração de dados, a ponto de serem cunhados termos como time series data mining ou temporal data mining. Além disso, várias conferências da área de Knowledge Discovery e Machine Learning, por exemplo, têm dedicado sessões ao tema série temporal.

As séries temporais aparecem nos mais variados domínios de aplicação: engenharia (monitoramento baseado em sensores), pesquisa científica (missões espaciais), finanças (predição de dados financeiros), medicina (monitoração cardíaca, diagnósticos e comportamentos de pacientes), etc. Em computação e telecomunicações, por exemplo, é utilizada em sistemas de monitoração baseados em logs (informações gravadas).

Os primeiros trabalhos sobre recuperação de séries temporais consideravam "casamento exato" de séries. No entanto, atualmente existe um consenso de que a recuperação de dados do tipo série temporal deve ser baseada em "similaridade". Critérios de similaridade săo usados tanto em recuperação (queries) quanto em várias tarefas de mineração de séries temporais. Entre as operações de mineração de séries temporais destacam-se a descoberta de regras de associação, classificação, aglomeração e predição [JMF99]. Diretamente relacionadas ao conceito de similaridade encontram-se as questões sobre representação de séries temporais.

Várias abordagens para representação de séries temporais, conceitos de similaridade de séries temporais e técnicas eficientes de indexação têm sido propostas nos últimos anos. A mineração de séries temporais é uma área emergente que ainda não possui um conjunto de fundamentos bem estabelecidos [KCMP01a].

Um dos problemas mais estudados no contexto de análise computacional de séries temporais é o da "redução de dimensionalidade", ou seja, abordagens para gerar uma representação mais compacta para as séries temporais. O tamanho das séries temporais pode ser bastante grande e isso afeta diretamente a eficiência computacional de qualquer sistema de base de dados e também dos algoritmos de análise de dados. Em geral, o tamanho das séries temporais é reduzido utilizando-se alguma técnica de amostragem ou transformação de dados. Em vez das séries originais, manipulam-se as séries reduzidas e assim obtém-se maior eficiência computacional em grandes bases de dados.

Outro, e talvez principal, fato que motiva a redução de dimensionalidade é um fenômeno conhecido por maldição da dimensionalidade (curse of dimensionality). Este fenômeno está

\footnotetext{
${ }^{1}$ Utilizaremos o termo aglomeração ao invés de clustering
} 
relacionado a dados em espaços de alta dimensão e é observado em vários contextos, entre eles, nas técnicas de indexação multidimensional. Mais especificamente, uma série temporal de tamanho $n$ pode ser vista como um ponto no espaço $\mathbb{I R}^{n}$ e estruturas de indexação multidimensional tais como $R$-trees poderiam ser usadas para indexar as séries temporais [BKSS90]. No entanto, sabe-se que o desempenho dessas estruturas degrada-se com o aumento da dimensão $n$ [KCMP01a]. Na prática, o número de dimensões usado em indexação multidimensional varia de 8 a 20. Portanto, em geral, a indexação de séries temporais leva em consideração alguma técnica para a redução da dimensionalidade.

\subsection{Objetivos}

Na literatura referente ao assunto podem ser encontrados vários algoritmos para a redução de dimensionalidade de séries temporais. No entanto, observa-se que ainda não existem padrões estabelecidos para a comparação dos mesmos. Muitas análises consideram apenas o desempenho computacional. Em geral, na escolha de um algoritmo, além do desempenho computacional, outro aspecto relevante é a sua eficácia (por exemplo, a qualidade dos resultados).

Este trabalho tem como objetivos estudar, implementar e avaliar sob o ponto de vista qualitativo alguns algoritmos de redução de dimensionalidade para séries temporais.

\subsection{Contribuições deste trabalho}

Este trabalho busca fazer uma avaliação qualitativa dos algoritmos de redução de dimensionalidade estudados. Por qualitativa não se deve entender subjetividade: deve-se entender a preferência pela análise de aspectos relacionados à qualidade (quão bem a relação entre as séries temporais são preservadas após a redução de dimensionalidade) em vez dos aspectos numéricos (tempo de execução, número de acesso a páginas de disco, etc).

Para isso, focamos as avaliações em duas atividades comuns no contexto de séries temporais: a busca $k$-NN e aglomeração. A busca $k$-NN é um tipo de busca por similaridade bastante comum em bases de dados multimídia. A aglomeração é uma das atividades comuns em mineração de dados. Como critérios de avaliação são propostos índices que servem para comparar o desempenho qualitativo dos diferentes algoritmos no contexto das duas atividades.

$\mathrm{Na}$ parte experimental do trabalho, a plataforma $R$ (http://www.r-project.org) foi adotada para as implementações. Os critérios que nortearam a escolha dessa plataforma são: 
a popularidade dessa plataforma, o fato dela ser um software público, o fato de ser possível agregar novas funcionalidades na forma de uma toolbox. Quatro algoritmos de redução de dimensionalidade foram implementados na plataforma $R$. Juntamente com esses algoritmos foram implementadas também algumas ferramentas de análise baseadas nos índices propostos.

A análise foi focada em um conjunto de dados provenientes de uma central de atendimento, portanto, as comparações efetuadas restringem-se a esse domínio de dados. Porém, a abordagem de análise proposta pode ser aplicada em quaisquer conjuntos de dados.

\subsection{Organização do texto}

No capítulo 2 explicamos o que são séries temporais, descrevemos diferentes formas de representação de séries temporais e critérios de similaridade entre séries temporais, que são importantes em consultas.

Os algoritmos de redução de dimensionalidade simplificam a série temporal ou efetuam uma transformação e assim, possibilitam a criação de índices e consultas temporais com tempos de resposta satisfatórios, baseados nas séries reduzidas. Quatro algoritmos de redução de dimensionalidade utilizados no contexto de séries temporais serão descritos no capítulo 3 .

Para analisar o desempenho qualitativo dos algoritmos de redução de dimensionalidade estudamos os efeitos dos algoritmos em duas atividades que envolvem séries temporais em bases de dados: busca por similaridade e aglomeração. Alguns critérios objetivos para avaliar o desempenho qualitativo desses algoritmos são propostos no capítulo 4 .

No capítulo 5 descrevemos inicialmente a massa de dados provenientes de uma central de atendimento e outro conjunto de dados, que foram utilizados em nossos experimentos. Em seguida apresentamos resultados referentes ao desempenho dos algoritmos de redução de dimensionalidade quanto aos critérios de avaliação propostos no capítulo 4.

No capítulo 6 apresentamos as conclusões deste trabalho e tecemos alguns comentários sobre futuros trabalhos. 


\section{Capítulo 2}

\section{Séries temporais}

Vimos no capítulo 1 as aplicações e importância das séries temporais nas bases de dados. Vimos também sua definição: uma seqüencia ordenada de valores medidos em instantes crescentes de tempo. Dependendo da natureza do evento da sequência temos dois tipos de sequências: se esta for composta de séries de símbolos nominais de um alfabeto em particular, então é uma sequiencia temporal discreta (temporal sequence) e se for composta de valores contínuos (números reais), então é conhecida por série temporal (time series).

Uma série temporal de tamanho $n$ será representada por um vetor $\vec{x}=\left[x_{i}\right], i=1,2, \ldots, n$. Cada componente $x_{i}$ é um número real, representando o valor de uma variável no instante $i$. A unidade de medida temporal é dependente do contexto que originou as séries temporais: podem ser dias, minutos, segundos, meses, anos, etc. Neste trabalho, consideramos unidades de tempo equiiespaçados, isto é, se para o instante $i$ a unidade de tempo for $t_{i}$ então para o instante $i+1$ temos $t_{i+1}=t_{i}+\Delta$, com $\Delta$ sendo uma constante. Por exemplo, a série

$$
\begin{aligned}
\vec{x}= & (49,20,49,44,20,33,39,44,33,23,28,38,23,23,28, \\
& 33,23,60,25,25,22,57,25,28,40,43,30,33,36,25,25)
\end{aligned}
$$

pode ser o registro das vendas diárias de um produto $A$ numa loja no mês de julho de um determinado ano. Neste caso temos $n=31$, pois são trinta e um valores de venda de produto, um valor por unidade de tempo (dia). O componente $x_{1}=49$ corresponde às unidades do produto $A$ vendidas no primeiro dia de julho, o componente $x_{2}=20$ às unidades do produto $A$ vendidas no segundo dia de julho, e assim por diante.

Uma série temporal pode também ser representada graficamente. No caso da série acima, a representação gráfica é mostrada na figura 2.1. Embora estejamos considerando unidades 
discretas de tempo, no gráfico a série será representada por uma curva contínua.

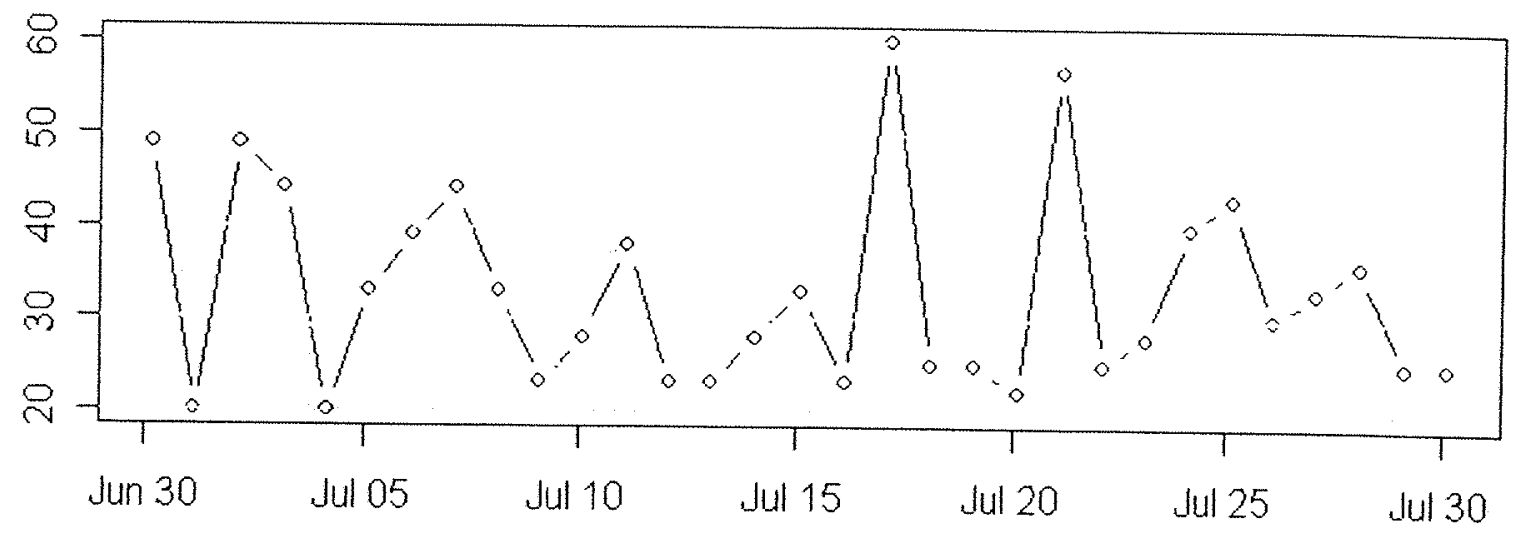

Figura 2.1: Representação gráfica de uma série temporal (No eixo $x$ (horizontal) estão os 31 dias de julho e no eixo $y$ (vertical) estão as unidades vendidas do produto $A$ )

Gráficos são formas úteis para a visualização e interpretação de dados e muitas vezes são utilizados como ferramentas auxiliares à análise de dados. No entanto, para um grande volume de dados a análise visual não é uma tarefa simples. Além disso, devido a dimensão tempo, a análise de uma coleção de séries temporais é, por si só, mais complexa que a análise de uma coleção de dados pontuais.

A análise de séries temporais é bastante estudada nas áreas de estatística e de processamento de simais. Esses estudos visam entender a série (no sentido de identificar como elas foram originadas ou de onde elas provêm) ou modelar a série para fins de previsões (por exemplo, baseado no comportamento do desempenho das ações de uma companhia nos últimos 3 anos, qual será o desempenho no próximo ano?).

Com o avanço da tecnologia e de sistemas gerenciadores de base de dados, que atualmente são capazes de armazenar um grande volume de dados e dados de diferentes tipos, a análise computacional de séries temporais vem recebendo cada vez mais atenção da comunidade científica e industrial.

Neste contexto, dois grandes problemas em estudo são: técnicas para indexação eficiente de séries temporais e mineração de séries temporais. A mineração de séries temporais é o termo que compreende a mineração de dados do tipo séries temporais.

O processamento de séries temporais envolve algumas questões comuns. Dentre elas, destacam-se as relacionadas à representação computacional e à escolha de critérios de similaridade. 


\subsection{Representação de séries temporais}

A representação da série temporal refere-se à modelagem e representação dos dados antes de sua indexação ou da aplicação de técnicas de mineração temporais. Essa representação pode ser resultante de uma transformação, quando necessário.

Por transformação referimo-nos à mudança de representação do domínio temporal para outros domínios. Por exemplo, em vez de considerarmos a representação dos dados em seu domínio temporal, podemos considerar sua correspondente representação no domínio das freqüências.

O principal objetivo no estudo de diferentes representações para as séries temporais é a obtenção de representações mais compactas ou mais fáceis de serem manipuladas, com perda mínima de características presentes na série original.

Neste texto, uma série temporal original será representada por um vetor e denotada por uma letra minúscula (como em $\vec{x}$ ) e sua correspondente série reduzida será denotada pelo. vetor de mesma letra em maiúscula (como em $\vec{X}$ ). Conforme já mencionamos anteriormente. o tamanho da série original será denotado por $n$. O tamanho da série reduzida será denotado por $N$.

\subsubsection{Representações contínuas em domínio temporal}

Uma abordagem bem simples para representar uma seqüência de elementos de números reais é utilizar os elementos iniciais ordenados pelo instante de sua ocorrência, sem qualquer pré-processamento [ALSS95, LR98]. Neste caso temos $\vec{X}=\vec{x}$ e $N=n$.

Uma alternativa consiste em encontrar segmentos de funções lineares de forma a aproximar a seqüência inicial. A seqüência inicial é particionada em várias subseqüências contíguas e cada uma delas é aproximada por um segmento de uma função linear. Para particionar a seqüência existem dois métodos principais: definir de antemão o número de segmentos ou determinar este número e em seguida identificar os segmentos correspondentes [DGM97, GS99]. O objetivo é obter uma representação que foque na deteç̧ão das mudanças significativas da seqüência, transformando-a em uma seqüência de segmentos de reta. Enquanto esta abordagem é uma representação relativamente direta, não ganha-se muito em termos de habilidade de manipular as representações geradas. Uma possível aplicação deste tipo de representação é a detecção de pontos de mudança (change-point), ou seja, pontos onde acontecem uma mudança significativa de "comportamento". 
Outra proposta é baseada na idéia da visão humana de que curvas suaves são transformadas em segmentos lineares. Consiste basicamente de unir iterativamente dois segmentos lineares similares. Escolher qual segmento será unido é baseado no critério de minimização do erro quadrático [KS97]. Uma extensão desse modelo consiste em associar a cada segmento um peso, o qual representa a importância relativa do segmento em comparação à seqüência completa. Deste modo, é possível comparar seqüências olhando-se os segmentos mais importantes [KP98].

Uma vantagen significativa destas abordagens é a habilidade de reduzir os impactos provenientes de ruídos. Entretanto, problemas como diferenças de amplitude (scaling problems) e existência de distorções ou "buracos" (gaps) ou deslocamentos no eixo do tempo (time axis distortion) não são abordados facilmente.

\subsubsection{Representações em outros domínios}

No caso de tranformações, a idéia principal é transformar a série temporal inicial do domínio temporal para outro domínio, e então utilizar um conjunto de elementos veste novo domínio para representar a série original.

Uma transformação bem conhecida é a transformada discreta de Fourier (Discrete Fourier Transform - DFT) [AFS93], em que a série original de tamanho $n$ no domínio temporal é convertida para um ponto no domínio das frequências. Para cada série, escolhem-se as $N$ primeiras frequêencias e então a série é vista como um ponto no espaço $N$-dimensional. Esta abordagem tem uma propriedade muito atraente na qual a amplitude dos coeficientes de Fourier são invariantes quando ocorrem deslocamentos nas séries, o qual permite estender este método para encontrar séries similares ignorando-se os deslocamentos [AFS93]. Detalharemos esta técnica no próximo capítulo.

Outra possibilidade proposta é representar cada série temporal de tamanho $n$ como um ponto no espaço $n$-dimensional. Esta representação pode ser vista como uma representação contínua do domínio temporal [JLS]. Entretanto, se cada série for mapeada para um ponto em um novo espaço com coordenadas que são derivadas do ponto da série original, esta deve ser considerada uma abordagem de transformação de representação. Neste caso, a derivada em cada ponto é determinada pela diferença entre o ponto e seu ponto precedente [JLS].

Uma abordagem mais recente usa a transformação em ondaletas (Discrete Wavelet Transform - DWT) para converter cada série temporal do domínio do tempo para o domínio tempo/freqüência. É uma transformação linear que decompõe a série original em componentes diferentes de freqüência, sem perder a informação do instante de cada ocorrência de um ele- 
mento no tempo. A série é então representada por suas características, expressas através dos coeficientes de ondaletas. Igualmente à abordagem DFT, apenas alguns poucos coeficientes são necessários para aproximar a representação da série temporal. As séries armazenadas como vetor de características podem ser indexadas multidimensionalmente por algumas estruturas, como por exemplo, árvores $\mathrm{R}$.

Com estes tipos de representações, uma série temporal torna-se um objeto mais gerenciável, que permite a definição de medidas de similaridade eficientes e aplicações comuns de mineração de dados.

\subsubsection{Representações discretas}

Uma terceira abordagem para lidar com séries temporais é a conversão da série inicial (com elementos no domínio real) em séries discretas, composta por símbolos de um alfabeto, também chamada discretização (discretization). Uma linguagem para descrever os símbolos de um alfabeto e a relação entre duas séries temporais é proposta em [APWZ95]. Esta Linguagem Definida por Formas (SDL - Shape Definition Language) é capaz de descrever consultas baseadas em formas para lidar com bancos de dados temporais, já que permite blurry match. Nesse tipo de consulta, o que importa é a forma geral, não importando os detalhes mínimos de uma série particular.

O primeiro passo no processo de representação é definir o alfabeto de símbolos e então converter a série inicial para a série simbólica. A conversão pode ser feita considerando-se as transições de um instante temporal para o próximo, e então atribuindo-se um símbolo do alfabeto descrito para cada transição.

Outra sugestão de segmentação de séries temporais [HY99] é computar a mudança que ocorre em um ponto e seu ponto consecutivo e representar todos os pontos consecutivos através de um único segmento. Um caso particular é quando estes segmentos são classificados em duas classes: alterações (flutuações) grandes (símbolo 1) ou pequenas (símbolo 0). Desta forma, cada série temporal é convertida em uma seqüência binária perfeitamente manipulável por algoritmos genéticos, por exemplo.

Uma abordagem diferente para converter uma série temporal em uma seqüência discreta é utilizar aglomeração. Primeiro a seqüência original é decomposta em um conjunto de subseqüencias de tamanho $w$, onde $w$ é o tamanho fixo da janela (ou frame). Então, o conjunto de todas as subseqüências é agrupado, originando $k$ agrupamentos e então um símbolo diferente é associado a cada agrupamento. A versão discreta da seqüência inicial é obtida substituindo 
cada subseqüência pelo símbolo associado ao agrupamento à qual ela pertence [DLM ${ }^{+} 98$ ].

Outro método para converter séries temporais em seqüências de símbolos é baseada no uso de Self-Organizing Maps (SOM) [GLT01, Gui00]. Esta conversão consiste de três etapas: primeiro, uma nova série é composta a partir da diferença entre dois valores consecutivos da série original. Depois, janelas de tamanho temporal $w$ (chamadas de janela de encaixe) são inseridas no SOM, que resulta em um nó dito vencedor. Cada nó é associado com um símbolo, o que significa que a seqüência resultante pode ser visto como uma seqüência de símbolos.

A vantagem dos métodos acima é que a série temporal é particionada de um modo natural, dependente de seus valores apenas. Entretanto, os símbolos do alfabeto são usualmente escolhidos externamente, o que significa que eles são impostos pelo usuário (que deveria saber os símbolos mais ajustáveis) ou são estabelecidos de uma maneira artificial. A série discreta é mais fácil de ser manipulada e processada do que a série original contínua.

\subsection{Similaridade entre séries temporais}

Muitas das consultas nos sistemas tradicionais de gerenciamento de base de dados podem ser especificadas de forma precisa. Por exemplo, em uma base de dados de funcionários, pode-se desejar recuperar as informações de todos os funcionários do sexo feminino que foram admitidos antes de uma certa data. Exceto pela quantidade de dados a serem pesquisadas, não há nenhuma dificuldade em se concretizar tal consulta. O resultado da consulta será o conjunto de todos os funcionários que satisfazem as restrições especificadas na consulta.

No entanto, quando consideramos dados mais complexos tais como séries temporais e imagens, a especificação das consultas torna-se mais complexa. Considere, por exemplo, uma base de séries temporais relacionados ao volume de vendas de uma rede de supermercados. Se desejarmos recuperar os dados sobre os produtos cujas séries apresentam características de crescimento de venda em datas próximas a feriados, haveria a necessidade de se especificar quais datas correspondem aos feriados, o que é considerado crescimento, se a série deve apresentar característica de crescimento necessariamente em todos os feriados, etc. Em outra aplicação, o usuário pode estar interessado em verificar todas as séries que apresentam tendência de crescimento no volume de vendas. Para tal, haveria necessidade de se especificar formalmente o significado de "tendência de crescimento". Da mesma forma, não é difícil imaginarmos diferentes tipos de consultas que poderiam ser realizadas em uma base de séries temporais. Uma linguagem de consulta que contemplasse todas as possibilidades seria possivelmente muito complexa e de difícil manipulação. 
O que se observa na prática para se lidar com esses tipos de dados são os chamados consultas por exemplo. O usuário apresenta ao sistema uma consulta na forma de um dado. A seguir, o sistema busca na base de dados todos aqueles que são "parecidos" com o dado de consulta.

O conceito de "ser parecido" pode ser expresso formalmente através de critérios de similaridade. Tais critérios geralmente correspondem a alguma medida (ou distância) e quanto menor a distância entre dois objetos, mais similares eles são.

Observe também que mesmo em situações nas quais deveriam existir várias séries supostamente iguais, dificilmente haverá casamento exato de séries, pois esses dados são geralmente sujeitos a ruídos (geralmente na fase de aquisição de dados). Portanto, mesmo nessas situações não faz sentido a realização de comparações exatas e sim comparações "próximas".

Identificar companhias com padrão de crescimento similar, determinar produtos com padrão similar de venda e descobrir ações com tendências similares no mercado de ações são alguns exemplos que ilustram a utilidade de busca por similaridade em base de dados temporais.

Os critérios de similaridade adequados dependem do domínio de aplicação e também da representação adotada. Para séries temporais contínuas (valores reais), uma possível medida é a norma $L_{p}$. Dadas duas séries temporais $\vec{x}=\left[x_{1}, \ldots, x_{n}\right]$ e $\vec{y}=\left[y_{1}, \ldots, y_{n}\right]$, define-se a norma (ou distância) $L_{p}, 1 \leq p \leq \infty$ como sendo:

$$
L_{p}(X, Y) \equiv \sqrt[p]{\sum_{i=1}^{n}\left(x_{i}-y_{i}\right)^{p}}
$$

Quando $p=1$ tem-se a distância Manhattan, dada por,

$$
D_{1}(\vec{x}, \vec{y}) \equiv \sum_{i=1}^{n}\left|x_{i}-y_{i}\right|
$$

e quando $p=2$ tem-se a distância euclidiana, dada por,

$$
D_{2}(\vec{x}, \vec{y}) \equiv \sqrt{\sum_{i=1}^{n}\left(x_{i}-y_{i}\right)^{2}} .
$$

A distância euclidiana é a mais utilizada para mensurar a similaridade entre séries temporais. 


\subsubsection{Tipos de busca por similaridade}

Existem dois tipos de consultas por similaridade bastante difundidas em bases de dados multidimensionais:

- range queries: retorna todas as séries que estão a uma distância $\epsilon$ da série de consulta. Mais formalmente, dada uma série de consulta $\vec{q}$, um conjunto de séries $B$, uma distância $D$ (critério de similaridade) qualquer e uma tolerância $\epsilon>0$, o conjunto de séries recuperadas é dado por:

$$
R=\{\vec{x} \in B: D(\vec{q}, \vec{x}) \leq \epsilon\}
$$

- k-vizinhos mais próximos: retorna as $k$ séries mais similares à série de consulta. Mais formalmente, consiste em determinar, na formulação dada para o range query, um $\epsilon$ tal que o conjunto resposta $R$ possua exatamente $k$ elementos, isto é, tal que $|R|=k$.

Nessas consultas, uma abordagem por força bruta, como a busca sequencial, para obter as respostas requer a comparação da série temporal de consulta $\vec{q}$ com todas outras séries do banco de dados. Claramente, esta abordagem não é praticável em bases de dados com grande volume de dados.

Índices multidimensionais são geralmente utilizados para a indexação de séries temporais, visando acesso e recuperação eficiente de dados. No entanto, o tamanho $n$ das séries temporais, que é interpretado como sendo o número de dimensōes na indexação, é em geral muito grande. A degradação de desempenho dos índices multidimensionais para dimensões muito altas é um fenômeno bastante conhecido. Para contornar essa dificuldade, a abordagem mais utilizada é a redução de dimensionalidade. As séries temporais são reduzidas ou sintetizadas, usando por exemplo, alguma das abordagens de representação descritas anteriormente.

No caso de buscas do tipo range query, existe uma técnica bem conhecida que pode ser descrita pelos seguintes passos [FRM94]:

- obter a representação reduzida de cada seqüência na base de dados

- construir um índice multidimensional para esses dados reduzidos

- numa busca do tipo range query, na qual a série de consulta é $\vec{q}$ e a tolerância é $\epsilon$, obter a representação reduzida $\vec{Q}$ de $\vec{q}$ e usar o índice para recuperar todas as séries (reduzidas) a uma distância menor ou igual a $\epsilon$ de $\vec{Q}$ (a distância considerada para as séries reduzidas não necessariamente precisa ser a mesma da considerada para as séries originais). 
- realizar um pós-processamento para descartar os falso-positivos.

Ao se utilizar a técnica descrita acima, um aspecto importante a ser considerado é a questão dos falsos positivos e falsos negativos. Falsos positivos ocorrem quando as séries aparentam estar próximas com respeito ao índice construído, porém elas realmente encontram-se distantes uma da outra. Como este problema pode ser resolvido em um estágio de pós-processamento, falsos-positivos podem ser tolerados. Por outro lado, falsos negativos ocorrem quando séries que estão próximas não são consideradas próximas pelo esquema de indexação e não são recuperadas. Falsos negativos não são aceitáveis em um esquema de indexação.

O que torna interessante a utilização da técnica descrita acima é a existência de um teorema que apresenta as condições suficientes para a não existência de falsos negativos [AFS93].

Teorema 2.1 Sejam $D_{\text {original }}$ e $D_{\text {reduzida }}$ as medidas de similaridade usadas respectivamente para as séries originais e para as respectivas séries reduzidas. Para garantir a existência de nenhum falso negativo para busca; do tipo range query devemos ter, para quaisquer pares de séries $\vec{x}_{i}$ e $\vec{x}_{j}$,

$$
D_{\text {reduzido }}\left(\vec{X}_{i}, \vec{X}_{j}\right) \leq D_{\text {original }}\left(\vec{x}_{i}, \vec{x}_{j}\right)
$$

Este teorema garante que, desde que as distâncias $D_{\text {original }}$ e $D_{\text {reduzida }}$ utilizadas satisfaçam a relação dada pela equação 2.1 , a utilização da técnica descrita acima não apresentará falsos negativos, ou seja, todas a séries de interesse (e eventualmente mais algumas outras) serão recuperadas. 


\section{Capítulo 3}

\section{Algoritmos de redução de dimensionalidade}

Os algoritmos de redução de dimensionalidade são bastante conhecidos e utilizados nas
áreas de reconhecimento de padrões e processamento de sinais. Vários dos algoritmos utiliza-
dos na redução de dimensionalidade de séries temporais são os mesmas ou então adaptações
daqueles algoritmos.

Neste capítulo descrevemos quatro algoritmos de redução de dimensionalidade utilizados em séries temporais: transformada discreta de Fourier (DFT), transformada discreta de Wavelets (DWT), pontos peceptualmente importantes (PIP) e Piecewise Aggregate Approximation (PAA).

Os dois primeiros geram representações reduzidas baseadas em uma transformação de domínio, enquanto os dois últimos são representações mais compactas (menores) no próprio domínio temporal. Não consideramos nenhum algoritmo cuja representação é discreta, no sentido discutido no capítulo anterior. A escolha dos quatro algoritmos não seguiu nenhum critério objetivo. Esses quatro algoritmos foram implementados e testados na plataforma $R$ (ver maiores informações sobre o $\mathrm{R}$ no capítulo 5 e maiores detalhes sobre a implementação desses algoritmos no apêndice $B)$. 


\subsection{DFT - Transformada discreta de Fourier}

A análise de Fourier, utilizando a transformada de Fourier tem-se mostrado uma ferramenta poderosa no estudo de séries temporais compostas de sinais estacionários (sinais que se repetem, que podem ser compostos de funções matemáticas sobrepostas como seno e co-seno).

Esta transformação utiliza-se do conceito de transformada discreta de Fourier (Discrete Fourier Transform - DFT) para mapear as sequiências temporais no domínio do tempo para o domínio das freqüências [AFS93].

A transformada discreta de Fourier de uma série temporal de $n$ pontos $\vec{x}=\left[x_{t}\right], t=1, \ldots, n$ é definida como a série de $n$ números complexos $X_{f}, f=1, \ldots n$ dada por

$$
X_{f}=1 / \sqrt{n} \sum_{t=1}^{n} x_{t} \exp (-j 2 \pi f t / n), f=1,2, \ldots, n
$$

na qual $j$ é a unidade imaginária $j=\sqrt{-1}$ e $X_{f}$ é um número complexo, com exceção de $X_{0}$, que é um número real se a série $\vec{x}$ for composta de números reais. A série $\vec{x}$ pode ser reconstruída pela transformada inversa de Fourier da seguinte forma:

$$
x_{t}=1 / \sqrt{n} \sum_{f=1}^{n} X_{f} \exp (j 2 \pi f t / n), t=1,2, \ldots, n .
$$

Para efeitos de redução de dimensionalidade, uma vez aplicada a transformada de Fourier, escolhem-se os $N$ primeiros coeficientes da série $X_{f}$ e descartam-se o restante dos coeficientes. Todos os coeficientes de Fourier contribuem globalmente para a série, porém, os primeiros coeficientes de Fourier possuem informações mais gerais sobre a série original, ao passo que os últimos coeficientes possuem detalhes locais da série original. Desta forma, a idéia geral do comportamento da série original pode ser expressa através dos primeiros coeficientes.

A figura 3.1 mostra uma série original e a respectiva série reconstruída utilizando-se os 10 primeiros coeficientes. Abaixo do gráfico são mostradas as senóides correspondentes a cada um dos coeficientes.

A figura 3.2 mostra uma série original, proveniente de uma central de atendimento, medindo-se o número de usuários atendidos via chat em intervalos de um minuto, dentro do período de 06:00:00 às 23:26:00 do dia 26/12/2005, contendo $n=1024$ pontos. A série original está em cor preta (série superior) e a série reduzida a $N=64$ pontos utilizando DFT 

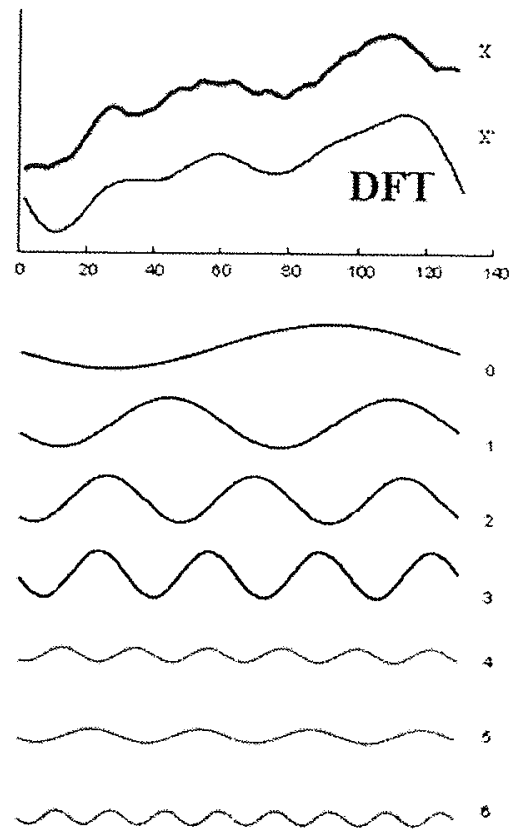

Figura 3.1: Transformada discreta de Fourier e coeficientes

(Série com 130 pontos no tempo e a representação de 10 coeficientes de Fourier. Note que os últimos coeficientes contribuem pouco para a reconstrução da série. A série original está em cor vermelha e a reconstruída em cor azul. Figura extraída de [Keo01].)

(6,25\% do tamanho da série original) e depois reconstruída, em vermelho (série inferior). A série original foi deslocada 15 unidades para cima, a fim de facilitar a comparação visual.

Um resultado importante com respeito ao DFT é que a distância euclideana entre duas séries no domínio temporal é exatamente igual à distância euclideana entre os coeficientes dessas séries. Em outras palavras, a DFT preserva a distância euclideana. Como conseqüênica, se apenas alguns coeficientes são utilizados para representar a série no domínio das frequêencias, então garante-se que a distância euclideana entre duas séries na representação reduzida não será superior à distância euclideana entre essas séries no domínio temporal. Este resultado é uma decorrência do teorema de Parseval (ver mais detalhes, por exemplo, em [AFS93]).

Outro fato importante no caso da DFT é a existência de um algoritmo rápido, a transformada rápida de Fourier ( Fast Fourier Transform - FFT) que calcula os coeficientes em tempo $O(n \log n)$. Além disso, a DFT não é sensível a deslocamentos verticais [AFS93], sendo muito utilizada em compressão de dados. 


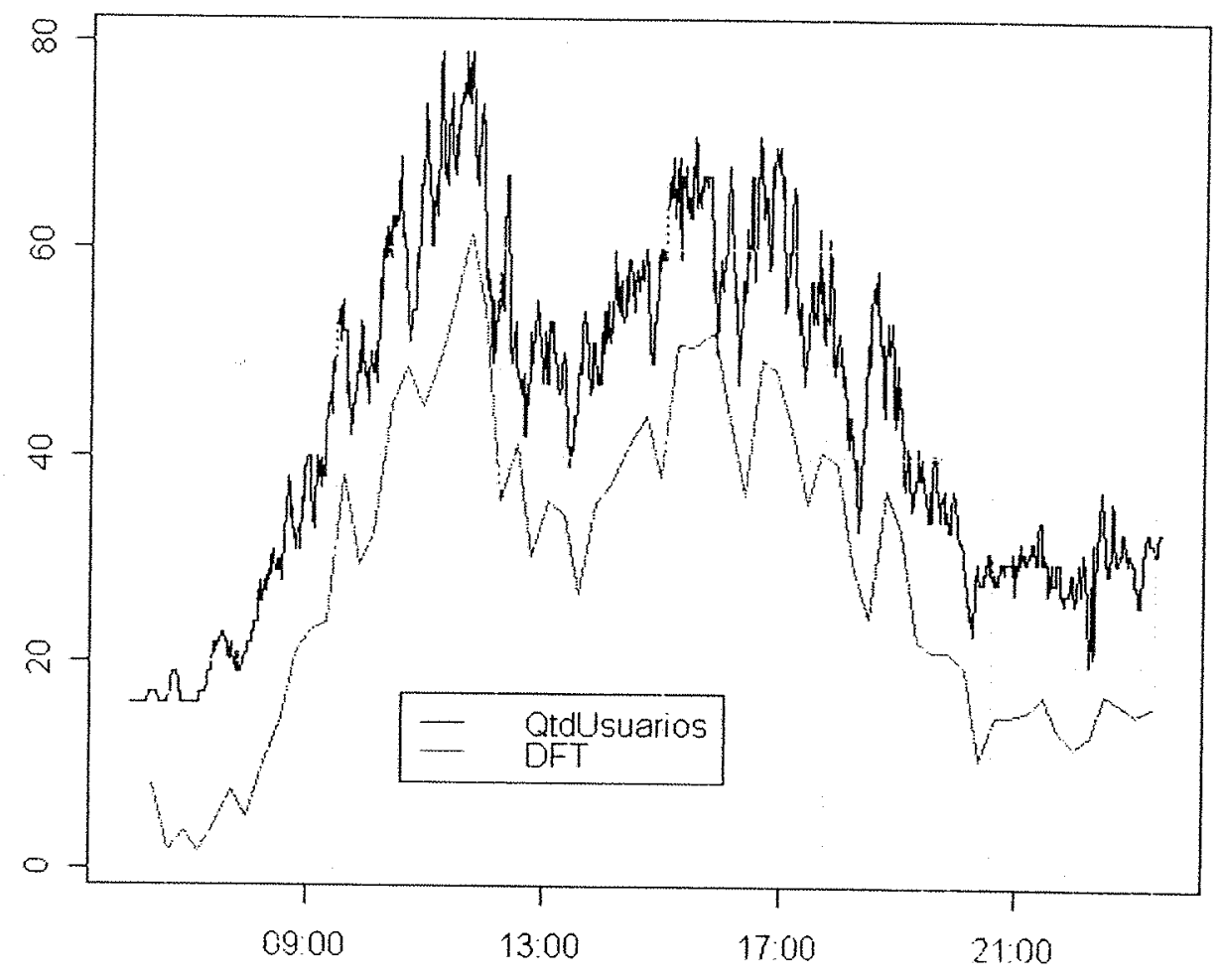

Figura 3.2: Série original e reconstituída com DFT

Uma restrição a DFT é que esta só pode ser aplicada a séries de tamanhos que sejam potência de 2. Além disso, outra característica negativa é que, ao efetuar a transformação, perde-se a referência à localização temporal.

\subsection{DWT - Transformada discreta de ondaletas}

As ondaletas são muito utilizadas em processamento e filtragem de sinais e atualmente são aplicadas nas áreas de finanças, estatística, fractais, compressão de dados, análise espectral, previsão, inteligência artificial, etc [Gra95].

A origem do nome "transformada discreta de ondaletas" vêm do inglês Discrete Wavelet Transform - DWT. Alguns autores de textos em língua portuguesa [Mor99] preferem o uso da tradução para o português "ondaletas", ou "pequenas ondas". Neste texto adotamos o uso do termo "ondaletas".

A transformada de ondaletas (Wavelet Transform - WT) ou transformada discreta de ondaletas são consideradas eficazes na substituição do algoritmo DFT em muitas aplicações de processamento gráfico, de imagens, de sinais e de fala [CF99]. Muito se aplica esta técnica 
em redução de séries temporais e buscas baseadas em conteúdo. DWT é uma versão discreta da transformação WT em sinais numéricos.

A idéia fundamental dessa transformação é expressar a série original como uma combinação de funções que representam pequenas ondas. O resultado é uma transformação que consiste de uma seqüência de coeficientes cujos tamanhos são ordenados através da potência de 2. Assim sendo, se o sinal possuir tamanho $n$, então o primeiro conjunto de coeficientes terá tamanho $2^{0}$, o segundo conjunto terá tamanho $2^{1}$, depois $2^{2}$, e assim sucessivamente até $2^{n-1}$. Cada conjunto de coeficientes representa a série temporal em uma determinada resolução. É como se estivéssemos aplicando um filtro "passa baixa" (low pass), que tem o efeito de suavizar um sinal (ou, no nosso caso, uma série temporal).

As ondaletas permitem a visualização de uma série temporal em diferentes resoluções. Cada resolução reflete uma freqüência diferente. A técnica consiste em obter médias e diferenças de uma série, dividindo a mesma em espectros. A transformação gera dois conjuntos de valores: o conjunto das médias e o conjunto das diferenças (este é chamado de coeficientes de ondaletas). A cada passo é produzido um conjunto de médias e coeficientes que são de tamanho metade do tamanho dos dados antes do início do passo. Por exemplo, se uma série tem tamanho $n=256$, então o primeiro passo produzirá 128 médias e 128 coeficientes. O conjunto de médias torna-se a entrada para o próximo passo, que irá gerar 64 médias e 64 coeficientes. A execução da transformação termina quando uma única média (representando a média da série original) e um único coeficiente são gerados $\left(2^{0}\right)$.

Formalmente [PW00], uma ondaleta é uma pequena onda que cresce e decresce em um período limitado no tempo. Cada ondaleta é uma função $\psi(\cdot)$ definida sobre o eixo dos números reais, $x \in(-\infty, \infty)$, satisfazendo duas propriedades básicas:

- A integral de $\psi(\cdot)$ é zero:

$$
\int_{-\infty}^{\infty} \psi(u) \mathrm{d} u=0
$$

- A integral do quadrado de $\psi(\cdot)$ é unitária:

$$
\int_{-\infty}^{\infty} \psi^{2}(u) \mathrm{d} u=1
$$

A primeira ondaleta surgiu em 1910 com A. Haar e é definida como:

$$
\psi(u)^{(H)} \equiv \begin{cases}-1 / \sqrt{2}, & -1<u \leq 0 \\ 1 / \sqrt{2}, & 0<u \leq 1 \\ 0, & \text { caso contrário }\end{cases}
$$


No contexto de redução de dimensionalidade de séries temporais, o uso desta transformada foi inicialmente proposta em [CF99] e sucessivas análises foram realizadas, por exemplo, em [WAA00a], [Mör03] e [SS99].

A figura 3.3 mostra uma série original (curva superior/vermelho) e a respectiva série reconstruída (curva inferior/azul) a partir de 8 ondaletas de Haar.
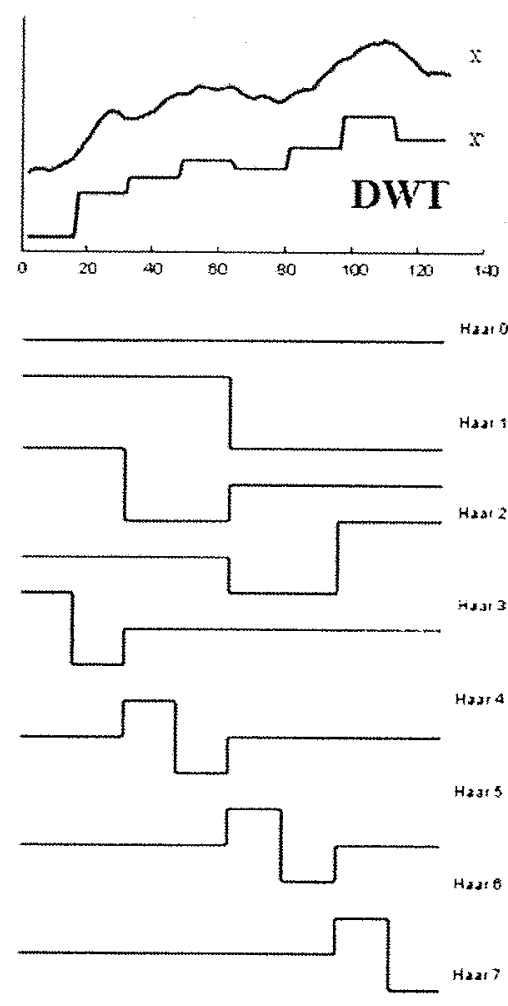

Figura 3.3: Transformada discreta de ondaletas

(Série com 130 pontos no tempo e a representação de 8 ondaletas de Haar. A série original está em cor vermelha e a reconstruída em cor azul. Figura extraída de [Keo01])

Ao passo que DFT mapeia uma série temporal discreta para o domínio temporal, DWT mapeia esta mesma série para um domínio à qual permite localização em ambos os domínios (temporal e das freqüências).

DWT não é sensivel a deslocamentos verticais da série temporal e o tempo de computação dos coeficientes de ondaletas é $O(n)$ [CF99].

Assim como a DFT, a DWT deve ser aplicada em séries ou sinais cujo tamanho seja uma potência de 2. Já o número $N$ de pontos desejados para a série reduzida pode ser qualquer número entre um e o tamanho da série.

Existem diversas famílias de ondaletas conhecidas: Haar, Daubechies, Coiflets e Symm- 
lets [Gra95], conforme figura 3.4. Cada família possui subclasses, que se distinguem pelo número de coeficientes e nível de resolução. As famílias de Haar e Daubechies são transformações ortonormais enquanto Coiflets e Symmlets são transformações bi-ortonormais.
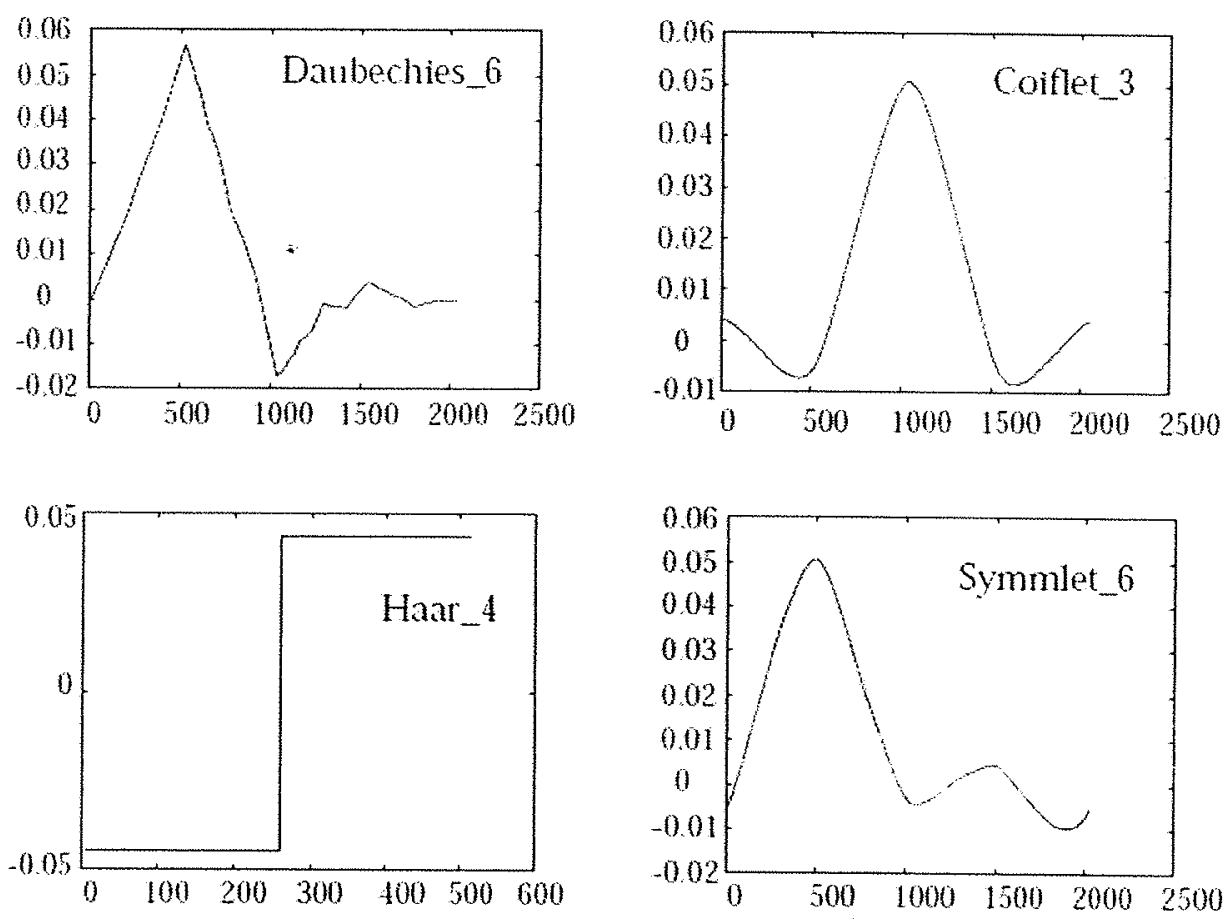

Figura 3.4: Diferentes famílias de ondaletas

(Figura extraída de [Gra95])

A figura 3.5 mostra uma série original, proveniente de uma central de atendimento, medindo-se o número de usuários atendidos via chat em intervalos de um minuto, dentro do período de 06:00:00 às 23:26:00 do dia 26/12/2005, contendo $n=1024$ pontos. A série original está em cor preta (série superior) e a série reduzida a $N=64$ pontos utilizando DWT (6,25\% do tamanho da série original) e depois reconstruída, em vermelho (série inferior). A série original foi deslocada 15 unidades para cima, a fim de facilitar a comparação visual.

\subsection{PIP - Pontos perceptualmente importantes}

Numa sequiência como em uma série temporal, os pontos críticos (por exemplo, aqueles cujos valores diferem abruptamente dos de seus vizinhos) podem ser considerados perceptualmente importantes. Um conjunto de pontos perceptualmente importantes (Perceptually Important Points - PIP) pode ser utilizado para representar uma série. Esta representação permite a comparação de séries temporais de diferentes tamanhos [FCLN04]. 


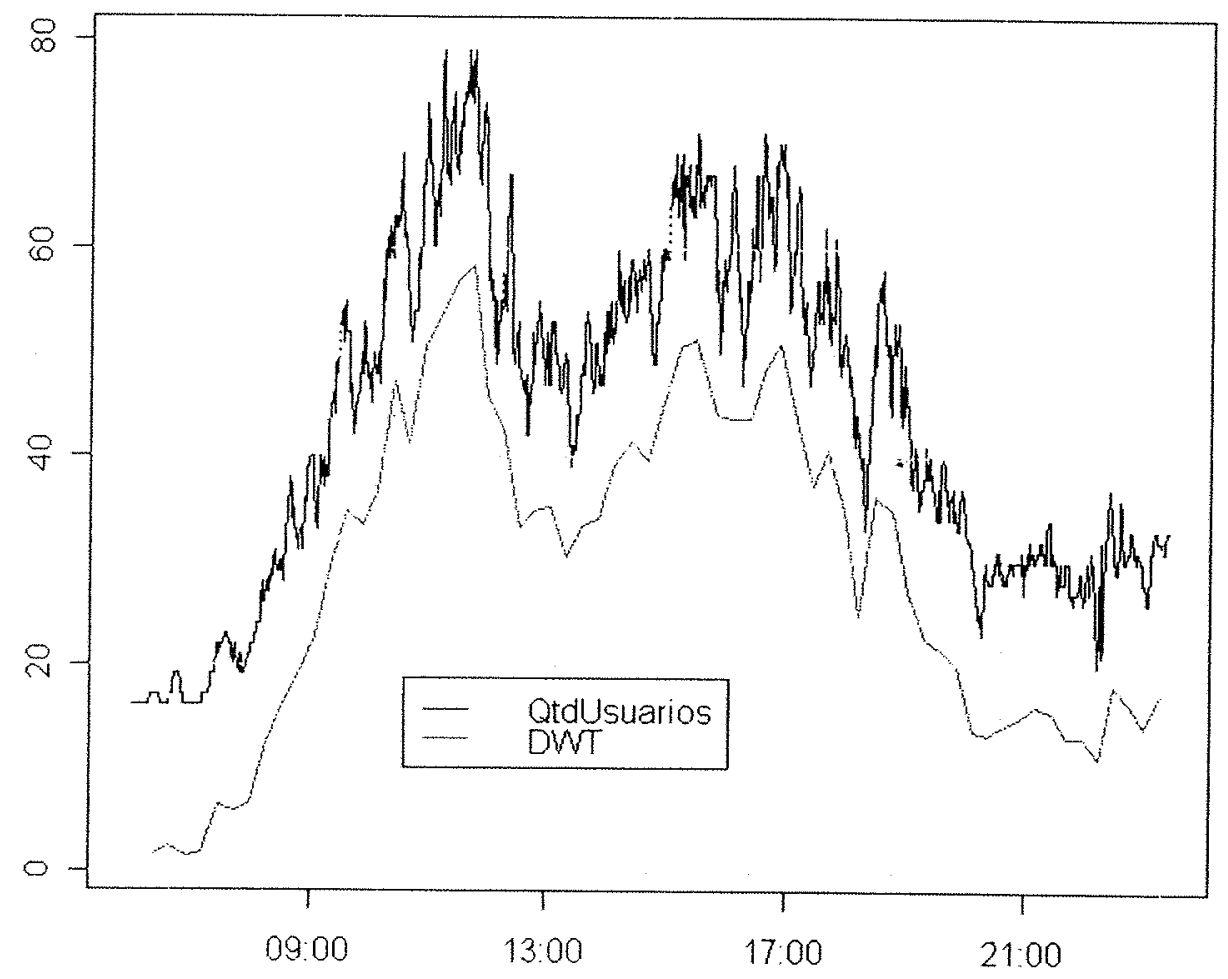

Figura 3.5: Série original e reconstituída com DWT

PIP é uma abordagem adaptada para séries temporais semelhantes a um eletrocardiograma, devido a seus comportamentos únicos como a periodicidade. Estas séries (eletrocardiogramas) são tipicamente caracterizadas por poucos pontos críticos e considerações a serem analisadas em períodos grandes e períodos curtos. Em adição, pode-se identificar comportamentos do mercado de ações, que possuem alta probabilidade de repetição de comportamento.

Esta é uma representação que originou-se de comparaçōes de séries temporais do mercado financeiro, onde as grandes oscilações nos movimentos das ações de empresas são os fatos mais importantes a serem analizados [FCLN04].

A figura 3.6 mostra 7 PIPs identificados em uma série temporal e a série reconstruída a partir desses 7 PIPs. Observe que pequenas oscilações da curva original não aparecem na curva reconstruída, mas a forma geral da curva é recuperada de forma satisfatória.

A identificação dos PIPs em uma série é realizada por um algoritmo iterativo. O primeiro e o último pontos da série são os dois PIPs iniciais, independente da série considerada. A partir destes dois PIPs, obtém-se o terceito PIP que será o ponto da série original que possui a maior distância vertical em relação ao segmento que liga os dois PIPs anteriores. Em seguida, o quarto PIP corresponde ao ponto que possui a maior distância vertical em relação aos dois segmentos adjacentes, um que liga o primeiro ao terceiro PIP e outro que liga o terceiro PIP 


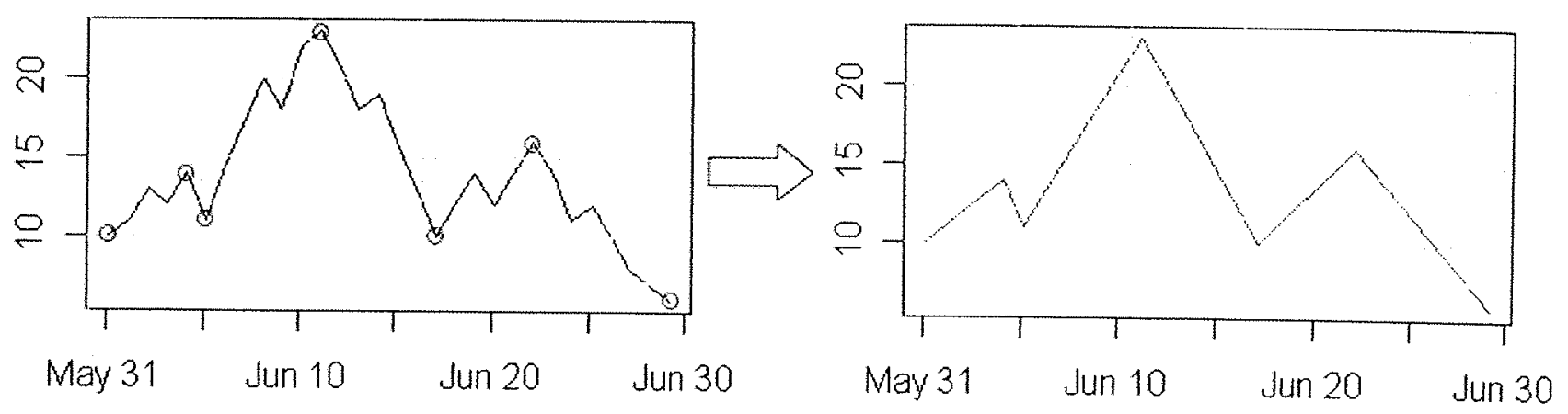

Figura 3.6: Identificação de 7 PIPs

(Resultado da identificação de 7 pontos importantes de percepção de uma série com 30 pontos. Série de vendas de um produto no mês de junho de determinado ano)

ao segundo. Após a identificação do quarto PIP, pode-se formar três segmentos de reta, cada um ligando um PIP ao PIP adjacente. O processo continua iterativamente até que o número de PIPs encontrados seja igual ao tamanho da série, ou até que o número desejado de PIPs seja encontrado.

Ao invés de armazenar os PIPs de acordo com o tempo (eixo temporal), os PIPs são armazenados de acordo com sua respectiva importância, ou seja, de acordo com a ordem de identificação. Utilizando-se tal ordenação, pode-se escolher um número menor de representantes para simplificar a sua representação.

A figura 3.7 mostra os passos de identificação dos 5 primeiros PIPs em uma série temporal, enquanto a figura 3.8 mostra os 10 primeiros PIPs identificados.

A figura 3.9 mostra uma série original, proveniente de uma central de atendimento, medindo-se o número de usuários atendidos via chat em intervalos de um minuto, dentro do período de 06:00:00 às 23:26:00 do dia 26/12/2005, contendo $n=1024$ pontos. A série original está em cor preta (série superior) e a série reduzida para $N=64$ PIPs $(6,25 \%$ do tamanho da série original) e depois reconstruída está em vermelho (série inferior). A série original foi deslocada 15 unidades para cima, a fim de facilitar a comparação visual.

PIP é uma redução mais custosa computacionalmente pois analisa-se muitos pontos a cada passo do algoritmo. Seu tempo de execução é $O\left(n^{2}\right)$. 


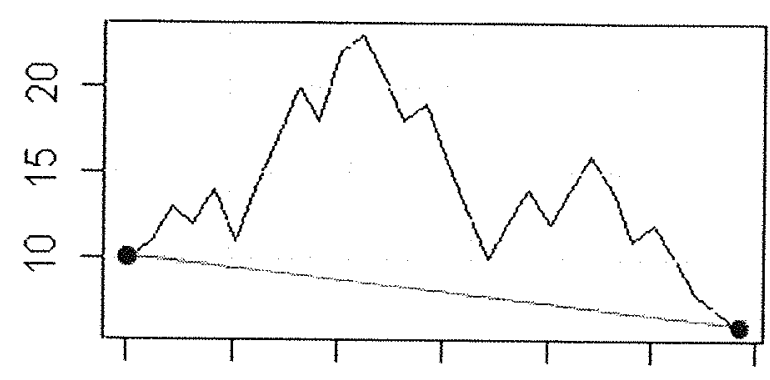

May 31 Jun $10 \quad$ Jun 20 Jun 30

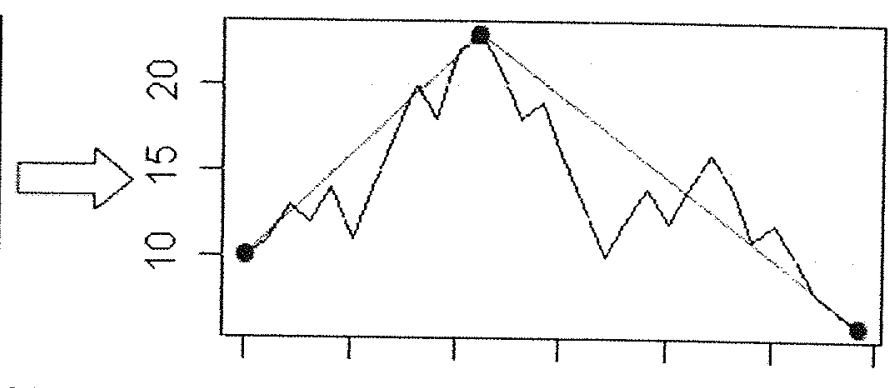

May 31 Jun 10

Jun 20

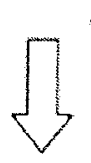

Jun 30

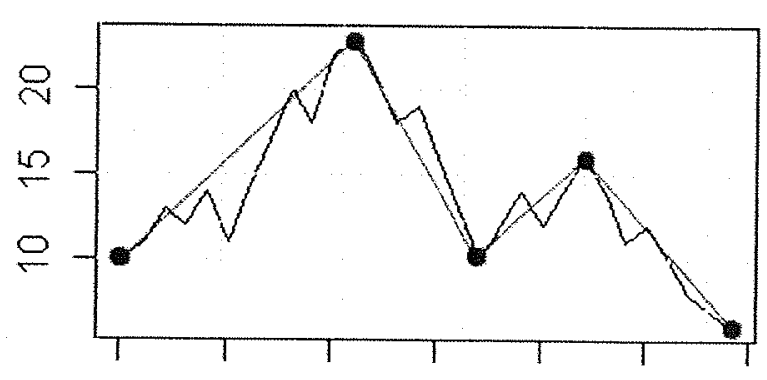

May 31

Jun 10

Jun 20

Jun 30

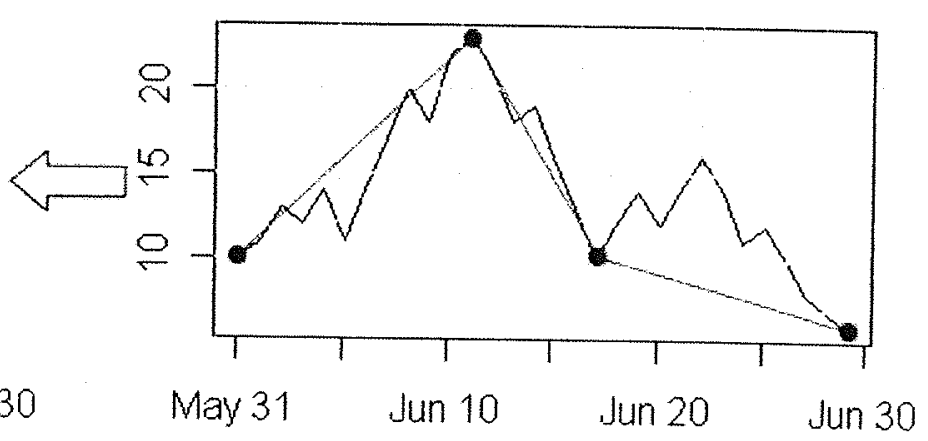

Figura 3.7: Identificação de 5 PIPs - passo 1

(Resultado da identificação de 5 pontos importantes de percepção da série da figura 3.6)

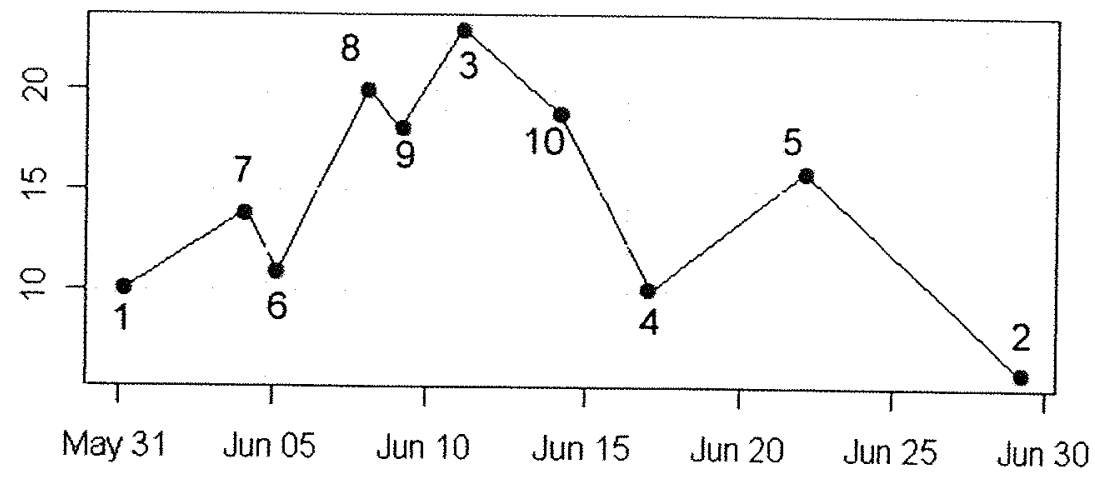

Figura 3.8: Ordenação de 10 PIPs identificados - passo 2

(Resultado da ordenação de 10 pontos importantes de percepção da série da figura 3.6)

\subsection{PAA}

PAA vem do inglês Piecewise Aggregate Approximation e decidimos fazer referência a este algoritmo simplesmente por PAA por não encontrarmos uma tradução adequada.

A idéia deste algoritmo consiste em dividir uma série em $N$ segmentos de tamanho fixo, adjacentes um ao outro, porém disjuntos, e calcular a média dos valores dos pontos dentro de 


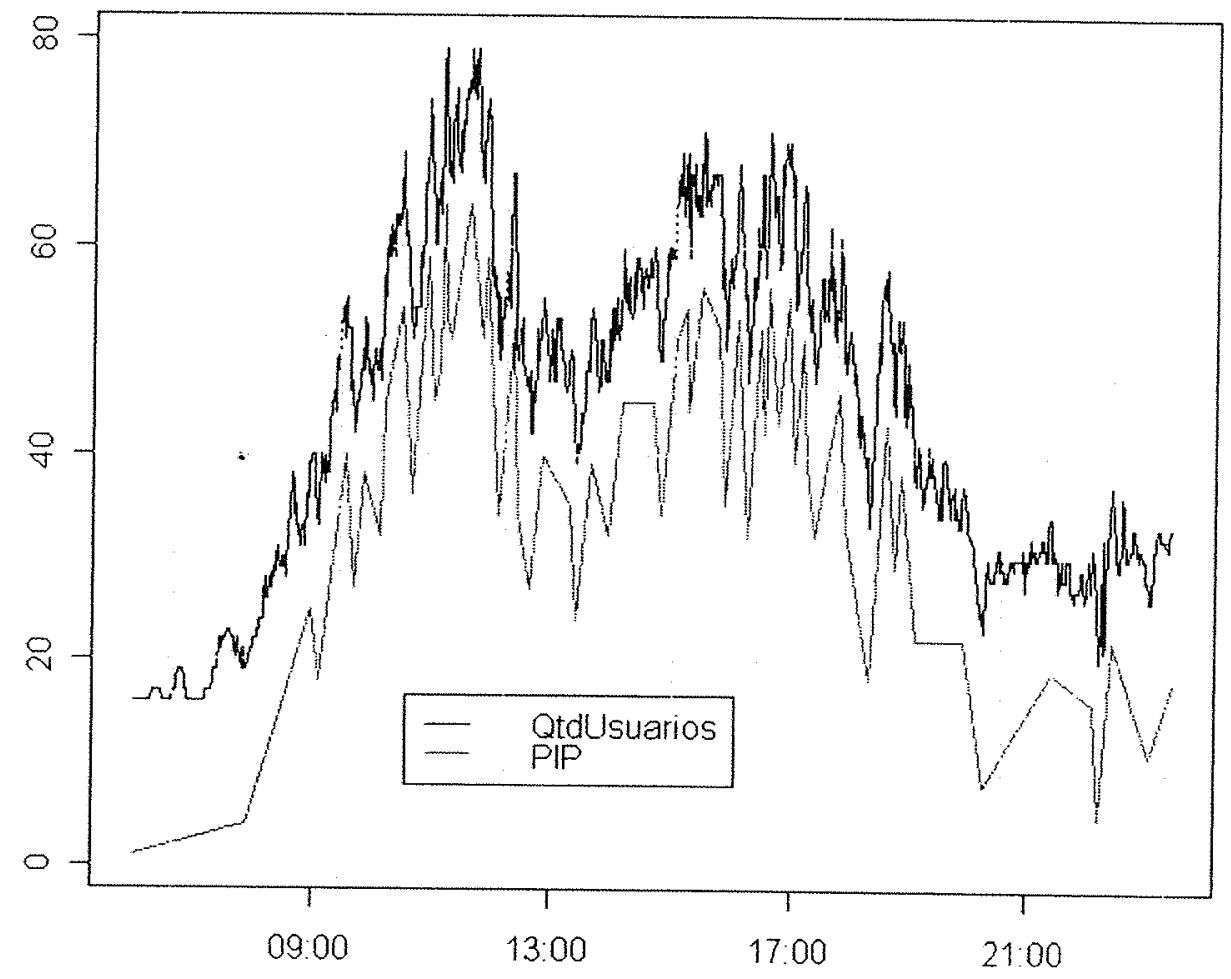

Figura 3.9: Série original e reconstituída com PIP

cada segmento, obtendo-se uma série formada pelos valores médios de cada um dos segmentos.

Todas as séries temporais devem ter o mesmo tamanho, ou seja, séries com $n$ pontos. $\mathrm{O}$ número de dimensões desejado $N$, tal que $1 \leq N \leq n$, será considerado um fator de $n$, embora isso não seja um requisito para o algoritmo.

A figura 3.10 ilustra a redução de uma série temporal de $n=8$ pontos para uma série de $N=2$ pontos. A série original $\vec{x}=(-1,-2,-1,0,2,1,1,0)$ foi dividida em dois segmentos e a média de cada um foi calculada. O vetor de médias $\vec{X}=$ (média $(-1,-2,-1,0)$, média $(2,1,1,0))=(-1,1)$ é a série temporal reduzida.

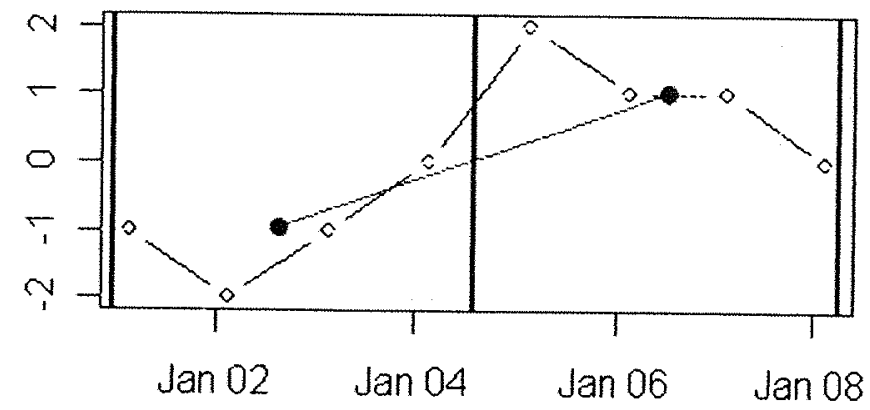

Figura 3.10: Exemplo de redução de dimensionalidade por PAA. 
A figura 3.11 mostra uma série original com 130 pontos (curva superior/azul) e a respectiva série reduzida (curva inferior/vermelho) por PAA para 8 pontos.

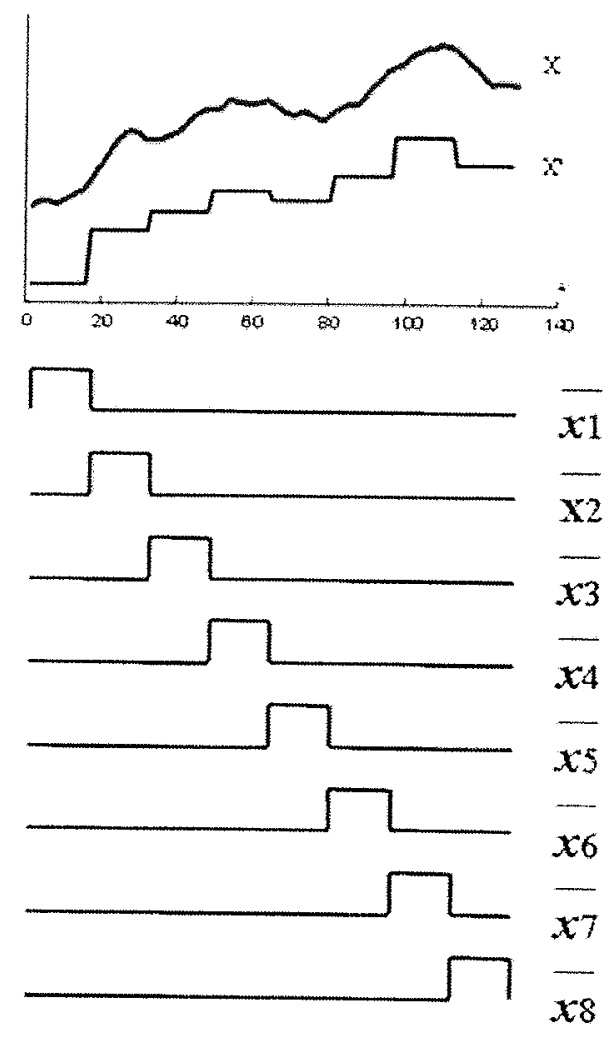

Figura 3.11: PAA - combinação de segmentos

(Série com 130 pontos no tempo e a representação agregada de segmentos. A série original está em cor vermelha e a reconstruída em cor azul. Note que a série reduzida é uma combinação de 8 funções do tipo "box". Figura extraída de [Keo01])

Dois casos não são interessantes. Quando $N=n$ não ocorre redução de dimensionalidade e quando $N=1$ temos apenas um ponto que equivale à média da série temporal.

A complexidade na construção deste índice para o problema da similaridade é $O(\mathrm{Nm})$.

A figura 3.12 mostra uma série original, proveniente de uma central de atendimento, medindo-se o número de usuários atendidos via chat em intervalos de um minuto, dentro do período de 06:00:00 às 23:26:00 do dia 26/12/2005, contendo $n=1024$ pontos. A série original está em cor preta (série superior) e a série reduzida a $N=64$ pontos utilizando PAA ( $6,25 \%$ do tamanho da série original) e depois reconstruída, em vermelho (série inferior). A série original foi deslocada 15 unidades para cima, a fim de facilitar a comparação visual. 


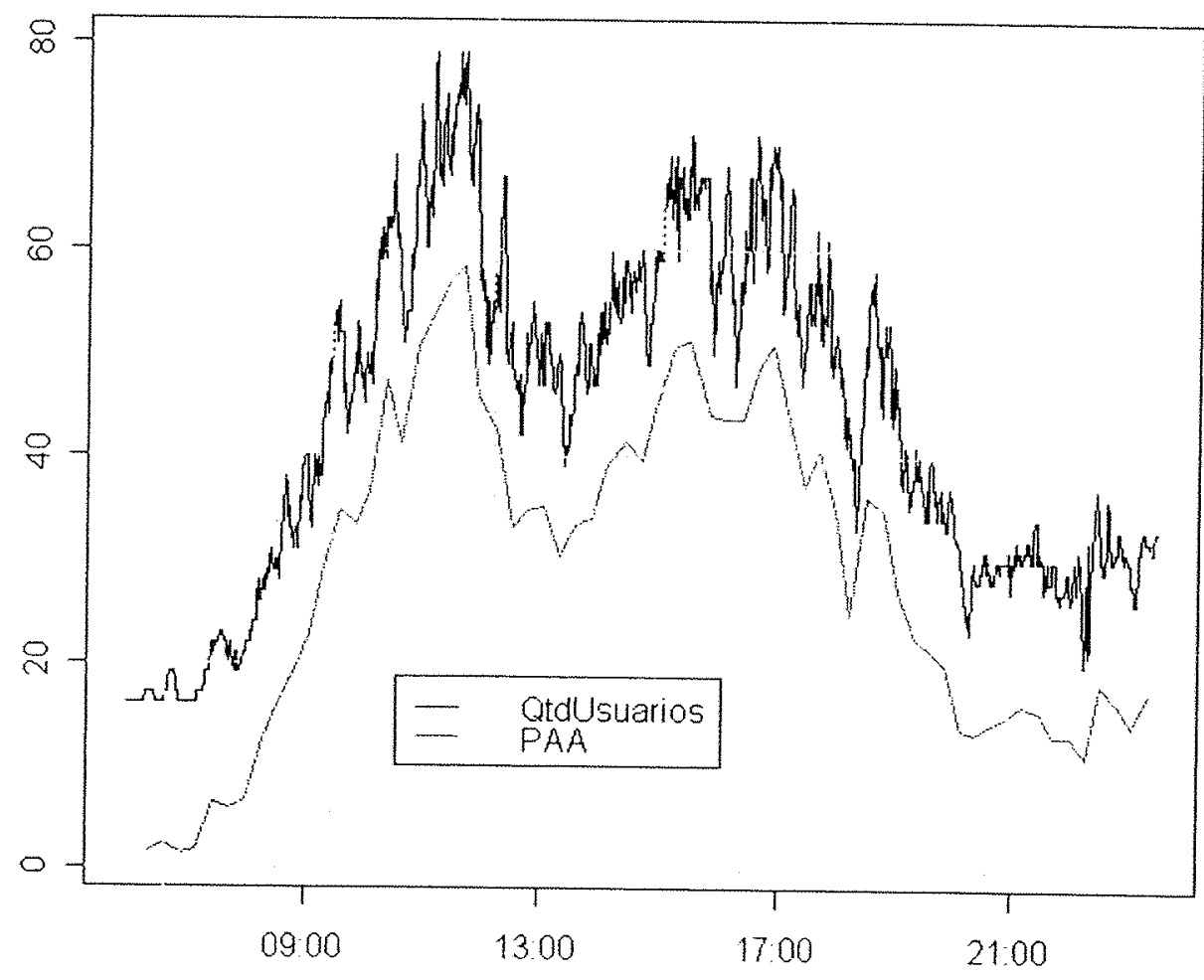

Figura 3.12: Série original e reconstituída com PAA

\subsection{Outros algoritmos}

Para que o leitor tenha uma idéia da diversidade de algoritmos utilizados para a redução de dimensionalidade de séries temporais, listamos os diferentes algoritmos que encontramos durante o estudo, juntamente com algumas referências:

- baseados em transformação de domínio

- Discrete Fourier Transform - DFT [AFS93];

- Discrete Wavelet Transform - DWT [CF99];

- Singular Value Decomposition - SVD ou Karhunen-Love transform $K L\left[\mathrm{WSA}^{+} 96\right]$;

- Singular Value Decomposition-D - SVDD [KJF97];

- Weighted Sum Singular Value Decomposition - WSSVD;

- representações mais curtas no próprio domínio temporal 
- Piecewise Aggregate Approximation - PAA [KCMP01a];

- Perceptually Important Points - PIP [FCLN04];

- Piecewise Linear (Constant) Approximation - PLA (PCA) [KP98];

- Adaptive Piecewise Constant Approximation - APCA [KCMP01b];

- representação discreta (domínio temporal)

- Symbolic Approximation - SA;

- Symbolic Aggregate ApproXimation - SAX [LKLC03];

- Aligned Subsequence Matchin/Generalized Sufix Tree - ASM/GST [PLC99];

- outras representações

- CHEByshev polynomials - CHEB [CN04];

- Self-Organising Maps - SOM [WSHA04];

- Approximate Distance Maps - ADM [SW90];

- Dynamic Time Warping - DTW/Derivative DTW - DDTW [KP01]

A figura 3.13 ilustra o efeito de alguns desses algoritmos sobre uma série temporal de tamanho 130. Em cada gráfico, a série original é a mostrada em cor vermelho (série superior) e a representação da respectiva série reduzida é mostrada em cor azul (série inferior). 

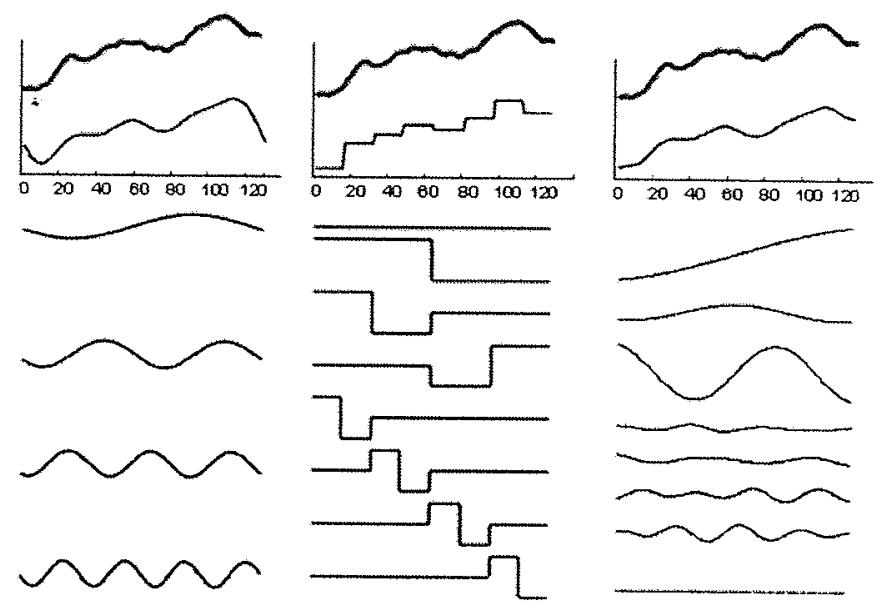

DFT

DWT

SVD
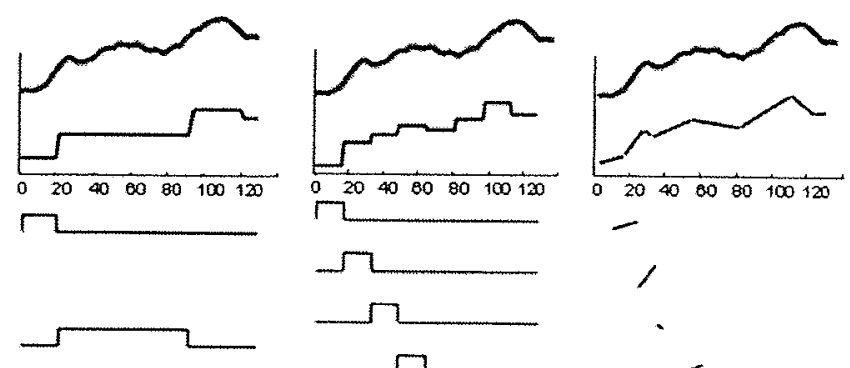

-
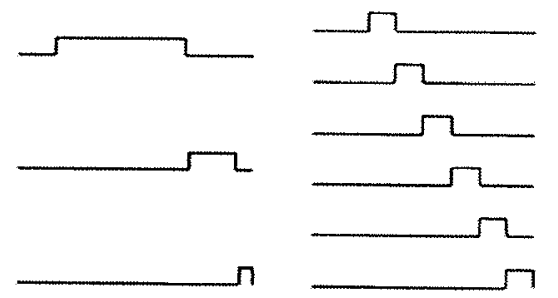

APCA

PAA

PLA

Figura 3.13: Alguns algoritmos de redução de dimensionalidade (Figura extraída de [Keo01]) 


\section{Capítulo 4}

\section{Avaliação dos algoritmos}

A avaliação de algoritmos com respeito ao desempenho computacional dos mesmos não é em geral uma tarefa simples. O desempenho computacional pode ser altamente dependente de diversos parâmetros tais como as particularidades de implementação, a configuração do equipamento utilizado e as características dos dados utilizados.

No caso específico de algoritmos de redução de dimensionalidade de séries temporais, uma avaliação bastante comum na literatura é a análise do desempenho dos algoritmos na construção de índices multidimensionais e na consulta sobre esses índices. Como exemplos de análises citados comumente, encontram-se o tempo gasto para efetuar a redução (que afeta diretamente o tempo de construção ou atualização de um índice), ou então o número de nós visitados em média por consulta (o que equivale ao número de acessos às páginas de disco, uma vez que cada nó do índice geralmente é armazenado em uma página de disco), recursos de memória, processamento e tempo de execução, etc.

Em particular, há várias publicações com avaliações sobre os quatro algoritmos estudados neste trabalho: Perceptually Important Points - PIP [FCLN04, CFNL04, Gon04], Piecewise Aggregate Approximation - PAA [KCMP01b, KCMP01a], Discrete Fourier Transform DFT [WAA00a, KP00, KCMP01b, KCMP01a, Mör03, WAA00b] e Discrete Wavelet Transform - DWT [WAA00a, KCMP01b, KCMP01a, Mör03, WAA00b].

Os dados quantitativos avaliados dependem não apenas das particularidades de implementação, mas também de outros fatores como o hardware utilizado, a estrutura de índice utilizada, os tipos de dados utilizados. Portanto, análises deste tipo são úteis apenas para uma determinada configuração de uso.

Trabalhos mais recentes mostram uma maior preocupação com avaliações que sejam inde- 
pendentes de implementação. No contexto de busca por similaridade, pode-se encontrar com relativa freqüência o uso de conceitos como "poder de poda" (prunning power), "precisão" (precision) e "reconhecimento" (recall), a serem descritos adiante.

Neste trabalho, decidimos realizar avaliações qualitativas dos algoritmos de redução de dimensionalidade estudados. Para tanto, centramos os estudos em duas atividades comuns sobre bases de dados: busca, que no caso específico de séries temporais é uma busca por similaridade, e aglomeração, uma análise exploratória utilizada em processos de mineração de. dados. A seguir descrevemos critérios propostos para as avaliações qualitativas referentes a essas duas atividades.

\subsection{No contexto de busca por similaridade}

Conforme descrito no capítulo 2 , em buscas por similaridade têm-se uma série temporal de consulta $\vec{q}$, um conjunto de séries temporais $B$ (base de dados) e uma distância $D_{\text {orig }}$ definida entre séries temporais. No caso de range query, é dado também uma tolerância $\epsilon$ e deseja-se recuperar todas as séries na base $B$ que estejam a uma distância não superior a $\epsilon$ de $\vec{q}$. No caso da busca pelos vizinhos mais próximos, é dado um inteiro $k$ e deseja-se recuperar os $k$ vizinhos mais próximos de $\vec{q}$ em $B$.

$\mathrm{Na}$ prática, as séries originais da base $B$ são reduzidas utilizando-se algum algoritmo de redução de dimensionalidade, gerando-se um conjunto $B_{r}$ de séries reduzidas que são usadas para a construção de um índice. Em qualquer categoria de busca, a série de consulta $\vec{q}$ é reduzida, gerando uma série temporal reduzida $\vec{Q}$, e é esta última que é utilizada nas buscas. A resposta fornecida pela busca é pós-processada a fim de se eliminar os falsos positivos, antes de ser devolvida para o usuário. É importante relembrarmos que as condições suficientes para a existência de nenhum falso negativo são dadas pelo teorema 2.1, citado no capítulo 2 .

Denotemos por $R$ o conjunto de séries temporais em $B$ satisfazendo a consulta original e por $R^{\prime}$ o conjunto de séries temporais em $B_{r}$ satisfazendo a consulta com a série reduzida. Neste contexto, o ideal seria que o conjunto $R^{\prime}$ fosse equivalente ao conjunto $R$. Mas, em geral têm-se que $R^{\prime}$ é um superconjunto de $R$, ou seja, contém mais séries temporais que aquelas que satisfazem a consulta. Quanto maior o número de elementos excedentes em $R^{\prime}$, mais tempo será necessário para o pós-processamento. Portanto, quando consideramos algoritmos de redução de dimensionalidade, um dos aspectos que podem ser avaliados é a relação entre $R$ e $R^{\prime}$. 
Na literatura encontramos alguns critérios utilizados para tal análise. Descrevemos a seguir, três deles.

Poder de poda (Prunning power) [KCMP01a]:

$$
P P=\frac{\text { Número de objetos examinados }}{|B|}
$$

Precisão (precision): indica qual proporção dos dados recuperados são de fato os que satisfazem a consulta e é definida por

$$
P(q, n, N)=\frac{\left|R \cap R^{\prime}\right|}{\left|R^{\prime}\right|}
$$

Reconhecimento (Recall): indica qual proporção dos dados que satisfazem a consulta são recuperados e é definida por

$$
R(q, n, N)=\frac{\left|R \cap R^{\prime}\right|}{|R|}
$$

Note que no caso de busca $k$-NN a precisão $P$ e o reconhecimento $R$ coincidem pois $|R|=\left|R^{\prime}\right|$

Neste trabalho propomos um novo critério, na tentativa de responder à seguinte pergunta. Supondo-se que as medidas de distância $D_{\text {orig }}$ e $D_{\text {reduzida }}$ utilizadas satisfazem as condições do teorema 2.1, em buscas do tipo $k$-NN qual deve ser o número de vizinhos mais próximos $k^{\prime}$ que devemos buscar no índice (das séries reduzidas) para se garantir a recuperação dos $k$ vizinhos mais próximos?

Visto de outra forma, supondo que a maior distância entre a consulta $\vec{q}$ e os seus $k$ vizinhos mais próximos seja $\epsilon$, então $k^{\prime}$ será no máximo igual ao tamanho do conjunto de séries reduzidas que estão a distância não superior a $\epsilon$ de $\vec{Q}$.

\subsection{1 Índice de Manutenção de Proximidade}

Seja $B=\left\{\vec{x}_{1}, \vec{x}_{2}, \ldots, \vec{x}_{m}\right\}$ um conjunto com $m$ séries temporais e seja $B_{r}=$ $\left\{\vec{X}_{1}, \vec{X}_{2}, \ldots, \vec{X}_{m}\right\}$ o conjunto com as respectivas séries temporais reduzidas.

Para cada $i \in\{1,2, \ldots, m\}$, considere o conjunto $B_{i}=B \backslash\left\{\vec{x}_{i}\right\}$, i.e., o conjunto B a menos da série $x_{i}$. Similarmente, seja $B_{r i}=B_{r} \backslash\left\{\vec{X}_{i}\right\}$. Tomando-se $\vec{q}=\vec{x}_{i}$, podemos calcular os $k$ vizinhos mais próximos de $\vec{q}$ em $B_{i}$, os quais denotamos pelo conjunto $R(k, i)$. Não é difícil 
verificar que $R(k, i) \subset R\left(k^{\prime}, i\right)$ para qualquer $k^{\prime}>k$. Similarmente, denotamos por $R^{\prime}(k, i)$ os $k$ vizinhos mais próximos de $\vec{X}_{i}$ em $B_{r i}$.

Para compararmos os conjuntos $R(k, i)$ e $R^{\prime}(k, i)$ consideramos os índices das séries contidos nesses conjuntos. Assim, $j \in \operatorname{Ind}(R(k, i)) \Longleftrightarrow \vec{x}_{j} \in R(k, i)$, para qualquer $j \in\{1,2, \ldots, m-$ 1\}. De forma similar definimos o conjunto $\operatorname{Ind}\left(R^{\prime}(k, i)\right)$.

Pergunta: Dado $k$, qual é o menor inteiro $k_{i}^{\prime}, k_{i}^{\prime} \geq k$, tal que $\operatorname{Ind}(R(k, i)) \subseteq \operatorname{Ind}\left(R^{\prime}\left(k_{i}^{\prime}, i\right)\right)$ ?

O critério propostó é dado por :

$$
I M P=\frac{1}{m} \sum_{i=1}^{m} \min \left\{k_{i}^{\prime}: \operatorname{Ind}(R(k, i)) \subseteq \operatorname{Ind}\left(R^{\prime}\left(k_{i}^{\prime}, i\right)\right)\right\}
$$

Este critério pode ser interpretado como o número médio estimado de vizinhos que devem ser recuperados no índice para se garantir que as séries reduzidas de todos os $k$ primeiros vizinhos da série original estejam presentes no conjunto recuperado.

\subsection{No contexto de cálculo de aglomerados}

Dado um conjunto de objetos, a aglomeração (clustering) é um processo de divisão de dados em aglomerados (clusters) de objetos similares, segundo algum critério de similaridade. Tratase de uma técnica de análise exploratória de dados em que se busca separar os objetos ou as observações em classes "naturais" de forma que os elementos pertencentes a um mesmo grupo tenham um alto grau de semelhança ou similaridade, enquanto que elementos pertencentes a grupos distintos tenham pouca semelhança entre si [And73].

O cálculo de aglomerados é uma atividade comum em mineração de dados. No contexto de séries temporais, o cálculo de aglomerados pode ser usado, por exemplo, para detectar padrões de comportamento distintos (cada aglomerado corresponderia a um tipo de comportamento).

Uma vez que o cálculo de aglomerados envolve o cálculo de similaridade entre os objetos, o tamanho das séries temporais afeta diretamente o tempo de processamento. Para reduzir o tempo de processamento pode-se considerar no processo de aglomeração o conjunto das séries reduzidas em vez do conjunto das séries originais.

Porém, ao se adotar tal procedimento, devemos questionar se os aglomerados encontrados no conjunto das séries reduzidas refletem os aglomerados naturais existentes no conjunto das séries originais. Como podemos avaliar de que forma os algoritmos de redução de dimension- 
alidade afetam os resultados de aglomeração?

Para responder a essas perguntas, propomos o uso de índices que comparam aglomerações no sentido de indicar quão parecidos são duas aglomerações.

A seguir descrevemos formalmente o processo de aglomeração e discutimos alguns índices para comparação de aglomeraçōes.

\subsubsection{Comparação de aglomerações}

Seja $B$ um conjunto de objetos não vazio. Em sua maneira mais simples, um processo de aglomeração de $B$ é uma partição do conjunto $B$ em $c$ subconjuntos $C_{1}, C_{2}, \ldots, C_{c}$ chamados agrupamentos (ou aglomerados) tais que:

1. os subconjuntos $C_{1}, C_{2}, \ldots, C_{c}$ são dois a dois disjuntos, i.e., $C_{i} \cap C_{j}=\emptyset, \forall i, j \in$ $\{1, \ldots, c\}, i \neq j$

2. a uniāo dos subconjuntos $C_{1}, C_{2}, \ldots, C_{c}$ é exatamente igual a $B$, i.e., $\bigcup_{i=1}^{c} C_{i}=B$.

Seja $m$ o número de objetos em $B$ e $m_{i}$ o número de objetos no aglomerado $C_{i}$. Então:

$$
m=\sum_{i=1}^{c} m_{i}
$$

Assume-se que $m_{i}>0$, ou seja, que todos os aglomerados são não vazios.

Existem várias abordagens e algoritmos para se obter uma aglomeração a partir de um conjunto de dados. Por se tratar de um tema vastamente explorado na literatura e por não se tratar de assunto central deste trabalho, não incluiremos nenhuma descrição sobre algoritmos de aglomeração nesta seção. O apêndice A descreve os dois algoritmos de aglomeração, PAM e CLARA, utilizados na parte experimental deste trabalho. Maiores informações sobre algoritmos de aglomeração podem ser encontrados em referências como [JMF99, XW05, TK06].

Tanto em situações em que desejamos comparar diferentes algoritmos de aglomeração ou em situações em que conhecemos os aglomerados existentes e desejamos avaliar se um algoritmo é capaz de identificar esses aglomerados corretamente surge a necessidade de comparar duas aglomeraçōes. Numa comparação desejamos saber, por exemplo, o quão parecidos são as duas aglomerações. 
Existem alguns trabalhos que propõe índices para comparar duas aglomerações distintas de um mesmo conjunto de dados. Um dos trabalhos pioneiros é devido a William M. Rand [Ran71] e várias variantes do índice proposto por ele, além de outros índices, foram introduzidas subsequentemente [Mei02].

Nesta seção descrevemos dois critérios para a comparação de aglomerações. Antes disso, porém, introduzimos algumas notações e conceitos.

Seja $B$ um conjunto de dados e sejam $C=\left\{C_{1}, C_{2}, \ldots, C_{c}\right\}$ e $C^{\prime}=\left\{C_{1}^{\prime}, C_{2}^{\prime}, \ldots, C_{c}^{\prime}\right\}$ duas aglomerações com, respectivamente, $n_{c}$ e $n_{c}^{\prime}$ aglomerados.

Os critérios descritos a seguir, assim como a maior parte dos existentes [Mei02] podem ser relacionados com a matriz de confusão, descrita a seguir.

A matriz $M$ de confusão das aglomerações $C$ e $C^{\prime}$ é uma matriz $c \times c^{\prime}$ cujo $i j$-ésimo elemento é o número de observações da interseç̧ão dos aglomerados $C_{i}$ de $C$ e $C_{j}^{\prime}$ de $C^{\prime}$ :

$$
m_{i j}=\left|C_{i} \cap C_{j}^{\prime}\right|
$$

Critérios inicialmente propostos como o índice de Rand [Ran71] fazem uso de contagem de pares de elementos que pertencem ou não a um mesmo aglomerado de acordo com as duas aglomerações. Qualquer par de elementos de $B$ pode ser considerado como fazendo parte de um dos seguintes grupos:

$N_{11}$ número de observações que estão no mesmo aglomerado em $C$ e $C^{\prime}$;

$N_{00}$ número de observações que estão em diferentes aglomerados em $C$ e $C^{\prime}$;

$N_{10}$ número de observações que estão no mesmo aglomerado em $C$ mas não em $C^{\prime}$

$N_{01}$ número de observações que estão no mesmo aglomerado em $C^{\prime}$ mas não em $C$

Muitos dos índices propostos na literatura utilizam uma combinação dos valores dos grupos acima [Mei02].

\subsection{2 Índice de Permanência em Aglomerados}

Suponha que temos um conjunto $B$ contendo 21 séries temporais no espaço $n$-dimensional, mas que serão representadas, sem perda de generalidade, por pontos no espaço 2-dimensional, 
conforme figura 4.1. Suponha também que após aplicar o processo de aglomeração com $c=3$ obtemos o resultado ilustrado na figura 4.2 , cujos aglomerados são identificados por $C_{1}, C_{2} \mathrm{e}$ $C_{3}$.

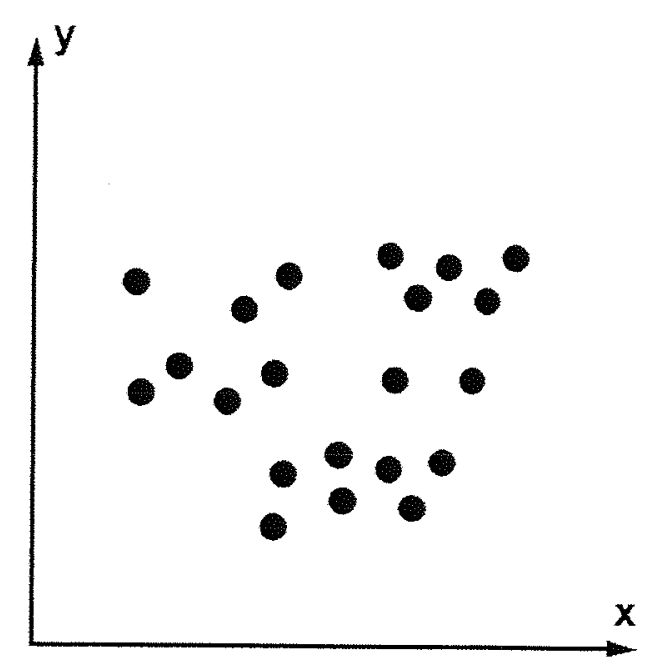

Figura 4 1: Representação de 21 séries em duas dimensões

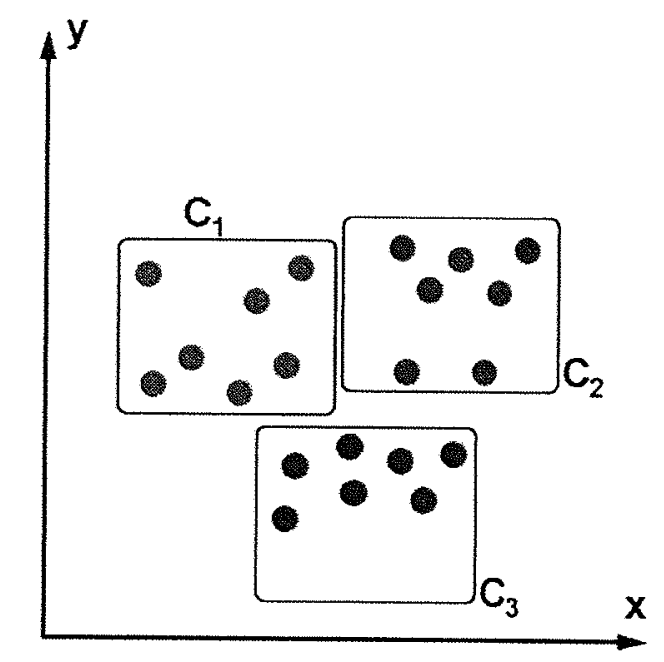

Figura 4.2: Aglomeração das 21 séries em 3 aglomerados

Agora aplicamos a redução em todas as 21 séries temporais utilizando os algoritmos de redução de dimensionalidade vistos anteriormente. Algum deslocamento, seja ele pequeno ou grande, acontecerá nas séries no espaço 2-dimensional, representadas na figura 4.3. Com os dados das 21 séries reduzidas como entrada para um novo processo de aglomeração $\operatorname{com} c=3$ aglomerados, obtemos três aglomerados rotulados de $C_{1}^{\prime}, C_{1}^{\prime}$ e $C_{3}^{\prime}$, conforme figura 4.4 .

Note que algumas séries que pertenciam ao aglomerado $C_{1}$ migraram para o aglomerado $C_{2}^{\prime}$, assim como houveram outras alteraçōes. Para percebermos qual foi a movimentação entre 


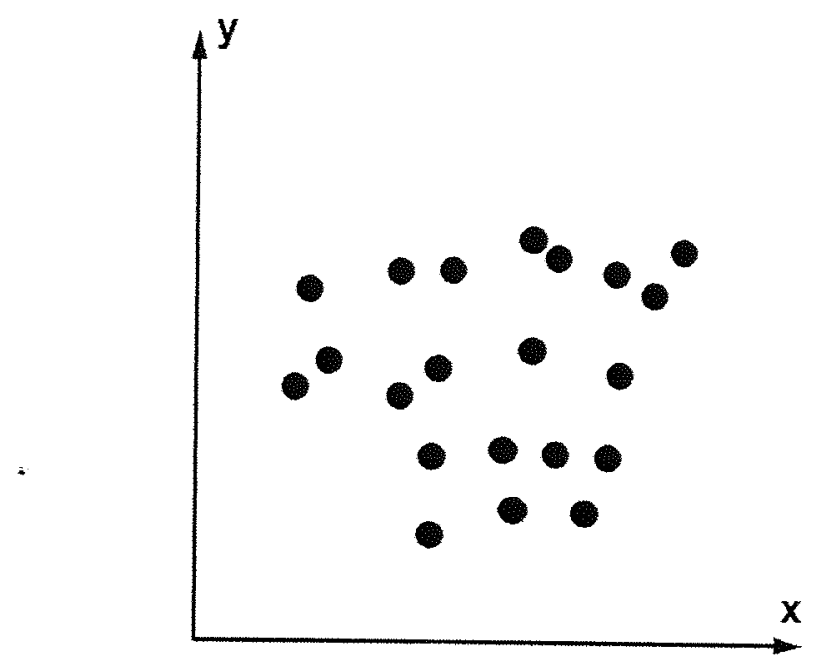

Figura 4.3: Representação de 21 séries reduzidas em duas dimensões

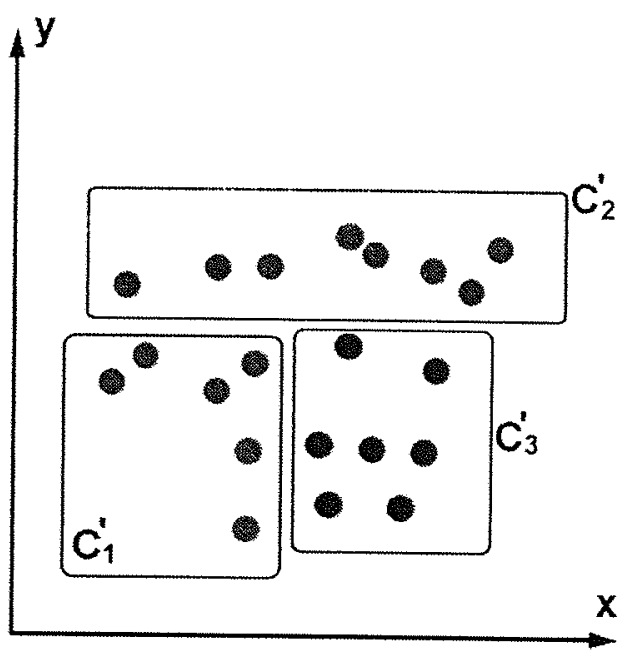

Figura 4.4: Aglomeração das 21 séries reduzidas em 3 aglomerados

os agrupamentos, representaremos os pontos das séries reduzidas no espaço 2-dimensional com o resultado dos dois processos de aglomeração conforme figura 4.5.

Um fato importante a ser notado na figura 4.5 é a quantidade de séries que permaneceram nos aglomerados. No aglomerado original $C_{1}$, permaneceram quatro séries em relação ao aglomerado $C_{1}^{\prime}$. No aglomerado $C_{2}$ permaneceram cinco séries com relação ao aglomerado $C_{2}^{\prime}$ e no aglomerado $C_{3}$ permaneceram cinco séries em relação ao aglomerado $C_{3}^{\prime}$. Logo a quantidade de séries que permaneceram em seus respectivos aglomerados foi de $4+5+5=14$, o que nos dá uma taxa de permanência em aglomerados de $14 / 21=67 \%$, ou seja, sessenta e sete por cento das séries se mantiveram em seus respectivos aglomerados. Isso se considerarmos que a relação entre os aglomerados é $C_{1} \simeq C_{1}^{\prime}, C_{2} \simeq C_{2}^{\prime}$ e $C_{3} \simeq C_{3}^{\prime}$. 


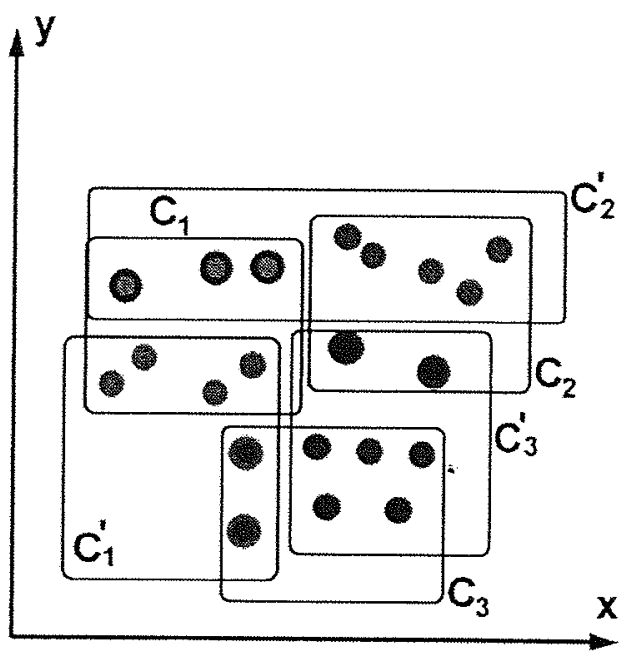

Figura 4.5: 21 séries reduzidas em 6 aglomerados de dois processos de aglomeração (O resultado do primeiro processo de aglomeração está nos três retângulos pretos e o resutado do processo de aglomeração da série reduzida está nos três retângulos azuis)

Um passo importante é identificar qual a relação entre os aglomerados das séries originais e os aglomerados das séries reduzidas. Para tanto é necessário computar as c! permutações possíveis que se relacionariam com os aglomerados $C_{1}, C_{2}$ e $C_{3}$.

Para descobrir qual a relação entre os aglomerados montamos uma tabela semelhante à matriz de confusão para as $c$ ! combinações e calculamos a taxa de pemanência para toda as c! permutações possíveis dos aglomerados nas séries reduzidas, conforme tabela 4.1.

\begin{tabular}{|c|c|c|c|}
\hline Aglomerado $C_{1}$ & Aglomerado $C_{2}$ & Aglomerado $C_{3}$ & $(\%)$ \\
\hline \hline$C_{1}^{\prime}$ & $C_{2}^{\prime}$ & $C_{3}^{\prime}$ & $(4+5+5) / 21=67$ \\
\hline$C_{1}^{\prime}$ & $C_{3}^{\prime}$ & $C_{2}^{\prime}$ & $(4+2+0) / 21=29$ \\
\hline$C_{2}^{\prime}$ & $C_{1}^{\prime}$ & $C_{3}^{\prime}$ & $(3+0+5) / 21=38$ \\
\hline$C_{2}^{\prime}$ & $C_{3}^{\prime}$ & $C_{1}^{\prime}$ & $(3+2+2) / 21=33$ \\
\hline$C_{3}^{\prime}$ & $C_{1}^{\prime}$ & $C_{2}^{\prime}$ & $(0+0+0) / 21=00$ \\
\hline$C_{3}^{\prime}$ & $C_{2}^{\prime}$ & $C_{1}^{\prime}$ & $(0+5+2) / 21=33$ \\
\hline
\end{tabular}

Tabela 4.1: Combinações dos aglomerados e IPA

Tomemos a linha de correspondência onde a taxa de permanência possui o maior valor dentre todos calculados. A esta taxa daremos o nome de Índice de Permanência em Aglomerados (IPA). No caso da tabela 4.1 o IPA $=67 \%$, onde a correspondência é dada por $C_{1} \simeq C_{1}^{\prime}$, $C_{2} \simeq C_{2}^{\prime}$ e $C_{3} \simeq C_{3}^{\prime}$. Podemos indicar essa correspondência através de uma função match que para cada aglomerado de $C$ associa o correspondente aglomerado em $C^{\prime}$. No caso da tabela acima temos $1=\operatorname{match}(1), 2=\operatorname{match}(2)$ e $3=\operatorname{match}(3)$. 
Após propormos este índice, descobrimos que ele já existia e havia sido proposto em [MH01]. Conforme [Mei02], esse índice pode ser definido formalmente por:

$$
I P A=\frac{1}{m} \sum_{j=\operatorname{match}(i)} m_{i j}
$$

onde $i$ e $j$ são, respectivamente, os índices de um aglomerado em $C$ e $C^{\prime}$, e $m_{i j}$ é uma entrada na matriz de confusão.

Além disso, a função match pode ser calculada diretamente a partir da matriz de confusão usando um algoritmo guloso. A idéia do algoritmo é a seguinte: procura-se na matriz de confusão $\mathrm{M}$ a entrada de maior valor; se esta for $m_{i j}$ significa que o aglomerado $j$ é o correspondente ao aglomerado $i$. A seguir procura-se pelo próximo maior valor na matriz $\mathrm{M}$, exceto na linha $i$ e coluna $j$. O índice do elemento encontrado indica mais uma correspondência entre aglomerados de $C$ e $C^{\prime}$. Repete-se o processo até que todas as correspondências tenham sido estabelecidas.

Podemos utilizar variantes desta medida, como ponderar (colocar pesos) os aglomerados originais, quando desejarmos dar maior importância a um ou mais aglomerados, em relação aos demais. Um exemplo típico é darmos mais importância a um aglomerado de séries composto por séries mais atuais no tempo, em vez de aglomerados que possuem séries mais antigas no tempo. Em nossa análise não consideramos ponderação dos aglomerados.

\section{Limites inferior e superior de IPA}

Para considerar o pior caso, suponha sem perda de generalidade que $m$ é divisível por $c$ e que o número de elementos em cada aglomerado é $n / c$.

Para cada aglomerado $C_{i}$ de $C$, divida as $n / c$ séries distribuindo $n / c^{2}$ séries em cada agrupamento $C_{j}^{\prime}$ de $C^{\prime}$. Cada aglomerado de $C^{\prime}$ conterá uma série de cada aglomerado $C_{i}$. Então, o IPA será igual para qualquer combinação de aglomerados entre $C$ e $C^{\prime}$., e pode ser dado por:

$$
\frac{\overbrace{\frac{n}{c^{2}}+\frac{n}{c^{2}}+\ldots+\frac{n}{c^{2}}}^{c \text { vezes }}}{n}=\frac{c}{n} \frac{n}{c^{2}}=\frac{1}{c}
$$


Imagine, por exemplo, que um aglomerado $C_{1}^{\prime}$ de $C^{\prime}$ não tenha recebido uma série do aglomerado $C_{1}$ de $C$. Então outro agrupamento diferente de $C_{1}^{\prime}$, por exemplo, $C_{2}^{\prime}$ receberia esta série. Então, a correspondência entre $C_{2}$ e $C_{2}^{\prime}$ será a de maior valor de taxa de permanência na matriz de combinações de aglomerados. Logo, o número de elementos que não se deslocaram seria maior e, portanto, o IPA desta combinação seria maior, o que não desejamos por ser um estudo de limite mínimo. Logo, temos que:

$$
\frac{1}{c} \leq I P A
$$

Como limite superior, é fácil concluir que se não houver alterações nas séries em ambos os processos de aglomeração, teremos $C_{i}=C_{i}^{\prime}$ para $i \in\{1,2, \ldots, c\}$ e apenas uma linha da matriz de combinações terá valor máximo igual a $100 \%$ e as outras terão valores menores de IPA. Logo:

$$
\frac{1}{c} \leq I P A \leq 1
$$

\subsection{3 Índice de Variação de Informação}

Descrevemos o critério de variação de informação, proposto por [Mei02]. Se tivéssemos de escolher uma série temporal de $B$, onde $B$ é o conjunto de todas as séries temporais a serem aglomeradas, a probabilidade desta série estar no aglomerado $C_{i}$ é dada por:

$$
P(i)=\frac{m_{i}}{m}
$$

onde $m_{i}$ é o número de séries no aglomerado $C_{i}$ e $m$ é o número total de séries em $B$.

Usando-se do conceito de entropia, podemos definir a entropia do resultado de um processo de aglomeração conforme a seguir:

$$
H(C)=-\sum_{i=1}^{c} P(i) \log P(i)
$$

A informação mútua entre dois resultados de processos de aglomeração $C$ e $C^{\prime}$ é dado pela distribuição $P\left(c, c^{\prime}\right)$, que representa a probabilidade de uma série pertencer ao aglomerado $C_{i}$ nos aglomerados de $C$ e a mesma série percenter ao aglomerado $C_{j}^{\prime}$ nos aglomerados de $C^{\prime}$ : 


$$
P(i, j)=\frac{C_{i} \cap C_{j}^{\prime}}{n}
$$

Para ilustrar este conceito, vamos voltar à medida IPA. Seja o quadro dado na tabela 4.1. Temos que a correta correspondência entre os aglomerados é dada por $C_{1} \simeq C_{1}^{\prime}, C_{2} \simeq C_{2}^{\prime} \mathrm{e}$ $C_{3} \simeq C 3^{\prime}$. Podemos então montar a matriz de confusão para essa correspondência:

\begin{tabular}{|c|c|c|c|}
\hline & $C_{1}$ & $C_{2}$ & $C_{3}$ \\
\hline \hline$C_{1}^{\prime}$ & 4 & 0 & 2 \\
\hline$C_{2}^{\prime}$ & 3 & 5 & 0 \\
\hline$C_{3}^{\prime}$ & 0 & 2 & 5 \\
\hline
\end{tabular}

Tabela 4.2: Matriz de confusão para 21 séries

Para obter a matriz de informação mútua, basta dividirmos a matriz de confusão por $m$, obtendo-se as probabilidades de cada intersecção de aglomerados. A matriz de informação mútua correspondente à matriz dada na tabela é dada na tabela 4.2.3.

\begin{tabular}{|c|c|c|c|}
\hline & $C_{1}$ & $C_{2}$ & $C_{3}$ \\
\hline \hline$C_{1}^{\prime}$ & 0.190 & 0.000 & 0.095 \\
\hline$C_{2}^{\prime}$ & 0.143 & 0.238 & 0.000 \\
\hline$C_{3}^{\prime}$ & 0.000 & 0.095 & 0.238 \\
\hline
\end{tabular}

Tabela 4.3: Matriz de informação mútua para 21 séries

Define-se o índice de informação mútua como sendo:

$$
I\left(C, C^{\prime}\right)=\sum_{i=1}^{c} \sum_{j=1}^{c^{\prime}} P(i, j) \log \frac{P(i, j)}{P(i) P(j)}
$$

Finalmente, define-se o índice de variação de informação (IVI) entre dois processos de aglomeração como sendo:

$$
I V I\left(C, C^{\prime}\right)=H(C)+H\left(C^{\prime}\right)-2 I\left(C, C^{\prime}\right)
$$




\section{Capítulo 5}

\section{Resultados experimentais}

Antes da divulgação dos resultados e análise dos mesmos, faz-se necessária a compreensão da área na qual os dados foram gerados: central de atendimento.

Neste capítulo também descreveremos uma massa de dados bem interessante que utilizamos como massa de testes. Também detalharemos a plataforma $\mathrm{R}$ e enfim, os resultados obtidos.

\subsection{Centrais de Atendimento}

As centrais de atendimento (contact centers ${ }^{1}$ ) representam o centro de comunicação de uma empresa que provém a seus atuais clientes e potenciais clientes serviços de atendimento através de canais de comunicação como e-mail, chat, telefonia receptiva e ativa, fax, voz sobre IP (VoIP), entre outros, transformando este centro em uma verdadeira central de relacionamento. O nome dado ao atendimento e gerenciamento de clientes provém do inglês Customer Relationship Management - CRM.

Por meio de plataformas de software e hardware integrados nas centrais de atendimento, uma empresa pode atender o cliente no canal que ele escolheu comunicar-se e trabalhar com essas informaçōes de forma integrada e com uma interface de software única.

Isso facilita o gerenciamento dos contatos e consulta a históricos de atendimento, fazendo com que um operador (pessoa que representa a empresa realizando o atendimento) tenha em mãos as informações necessárias a um atendimento rápido e eficaz.

\footnotetext{
${ }^{1}$ Adotaremos o termo centrais de atendimento ao invés de contact center
} 
Uma empresa pode ter mais de uma central de atendimento com o intuito de realizar diferentes operações: suporte, vendas, cobrança, etc. Essas operações podem se encontrar em diferentes localizações, por exemplo, vendas localiza-se em São Paulo e suporte no Rio de Janeiro, porém, o sistema de informação de ambos os locais têm de ser integrados.

Devido aos altos custos que este setor demanda às empresas, tanto em termos de hardware e software como em termos de recursos humanos, muitas empresas terceirizam suas centrais de atendimento.

Surge aí o conceito de terceirização das centrais de atendimento: uma empresa desenvolve um sistema de gestão de informação dos contatos dos clientes e a mesma empresa (ou uma outra) disponibiliza espaço físico e hardware para os operadores utilizarem o sistema de atendimento.

Escolhemos uma empresa líder no segmento de soluções de software de atendimento e gerenciamento de clientes no Brasil e com base nos dados provenientes da base de dados gerada pelos atendimentos realizamos a análise dos algoritmos dos algoritmos de redução de dimensionalidade de séries temporais.

Tal empresa possui grande quantidade de clientes que terceirizaram suas respectivas centrais de atendimento. Estes, diariamente atendem seus milhares de clientes através de chat (bate-papo via web), telefone receptivo (quando o cliente liga para a operação a fim de efetuar uma reclamação, por exemplo), telefone ativo (quando a operação entra em contato com o cliente para informar um débito pendente, por exemplo), e-mail e auto-atendimento (o cliente navega na internet em Perguntas e Resposta (Frequently Asked Questions - FAQ), onde os itens visitados são armazenados.

A massa de testes escolhida foi o volume de atendimento diário via chat de cada central de atendimento. Os dados são relativos ao período de 14/04/2003 a 31/01/2006, totalizando 1024 dias de atendimento via bate-papo em mais de 200 operações de centrais de atendimento.

\subsection{Massa de Dados}

Dentre toda a base de dados descrita na seção 5.1 escolhemos dois subconjuntos não disjuntos de séries temporais que respeitam alguns critérios, a fim de eliminarmos dados de teste referentes a centrais de atendimento que não chegaram a operar, mas possuíam alguns poucos dados de teste de atendimento. 
Um destes conjuntos, composto por 100 séries temporais, foi obtido através da seleção de séries temporais que possuem volume total mínimo de 1000 atendimentos no período descrito na seção 5.1. O outro conjunto, contendo 197 séries temporais, foi obtido a partir da seleção de séries temporais que possuem volume mínimo de 100 atendimentos no mesmo período. Note que os conjuntos realmente são não disjuntos.

A fim de obtermos uma análise mais abrangente e não viciada por causa dos dados, além de avaliarmos os algoritmos aplicados aos dois conjuntos de dados descritos acima, obtivemos uma massa de dados de 600 séries temporais de tamanho $m=60$ cada uma provenientes de [Alc99]. Replicamos os últimos 4 valores de cada série a fim de aumentarmos o tamanho de cada série temporal para $m=64$ pontos (valor que é potência de 2).

Esta última massa de dados, armazenada em um arquivo de formato ASCII com 600 linhas e 60 colunas, é bem interessante, pois a mesma já foi previamente categorizada em seis grupos, conforme tabela 5.1 .

\begin{tabular}{|c|c|c|}
\hline linhas & característica & categoria \\
\hline \hline $1-100$ & normal & $\mathrm{C}$ \\
\hline $101-200$ & cíclico & $\mathrm{B}$ \\
\hline $201-300$ & tendência crescente & $\mathrm{E}$ \\
\hline $301-400$ & tendência decrescente & $\mathrm{A}$ \\
\hline $401-500$ & deslocamento vertical para cima & $\mathrm{D}$ \\
\hline $501-600$ & deslocamento vertical para baixo & $\mathrm{F}$ \\
\hline
\end{tabular}

Tabela 5.1: Conjunto de dados de 600 séries

Uma ilustração das características mencionadas acima para o conjunto de 600 séries temporais pode ser vista na figura 5.1.

\subsection{O Sistema R}

R é uma plataforma para análise estatística e visualização gráfica de dados [Tea05] cuja linguagem é próxima à linguagem $\mathrm{S}$ desenvolvida nos laboratórios da AT\&T Bell Laboratories por Rick Becker, John Chambers e Allan Wilks. As duas linguagens são implementadas diferentemente, mas semelhantes a tal ponto de um usuário trocar entre uma e outra de forma relativamente fácil. Consiste de uma linguagem e um meio ambiente gráfico com debugger, acesso a certas funções de sistema e habilidade de executar programas armazenados em scripts.

Esta linguagem é derivada da linguagem de ambientes S e S-Plus escritos por Bill Venables 

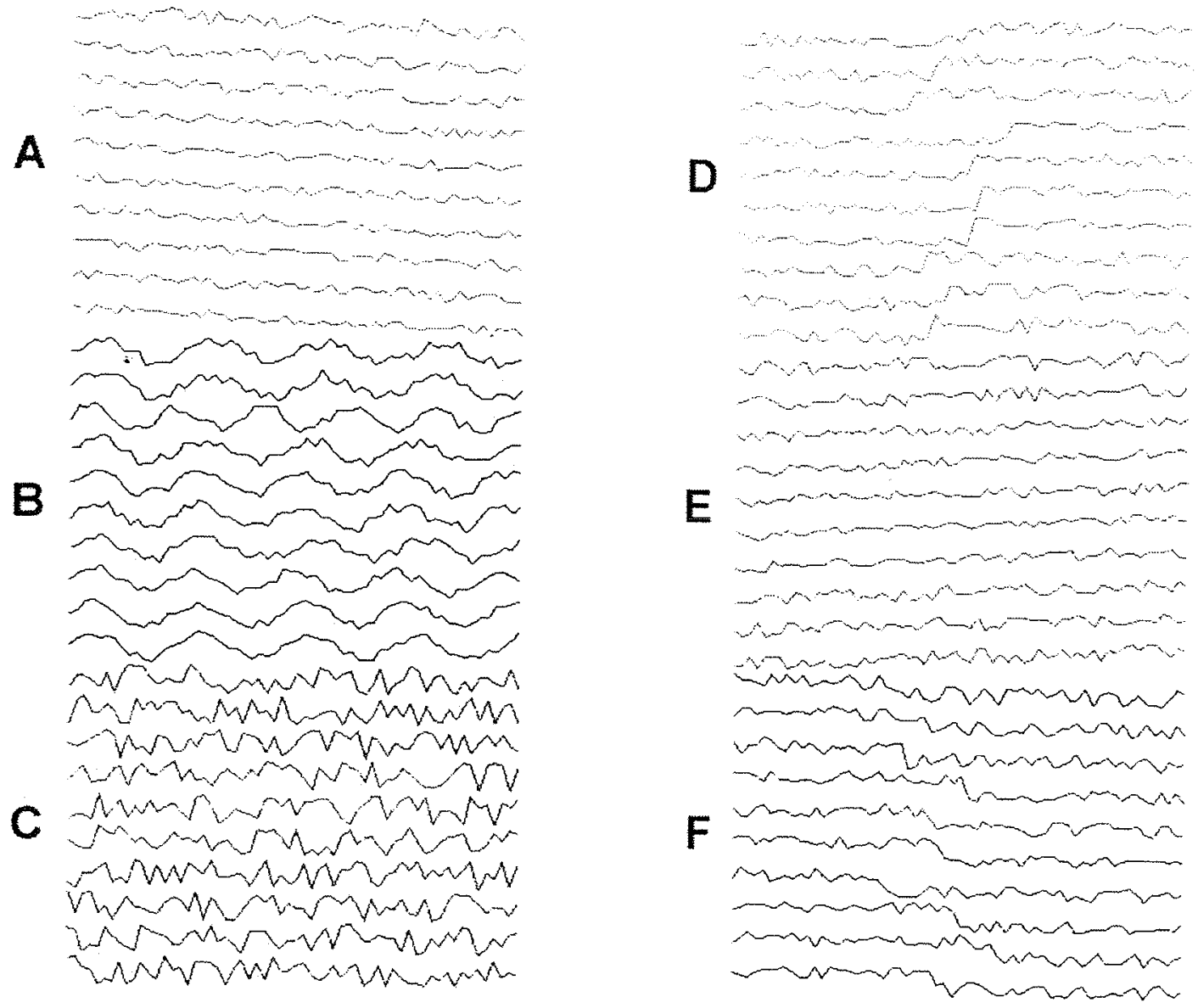

Figura 5.1: Características do conjunto de 600 séries (Resultado de 10 séries temporais de cada característica mencionada na tabela 5.1. Imagem cortesia de Eamonn J. Keogh, obtido de [Alc99])

e David M. Smith, ambos da Insightful Corporation.

O software continua em constante desenvolvimento, com muitos pacotes disponibilizados na internet, agregando assim muita funcionalidade através destes pacotes.

Esta plataforma de software livre está disponivel para uma grande variedade de sistemas operacionais: AIX, FreeBSD, GNU/Linux, HPUX, Irix, MacOS X, Solaris, Tru64 e Microsoft Windows (9x, ME, NT4, 2000 e XP).

Nossa escolha de implementação dos algoritmos nesta plataforma deu-se devido à portabilidade e alta expansibilidade desta plataforma através de seus pacotes e liberdade de criação de novos pacotes. 


\subsection{Descrição dos resultados de IMP}

Iniciamos a descrição dos resultados obtidos através do índice de manutenção de proximidade (IMP). Para $B$ como sendo uma das três bases de dados descritas na seção 5.2 , montamos uma matriz $M_{B}$ contendo todos os $k=1,2, \ldots, 25$ vizinhos mais próximos de cada série temporal $x$ de $B$. Escolhemos $k=25$, pois as consultas de $k$ vizinhos mais próximos tomam em geral valores baixos de $k$. Os resultados serão expressos na seguinte forma: média e desvio padrão dos valores de IMP (descrito pela equação 4.1) para cada $k$ com relação à base $B$. IMP é detalhado na seção 4.1.1.

Para todos os gráficos desta seção adotaremos o eixo $x$ como sendo $k=1,2, \ldots, 25$ de uma busca por $k$ vizinhos mais próximos e no eixo $y$ a média (ou desvio padrão) do IMP conforme descrito logo acima.

A figura 5.2 demonstra a variação do IMP para os quatro algoritmos analisados aplicados à massa de 100 séries temporais reduzindo-as a $N=4$ pontos.

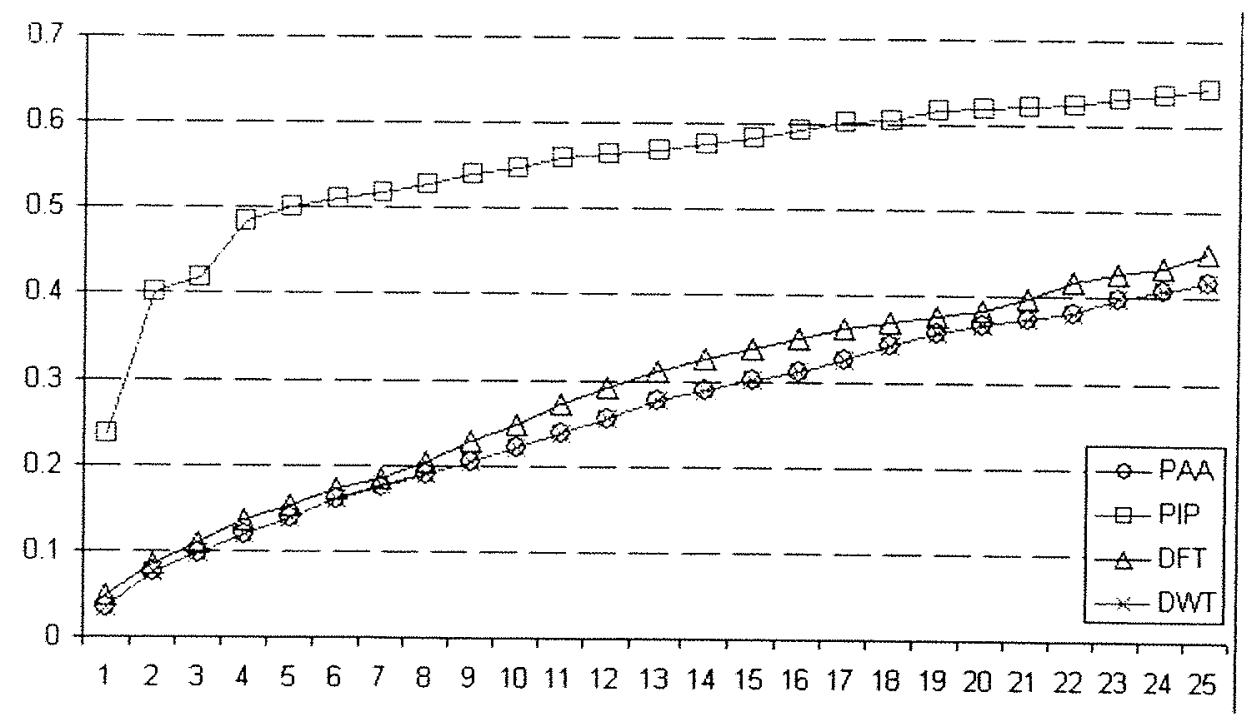

Figura 5.2: IMP de 100 séries temporais para $N=4$

Para não poluir o gráfico da figura 5.2, representamos em separado a variação do desvio padrão para os dados representados na figura 5.2, conforme visto no gráfico 5.3.

A figura 5.4 demonstra a variação do IMP mediante os quatro algoritmos de redução de dimensionalidade analisados aplicados à base de 197 séries temporais, reduzindo-as a $N=4$ pontos. O desvio padrão é representado na figura 5.5 .

A figura 5.6 demonstra a variação do IMP mediante os quatro algoritmos de redução de 


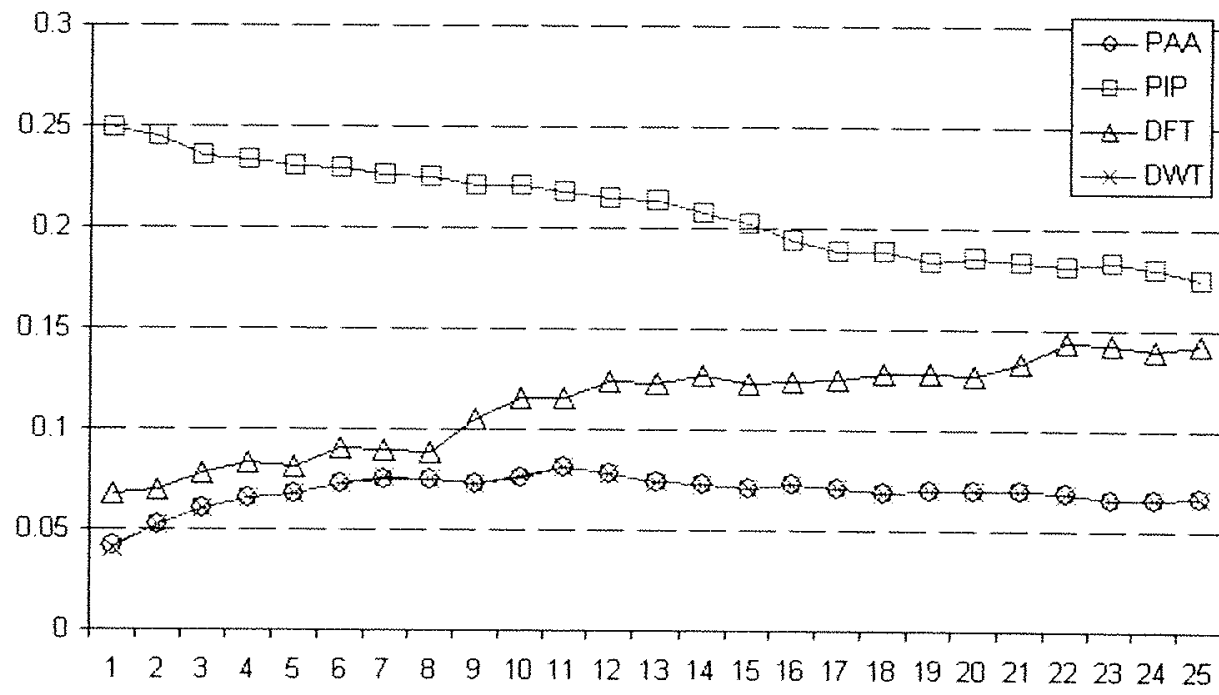

Figura 5.3: Desvio padrão do IMP de 100 séries temporais para $N=4$

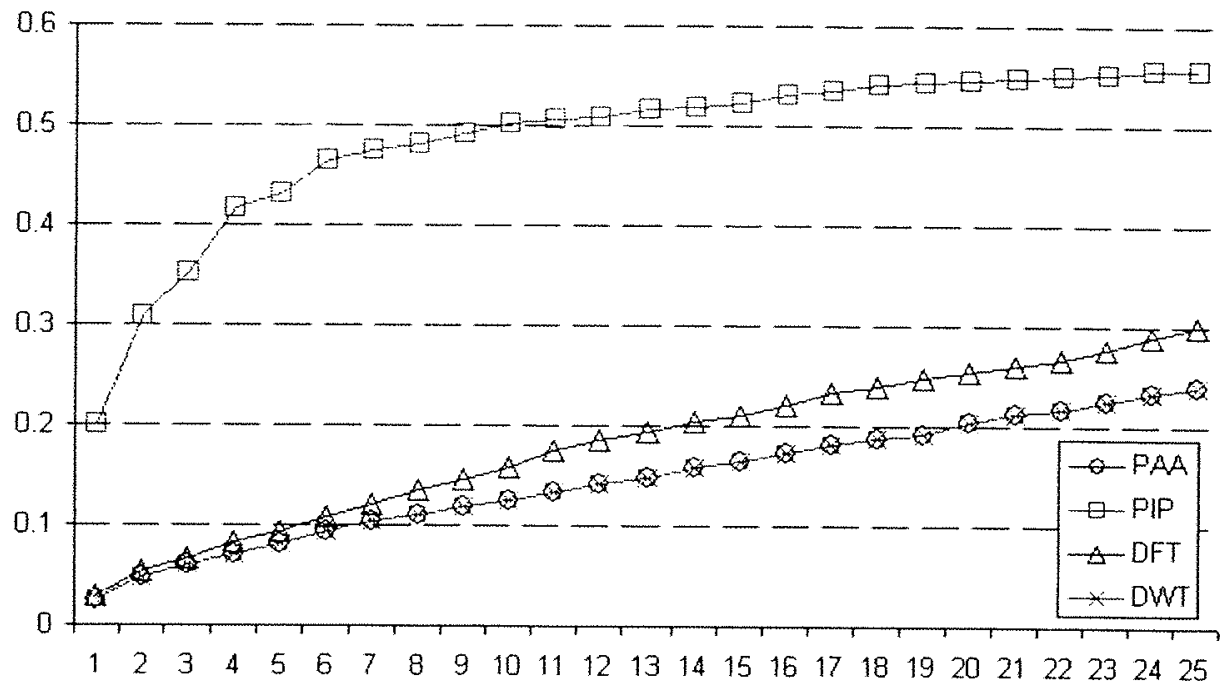

Figura 5.4: IMP de 197 séries temporais para $N=4$

dimentionalidade analisados. Reduzimos a massa de 600 séries temporais, cada uma a um $N=4$ pontos. O desvio padrão é representado na figura 5.7.

Note nas figuras 5.2, 5.4 e 5.6 que o algoritmo PIP destaca-se negativamente dos demais. Para alguns valores de $k$, vamos verificar a relação entre o IMP de PIP e a média do IMP dos demais algoritmos, considerando-se $N=4$. O resultado é expresso na tabela 5.2 .

Analisando a tabela 5.2, conforme aumentamos o valor de $k$, menor a relação de IMP entre PIP e os demais, ou seja, a necessidade de procurar um número menor de vizinhos a mais nas séries reduzidas tende a aproximar o desempenho de PIP em relação as demais. 


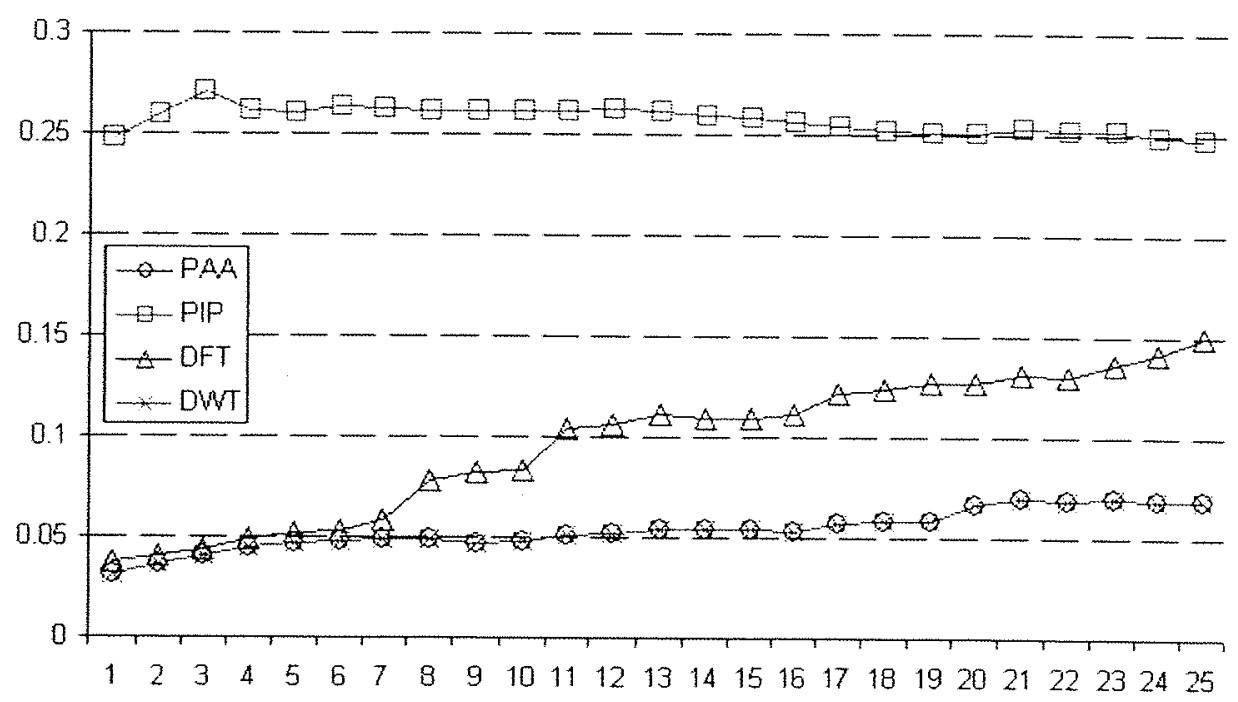

Figura 5.5: Desvio padrão do IMP de 197 séries temporais para $N=4$

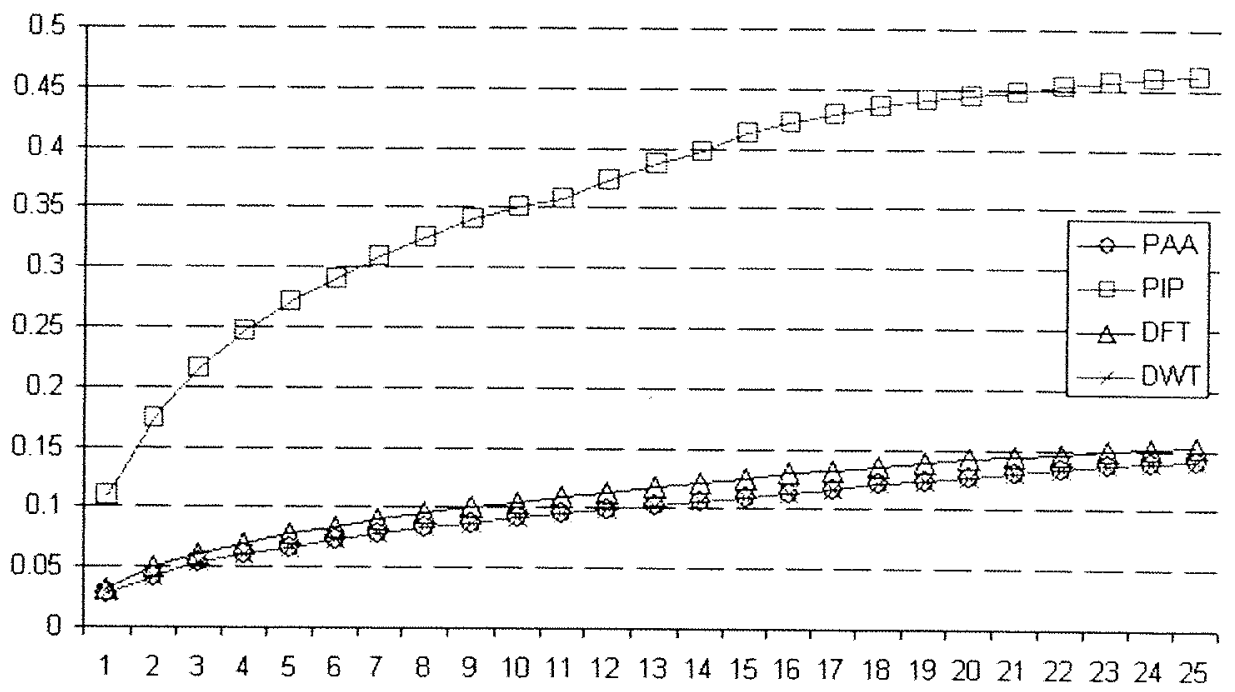

Figura 5.6: IMP de 600 séries temporais para $N=4$

\begin{tabular}{|c|c|c|c|}
\hline $\mathrm{k}$ & 100 séries & 197 séries & 600 séries \\
\hline \hline 5 & 3.5 & 5.0 & 3.9 \\
\hline 10 & 2.4 & 3.7 & 3.7 \\
\hline 15 & 1.9 & 2.9 & 3.6 \\
\hline 20 & 1.7 & 2.5 & 3.4 \\
\hline 25 & 1.5 & 2.1 & 3.2 \\
\hline
\end{tabular}

Tabela 5.2: IMP: Relação IMP de PIP/IMP de OUTROS algoritmos para $N=4$ 


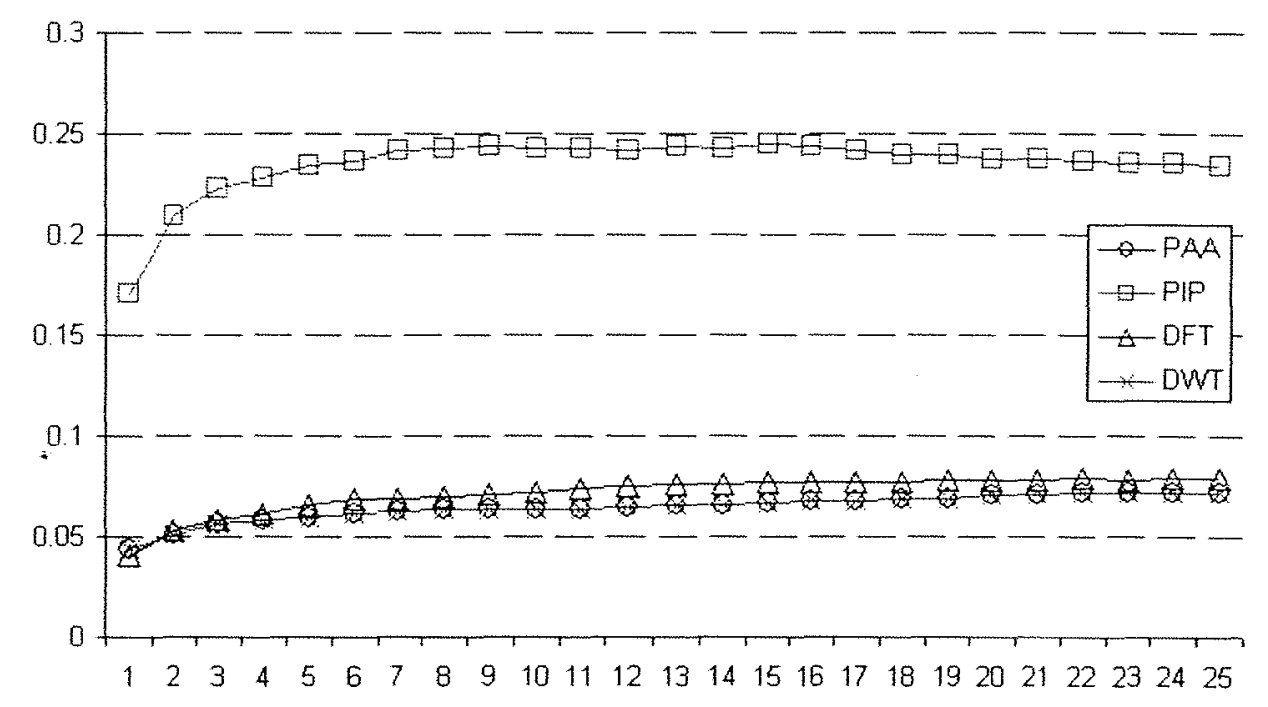

Figura 5.7: Desvio padrão do IMP de 600 séries temporais para $N=4$

O mesmo acontece para as séries reduzidas a $N=16$ conforme tabela 5.3, onde temos a relação entre o IMP de PIP e a média do IMP dos demais algoritmos, considerando-se $N=16$.

\begin{tabular}{|c|c|c|c|}
\hline $\mathrm{k}$ & 100 séries & 197 séries & 600 séries \\
\hline \hline 5 & 4.5 & 6.6 & 7.4 \\
\hline 10 & 3.2 & 4.6 & 6.1 \\
\hline 15 & 2.5 & 3.6 & 5.3 \\
\hline 20 & 2.1 & 3.0 & 4.6 \\
\hline 25 & 1.8 & 2.6 & 4.1 \\
\hline
\end{tabular}

Tabela 5.3: IMP: Relação IMP de PIP/IMP de OUTROS algoritmos para $N=16$

Analisando-se as figuras 5.3, 5.5 e 5.7 temos que o desvio padrão do IMP para o algoritmo PIP é bem superior à dos outros algoritmos.

Nas seis figuras apresentadas acima, nota-se também o desempenho semelhante de PAA e DWT.

Ainda sobre IMP, para o algoritmo DFT aplicado na base de 197 séries temporais temos os valores de $k$ e IMP variando sobre as diversas reduções efetuadas, para $N \in$ $\{2,4,8,16,32,64,128\}$, representados na figura 5.8. Para os outros algoritmos aplicados à esta base e às demais bases, o comportamento é o mesmo: quanto menor o valor de $N$, maior o valor de IMP para um determinado $k$. O valor de IMP para as reduções citadas acima é representado na figura 5.9. O comportamento descrito acima é verificado para todos os algoritmos em todas as bases e por isso suprimidos. 


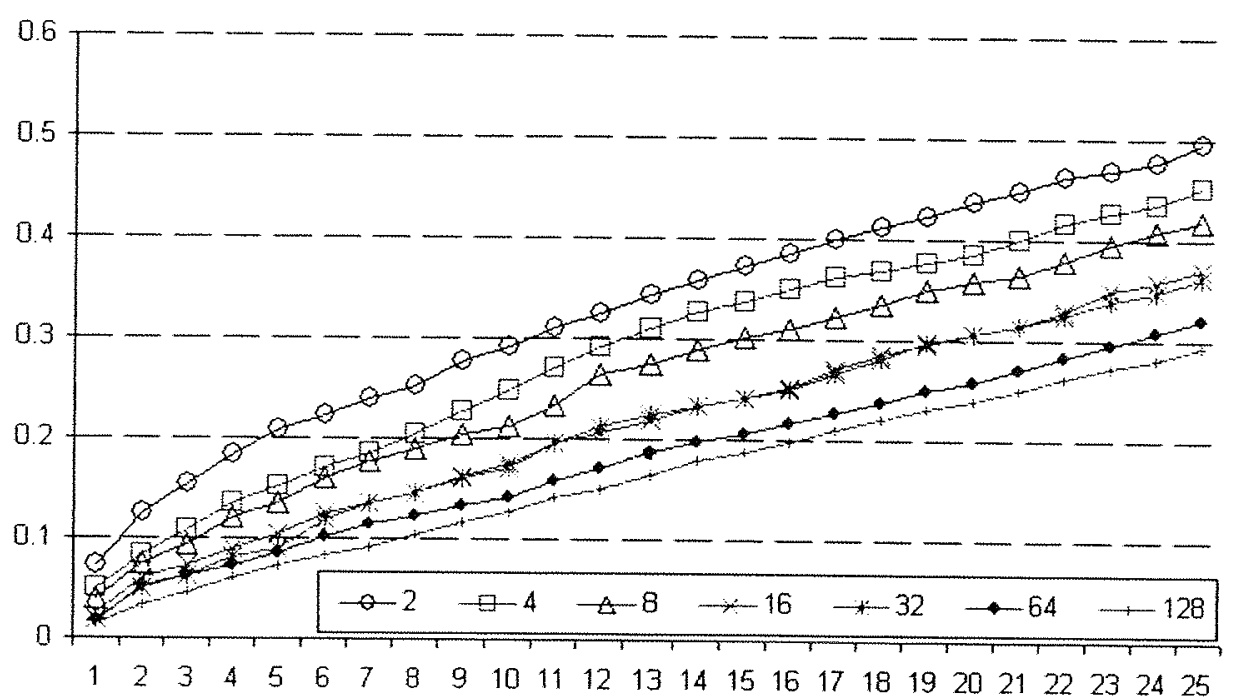

Figura 5.8: IMP de 100 séries temporais para DFT

O desvio padrão dos algoritmos frente às reduções realizadas é verificado na figura 5.9, representando o desvio padrão de IMP do algoritmo DFT do conjunto das 100 séries temporais de tamanho $n=1024$ reduzidas a $N \in\{2,4,8,16,32,64,128\}$. Os outros algoritmos (a exceção de PIP) possuem o mesmo comportamento, com tendência crescente do desvio padrão de IMP conforme aumenta-se o valor de $k$. PIP foge um pouco à esta regra para as bases de 100 e 197 séries temporais, possuindo tendência de queda nos valores do desvio padrão para o aumento de $k$, conforme figura 5.10.

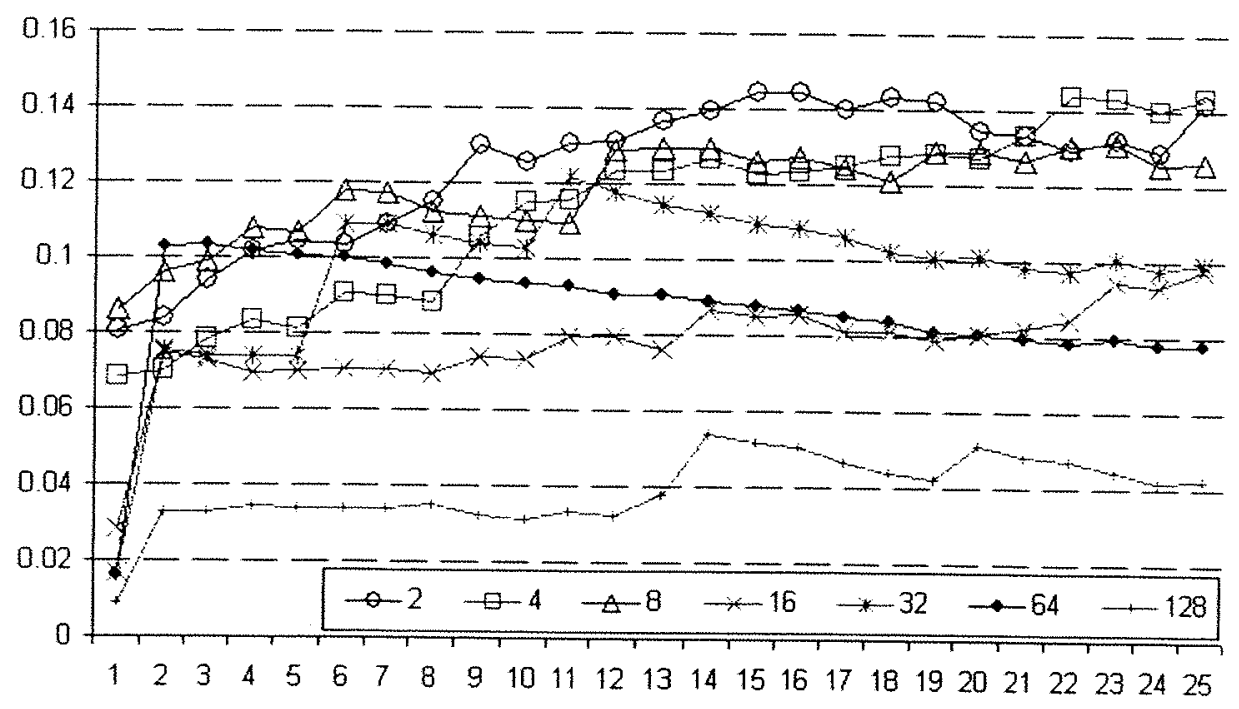

Figura 5.9: Desvio padrão do IMP de 100 séries temporais para DFT

A fim de não poluir nosso trabalho, representaremos apenas estes gráficos, suficientes 


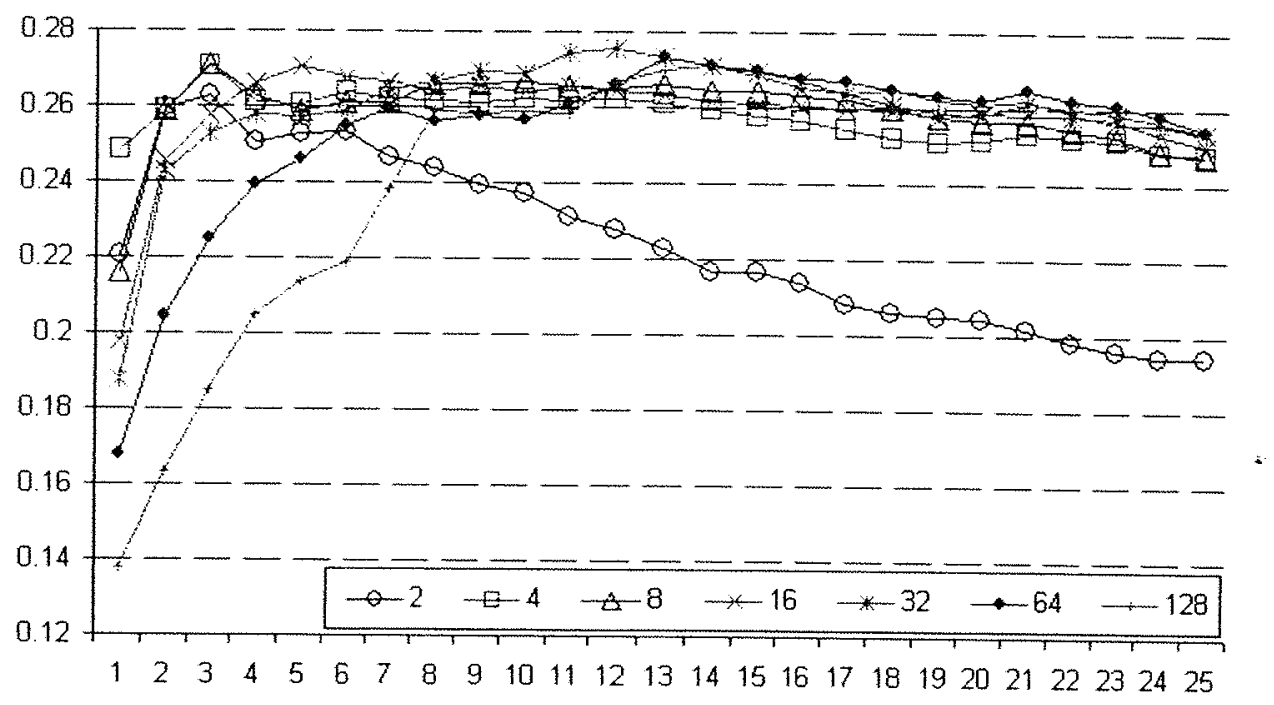

Figura 5.10: Desvio padrão do IMP de 197 séries temporais para PIP

para entender o comportamento das reduções. Os demais gráficos são pequenas variações dos gráficos aqui exibidos.

\subsection{Descrição dos resultados de IPA}

Daremos seqüência aos resultados obtidos com o índice de permanência em aglomerados (IPA), descrito na seção 4.2.2. Adotaremos gráficos tridimensionais para quantificar IPA (calculado pela equação 4.2) em relação ao número $c$ de aglomerados, número de pontos $N$ das séries reduzidas e algoritmos de redução de dimensionalidade. O eixo $z$ sempre corresponderá ao valor de IPA (em porcentagem).

Na figura 5.11 temos o resultado do IPA para a massa de 100 séries temporais. No eixo $y$ temos os algoritmos de redução de dimensionalidade e no eixo $x$ a variação de $c \in\{2,3, \ldots, 7\}$ aglomerados.

$\mathrm{Na}$ figura 5.11 notamos um valor decrescente do IPA conforme aumenta-se o número de aglomerados $c$, independente do algoritmo de redução de dimensionalidade. Isso deve-se ao fato de quanto maior o número de aglomerados, maiores as chances do processo de redução afetar a série temporal a fim de trocá-la de aglomerado no processo de aglomeração das séries reduzidas. Nesta figura também notamos que o algoritmo PIP afeta mais as reduções que outros algoritmos.

Na figura 5.12 temos o resultado do IPA para a massa de 197 séries temporais. No eixo $y$ 


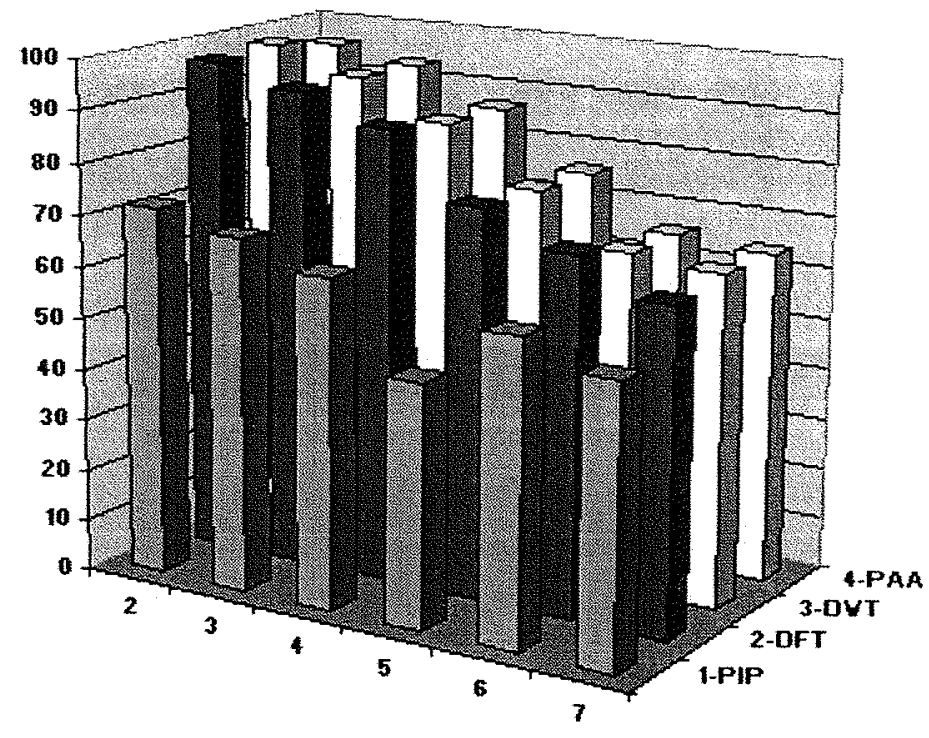

Figura 5.11: IPA de 100 séries temporais: algoritmos e número de aglomerados

temos os algoritmos de redução de dimensionalidade e no eixo $x$ a variação de $c \in\{2,3, \ldots, 7\}$ aglomerados. Nesta figura notamos que o IPA não diminui tanto quanto na figura 5.11, porém, nota-se o desempenho inferior de PIP em relação aos demais.

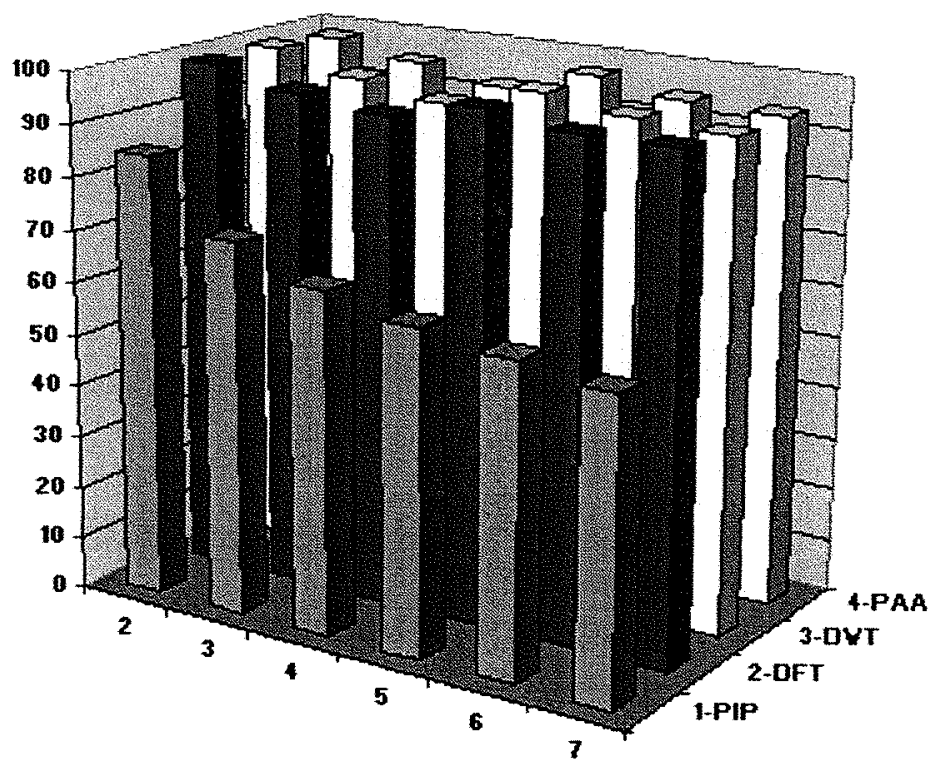

Figura 5.12: IPA de 197 séries temporais: algoritmos e número de aglomerados

Na figura 5.13 temos o resultado do IPA (em porcentagem) para a massa de 600 séries temporais. No eixo $y$ temos os algoritmos de redução de dimensionalidade e no eixo $x$ a variação de $c \in\{2,3, \ldots, 7\}$ aglomerados. Notamos que à medida que o número de aglomerados cresce, IPA diminui, o que já era esperado. 


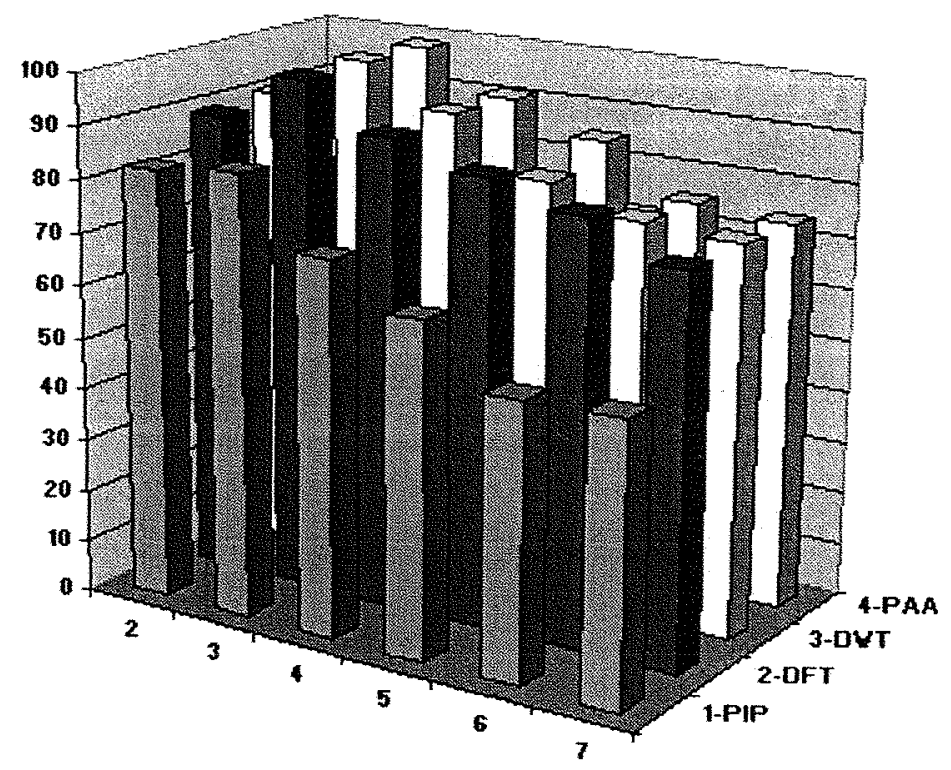

Figura 5.13: IPA de 600 séries temporais: algoritmos e número de aglomerados

O valor médio do IPA, independente do número de aglomerados, de algoritmo de aglomeração (PAM ou CLARA) e independente do tamanho da redução é avaliado na tabela 5.4. Por esta tabela nota-se um desempenho inferior do algoritmo PIP em relação aos demais. DFT mostra-se ligeiramente superior a PAA e DWT, estes dois últimos com desempenho semelhante neste quesito.

\begin{tabular}{|c|c|c|c|}
\hline & 100 séries & 197 séries & 600 séries \\
\hline \hline PIP & 60.61 & 66.57 & 68.01 \\
\hline DFT & 80.98 & 95.82 & 86.31 \\
\hline DWT & 80.52 & 95.33 & 85.24 \\
\hline PAA & 80.15 & 95.22 & 85.88 \\
\hline
\end{tabular}

Tabela 5.4: IPA médio de todos os algoritmos e massas de dados

Uma seguna análise relativa ao IPA é demonstrar qual a variação do IPA conforme o número de pontos das séries temporais reduzidas. Conforme figura 5.14 temos que as reduções DFT, DWT e PAA afetam mais as séries temporais conforme diminuimos o número de pontos da série reduzida. Com PIP acontece o inverso, ou seja, conforme diminuímos o número de pontos, mais ele se aproxima do desempenho dos outros algoritmos.

O mesmo fato acontece nas massas de dados de 197 e 600 séries temporais, conforme figuras 5.15 e 5.16 , respectivamente.

A tabela 5.5 ilustra a variação do IPA médio dos algoritmos de redução frente ao uso dos algoritmos de aglomeração PAM e CLARA. Nota-se que ambos os algoritmos de aglomeração 


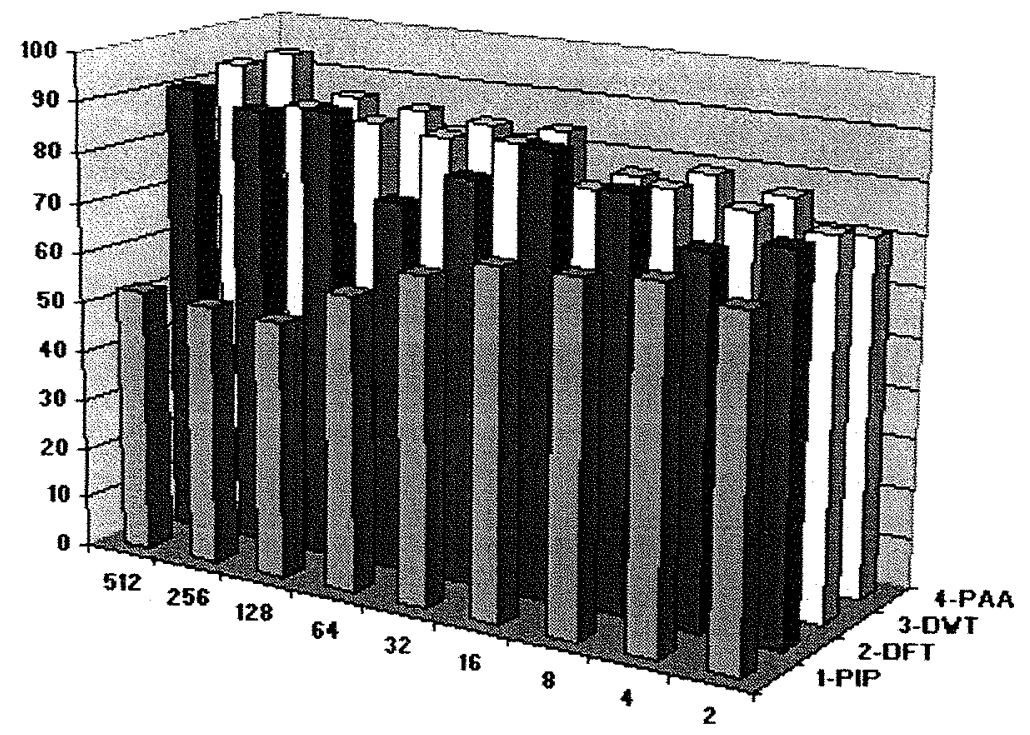

Figura 5.14: IPA de 100 séries temporais: algoritmos e número de pontos (Variação do IPA médio de 100 séries temporais em relação ao número de pontos das séries reduzidas)

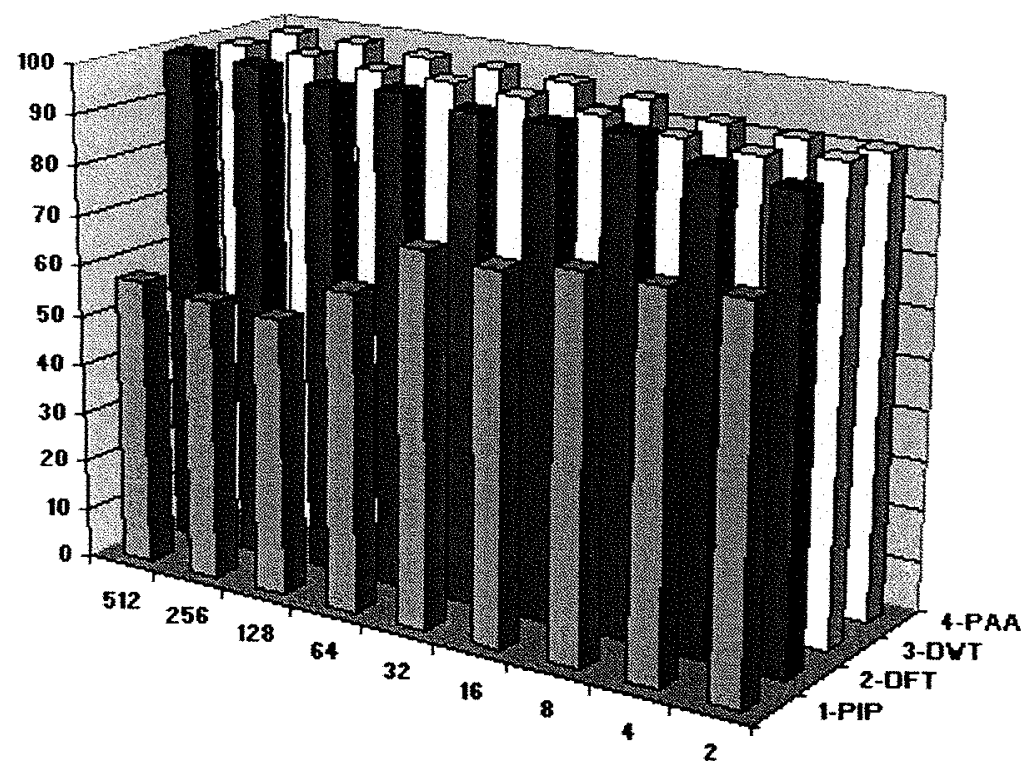

Figura 5.15: IPA de 197 séries temporais: algoritmos e número de pontos (Variação do IPA médio de 100 séries temporais em relação ao número de pontos das séries reduzidas)

possuem valores de IPA muito próximos. A maior variação constatada foi de $6 \%$ de PAM sobre CLARA, ou seja, o valor do IPA foi $6 \%$ melhor utilizando PAM que o IPA utilizando-se CLARA como algoritmos dos processos de aglomerações. 


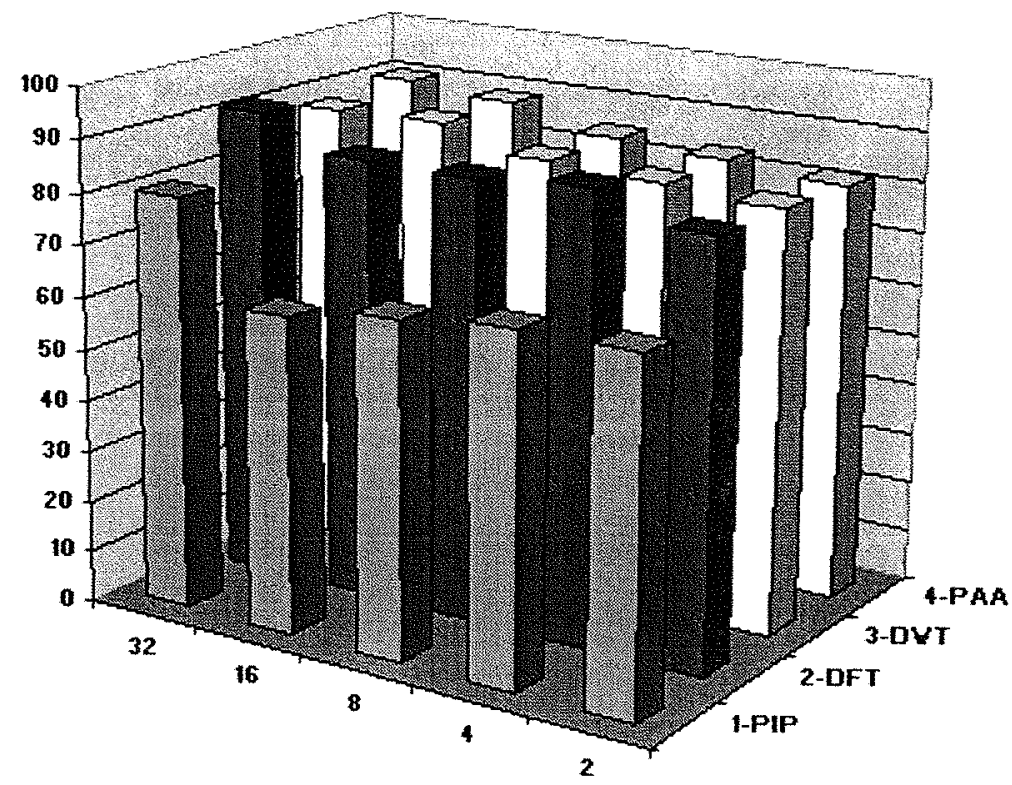

Figura 5.16: IPA de 600 séries temporais: algoritmos e número de pontos (Variação do IPA médio de 600 séries temporais em relação ao número de pontos das séries reduzidas)

\subsection{Descrição dos resultados de IPA}

Por fim temos os resultados obtidos no índice de variação de informação, descrito em 4.2.3. Adotaremos também gráficos tridimensionais para quantificar IVI (calculado pela equação 4.3) em relação ao número $c$ de aglomerados, número de pontos $N$ das séries reduzidas e algoritmos de redução de dimensionalidade. O eixo $z$ sempre corresponderá ao valor de IPA (em porcentagem).

$\mathrm{Na}$ figura 5.17 temos o resultado do IVI médio (independente do valor de $N$ ) para a massa

\begin{tabular}{|c|c|c|c|c|}
\hline Redução & Aglomeração & 100 séries & 197 séries & 600 séries \\
\hline \hline \multirow{3}{*}{ PIP } & CLARA & 60.6 & 66.6 & 66.2 \\
\cline { 2 - 5 } & PAM & 62.3 & 66.5 & 69.9 \\
\hline \multirow{2}{*}{ DFT } & CLARA & 81.0 & 94.9 & 85.0 \\
\cline { 2 - 5 } & PAM & 82.7 & 96.8 & 87.6 \\
\hline \multirow{2}{*}{ DWT } & CLARA & 80.6 & 95.0 & 84.0 \\
\cline { 2 - 5 } & PAM & 83.8 & 95.6 & 86.5 \\
\hline \multirow{2}{*}{ PAA } & CLARA & 80.1 & 95.0 & 85.0 \\
\cline { 2 - 5 } & PAM & 83.4 & 95.5 & 86.2 \\
\hline
\end{tabular}

Tabela 5.5: IPA médio por algoritmo de aglomeração 
de 100 séries temporais. No eixo $y$ temos os algoritmos de redução de dimensionalidade e no eixo $x$ a variação de $c \in\{2,3, \ldots, 7\}$ aglomerados. Nota-se uma tendência de aumento do IVI conforme aumenta-se o número de aglomerados (a exceção de PIP).

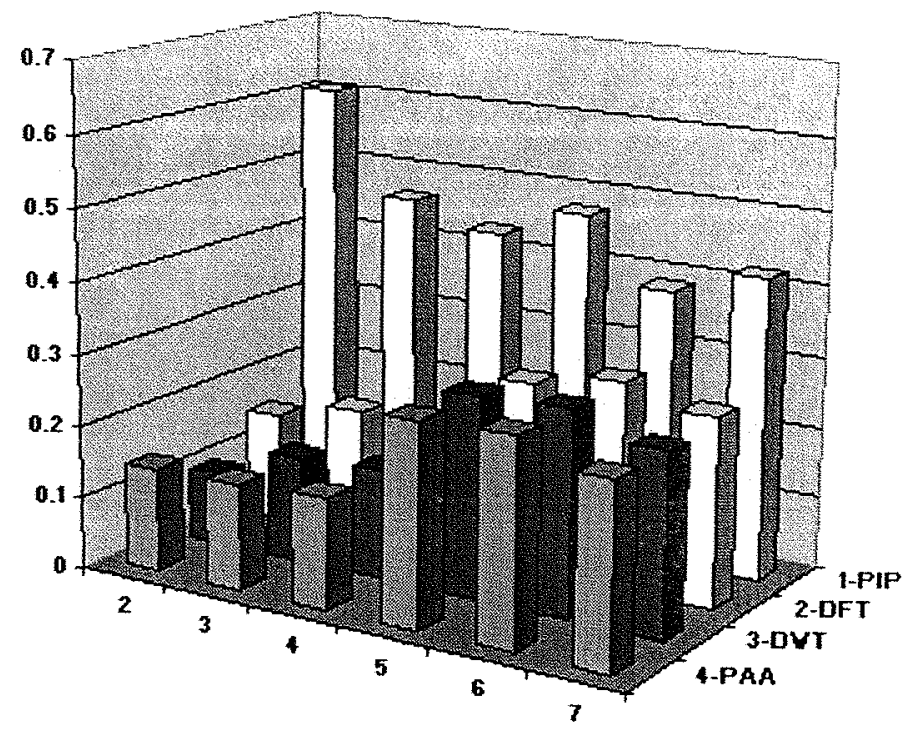

Figura 5.17: IVI de 100 séries temporais: algoritmos e número de aglomerados

Na figura 5.18 temos o resultado do IVI para a massa de 197 séries temporais. No eixo $y$ temos os algoritmos de redução de dimensionalidade e no eixo $x$ a variação de $c \in\{2,3, \ldots, 7\}$ aglomerados.

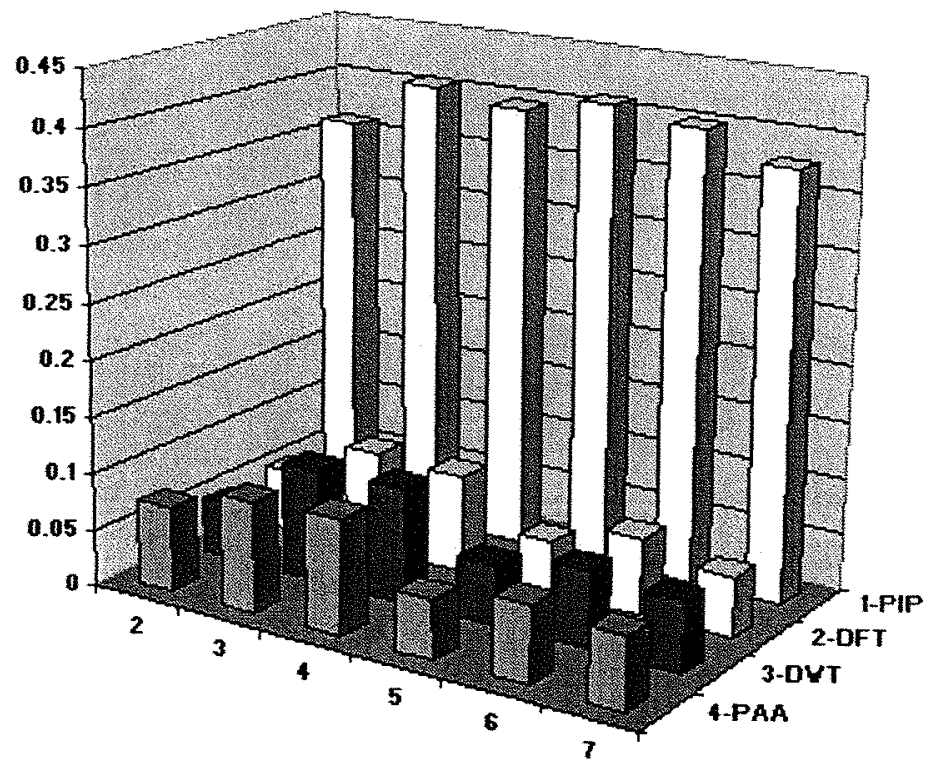

Figura 5.18: IVI de 197 séries temporais: algoritmos e número de aglomerados

E por fim na figura 5.19 temos o resultado do IVI para a massa de 600 séries temporais. 
No eixo $y$ temos os algoritmos de redução de dimensionalidade e no eixo $x$ a variação de $c \in\{2,3, \ldots, 7\}$ aglomerados. Nota-se uma tendência de aumento do IVI conforme aumentase o número de aglomerados.

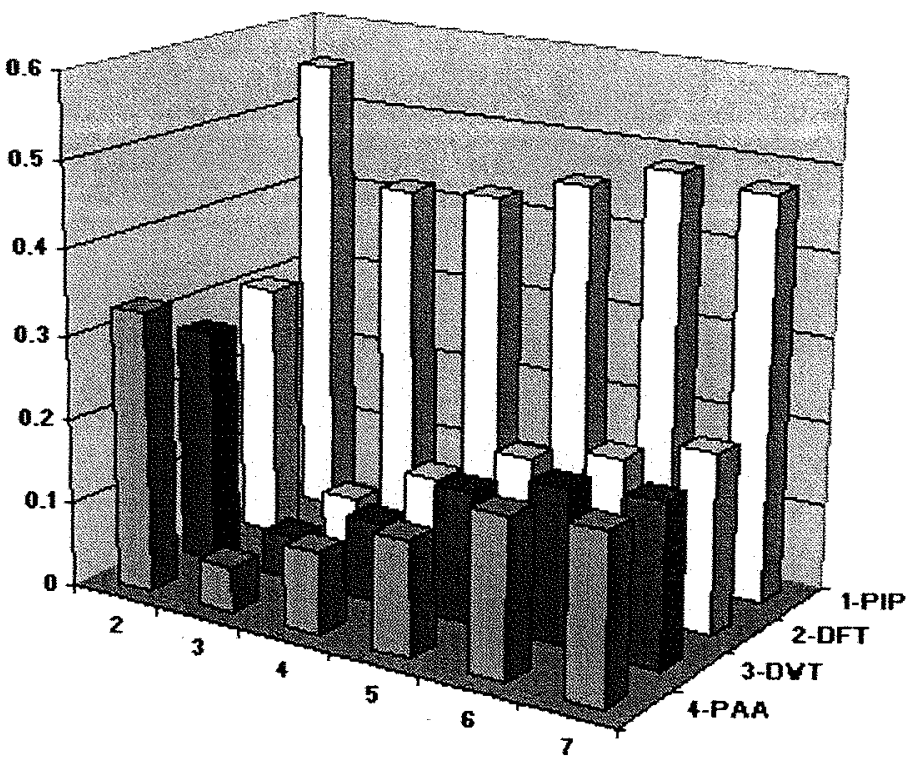

Figura 5.19: IVI de 600 séries temporais: algoritmos e número de aglomerados

Agora vamos verificar a variação do IVI em relação oa número de pontos $N$ às quais as séries temporais foram reduzidas. Na figura 5.20 temos esta variação média para a base de dados com 100 séries temporais reduzidas, independente do número de aglomerados. No eixo $x$ temos as reduções para $N \in\{2,4,8,16,32,64,128,256,512\}$ e no eixo $y$ os algoritmos de redução de dimensionalidade.

Na figura 5.20 temos a variação média do IVI para a base de dados com 197 séries temporais reduzidas, independente do número de aglomerados e representando-se no eixo $x$ as reduções para $N \in\{2,4,8,16,32,64,128,256,512\}$ e no eixo $y$ os algoritmos de redução de dimensionalidade.

Por fim temos a variação do IVI em relação à base de dados de 600 séries temporais na figura 5.22, representando-se no eixo $x$ as reduções para $N \in\{2,4,8,16,32,64,128,256,512\}$ e no eixo $y$ os algoritmos de redução de dimensionalidade.

Notamos que o comportamento é semelhante em todas as três massas de teste: quanto menor o número de pontos da série reduzida, maior é o índice IVI.

O IVI médio para todas as massas de dados segue na tabela 5.6 e o resultado do IVI médio, levando-se em consideração os algoritmos de aglomeração seguem na tabela 5.7. 


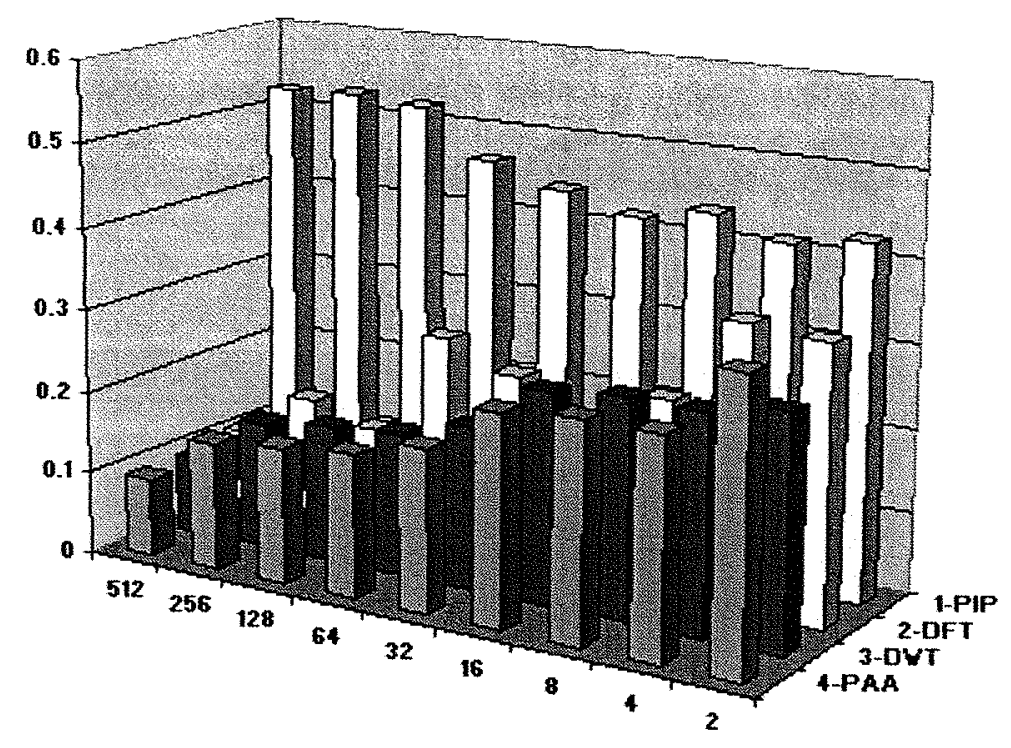

Figura 5.20: IVI de 100 séries temporais: algoritmos e número de reduções (Variação do IVI médio de 100 séries temporais em relação ao número de reduções)

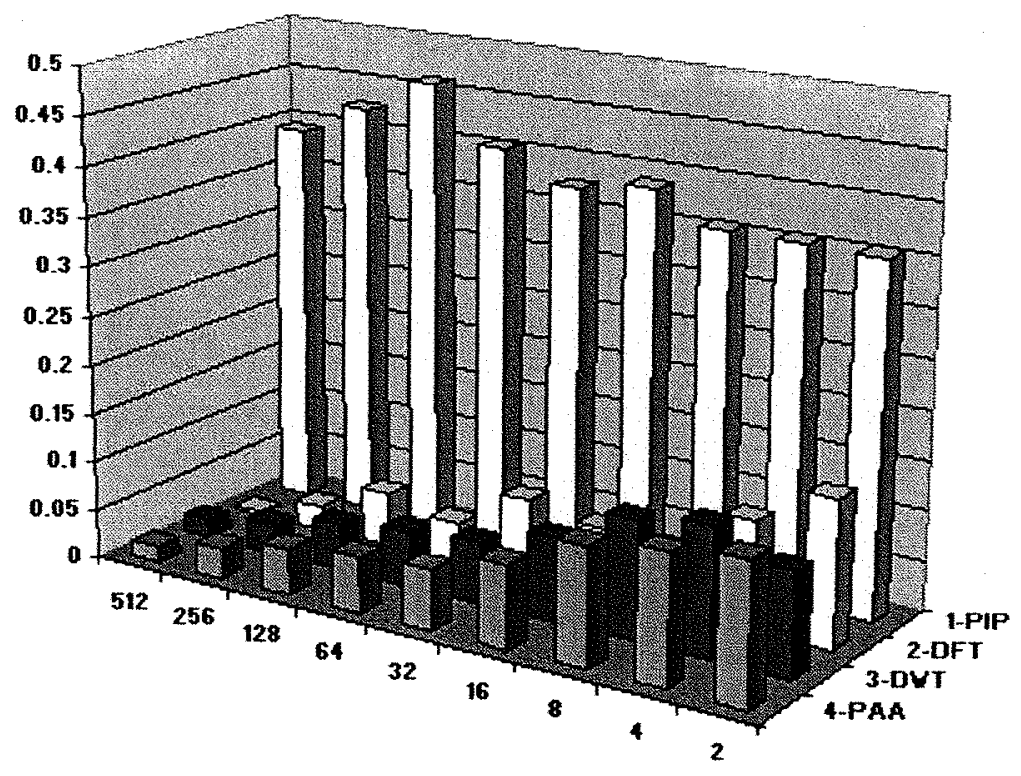

Figura 5.21: IVI de 197 séries temporais: algoritmos e número de reduções (Variação do IVI médio de 197 séries temporais em relação ao número de reduções)

\begin{tabular}{|c|c|c|c|}
\hline & 100 séries & 197 séries & 600 séries \\
\hline \hline PIP & 0.46 & 0.39 & 0.47 \\
\hline DFT & 0.22 & 0.07 & 0.17 \\
\hline DWT & 0.20 & 0.07 & 0.16 \\
\hline PAA & 0.21 & 0.08 & 0.17 \\
\hline
\end{tabular}

Tabela 5.6: IVI médio de todos os algoritmos de redução e massas de dados 


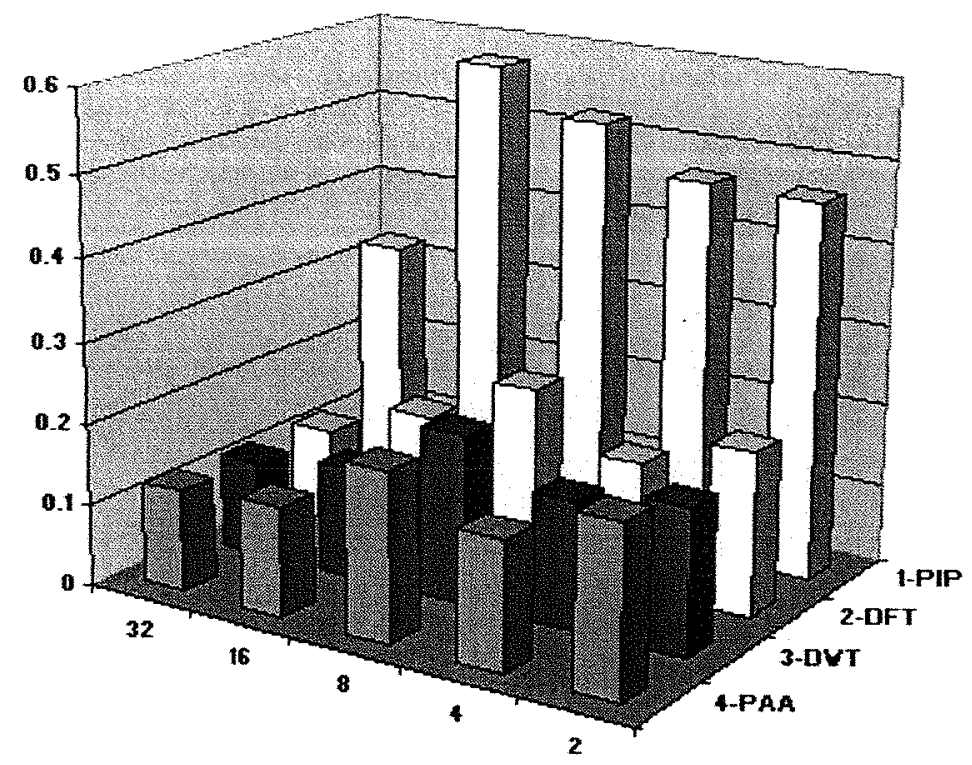

Figura 5.22: IVI de 600 séries temporais: algoritmos e número de reduções (Variação do IVI médio de 600 séries temporais em relação ao número de reduçōes)

\begin{tabular}{|c|c|c|c|c|}
\hline Redução & Aglomeração & 100 séries & 197 séries & 600 séries \\
\hline \hline \multirow{3}{*}{ PIP } & CLARA & 0.47 & 0.36 & 0.52 \\
\cline { 2 - 5 } & PAM & 0.46 & 0.42 & 0.42 \\
\hline \multirow{3}{*}{ DFT } & CLARA & 0.23 & 0.08 & 0.20 \\
\cline { 2 - 5 } & PAM & 0.22 & 0.05 & 0.14 \\
\hline \multirow{2}{*}{ PAA } & CLARA & 0.22 & 0.07 & 0.19 \\
\cline { 2 - 5 } & PAM & 0.19 & 0.08 & 0.13 \\
\cline { 2 - 5 } & CLARA & 0.23 & 0.07 & 0.18 \\
\cline { 2 - 5 } & PAM & 0.20 & 0.08 & 0.15 \\
\hline
\end{tabular}

Tabela 5.7: IVI médio por algoritmo de aglomeração 


\section{Capítulo 6}

\section{Conclusão}

Neste trabalho estudamos quatro algoritmos de redução de dimensionalidade no contexto de processamento de séries temporais: DFT, DWT, PIP e PAA. Para viabilizar um estudo comparativo destes algoritmos, os mesmos foram implementados na plataforma R. A avaliação realizada teve como foco a análise de aspectos qualitativos referentes ao desempenho dos algoritmos. Não foi realizada nenhuma avaliação quantitativa como análise do tempo de processamento ou da quantidade de memória utilizada.

Para as avaliações, consideramos duas atividades comuns em base de dados de séries temporais: busca por similaridade e aglomeração. Em busca de similaridade, o objetivo foi analisar de que forma a redução de dimensionalidade afeta as buscas. Mais precisamente, no caso de busca dos $k$ vizinhos mais próximos a uma série de consulta, quantas séries precisam ser buscadas efetivamente no índice construído a partir das séries reduzidas, para se garantir que todos os $k$ vizinhos no conjunto das séries originais são recuperados? No caso de aglomeração, procurou-se quantificar de que forma a redução de dimensionalidade afeta a aglomeração. Mais especificamente, a aglomeração obtida no conjunto das séries originais é mantida se esta for calculada após a redução de dimensionalidade?

Em ambos os casos foi proposta a utilização de critérios objetivos para avaliar as questões levantadas. Em busca de similaridade um índice que utiliza conceitos de proximidade foi utilizado. Em aglomeração, sugerimos o uso de critérios de comparação de aglomarações como forma de comparar o desempenho dos algoritmos de redução de dimensionalidade. Foram utilizados dois critérios de comparação de aglomerações. Para a parte experimental do trabalho foram utilizados dois conjuntos de dados. Um, proveniente de uma central de atendimento, e outro, dados artificiais disponíveis na web. 
Os índices propostos para análise de aglomerações não dependem dos algoritmos de redução de dimensionalidade, nem dos algoritmos de aglomeração. Embora tenham sido introduzidos na literatura como critérios para a comparação de diferentes aglomeraçōes de um mesmo conjunto de dados, sustentamos que é possível comparar aglomeraçōes do conjunto de séries originais com aglomerações do conjunto de séries reduzidas, pois há uma identificação um para um entre elementos do conjunto de séries originais e elementos do conjunto das séries reduzidas. Além disso, os critérios utilizados não levam em consideração características dos elementes que estão sendo aglomerados.

Alguns resultados expressos no capítulo 5 já eram esperados e foram confirmados, como o crescente aumento do IMP, IPA e IVI conforme reduzimos drasticamente as séries temporais. Em relação aos processos de aglomeração, era nossa expectativa que IPA e IVI aumentassem conforme aumento no número de aglomerados. Esse fato foi confirmado após a análise dos resultados obtidos.

O desempenho geral dos algoritmos DFT, DWT e PAA foram muito semelhantes, com pequena desvantagem para DFT. Já o algoritmo PIP teve um desempenho qualitativo não satisfatório aplicado às massas de dados. Como ele possui o foco apenas na detecção de grandes oscilações, torna-se interessante sua utilização em aplicações que detectem grandes alterações de comportamento nas séries temporais.

Disponibilizar os algoritmos de redução de dimensionalidade e de avaliação de desempenho implementados como um pacote do $\mathrm{R}$ e realizar avaliações sobre um volume maior de dados são atividades que estavam planejadas mas não foram realizadas por falta de tempo.

A avaliação realizada neste trabalho, para o caso de aglomerados, pode ser estendida para. diferentes algoritmos de aglomeração (e, portanto, também para diferentes números de aglomerados nas duas aglomerações a serem comparadas), para diferentes algoritmos de redução de dimensionalidade e para diferentes medidas de similaridade.

Como futuros passos para este trabalho consideramos a concretização das duas atividades não realizadas e a realização de avaliações do tipo descritas no parágrafo anterior. 


\section{Apêndice A}

\section{Algoritmos de aglomeração}

Tradicionalmente, as técnicas de aglomeração dividem-se em hierárquica e de particionamento. Algoritmos hierárquicos encontram sucessivos aglomerados usando os aglomerados previamente estabelecidos e estes são representados em uma estrutura conhecida por dendograma, que assemelha-se a uma estrutura do tipo árvore. O número de aglomerados final pode ser determinado analisando-se o dendograma. Os algoritmos baseados em técnicas de particionamento devolvem apenas um particionamento. O número de aglomerados deve ser informado.

Técnicas de aglomeração são bastante utilizados em diferentes contextos de análise de dados e existem várias publicações que tratam desse assunto. Uma boa referência é o artigo de Jain e outros [JMF99].

Neste trabalho usamos dois algoritmos baseados na técnica de particionamento $k$-medóides PAM e CLARA, explicados no apêndice A. O número de aglomerados será denotado por $c$ em vez de $k$, para evitar confusão com o valor $k$ das buscas do tipo $k$-NN.

No método de aglomeração de particionamento $k$-means define-se um valor para $c$ e então randomicamente escolhe-se $c$ centros para as observações (séries temporais). Então, calcula-se a distância entre cada observação e os respectivos centros, a fim de determinar a qual centro a observação é similar. A partir desta distância recalcula-se a nova média do centro e repete-se o processo até que cada uma das observações faça parte de um dos c agrupamentos. Em outras palavras, o valor médio das observações de um agrupamento é visto como seu centro de gravidade. Existem algumas variaçōes como o método $k$-Mode, que utiliza uma medida de distância diferente. K-means possui problemas de escalabilidade e produz agrupamentos de formas esféricas/convexas [Fei]. Também é afetado por ruídos, causando interferências na 
média dos agrupamentos.

Ao invés de ecolher a média dos objetos de um agrupamento como o centro do mesmo, escolhe-se o elemento mais central como o representante do agrupamento. A este elemento dá-se o nome de medóide. A técnica $k$-medoid é similar a k-means, porém as observações são atribuídas a um agrupamento baseando-se na similaridade ou proximidade que esta possue em relação ao medóide de um determinado agrupamento. A cada atribuição de uma observação a um agrupamento, um novo medóide é escolhido para o novo agrupamento. Esta técnica é menos sensivel a ruídos e sujeiras, embora computacionalmente mais demorada que $k$-means. Pelas vantagens citadas, escolhemos a técnica de $k$-medoid devido à menor sensibilidade a ruídos e sujeiras.

\section{A.1 PAM}

O algoritmo PAM (Partitioning Around Medoids), considerado tuma versão mais robusta do algoritmo $k$-means, baseia-se na busca por $c$ objetos representativos ou medóides entre todas as $n$ observações do conjunto de dados (banco de dados com $n$ séries temporais). Essas observações devem representar a estrutura dos dados. Após encontrar o conjunto de $c$ medóides, $c$ aglomerações são construídas através da atribuição de cada observação ao medóide mais próximo a esta observação. O objetivo é encontrar $k$ objetos representativos que minimizem a soma do quadrado das dissimilaridades das observaçōes a seus representantes. É considerado um algoritmo do tipo $k$-medoid [Fei].

Por padrão, quando os medóides não são especificados, o algoritmo primeiramente procura por um bom conjunto inicial de medóides (fase de construção - build). Então, tenta computar o mínimo local para a função objetivo, uma solução tal que não há uma única troca de observações com um medóide que decrementará a função objetivo (fase de troca ou rearranjo - swap). Uma das funções objetivo encontradas e mais utilizadas é encontrar o mínimo da soma do quadrado das distâncias euclidianas.

Quando os medóides são especificados inicialmente, a ordem deles não importa. Em geral este tipo de algoritmo é projetado para não depender da ordem das observações.

O algoritmo é extensamente descrito no capítulo 2 de [KR90]. Comparado à abordagem $k$ means, a implementação do algoritmo PAM no R por [MSH06] tem as seguintes características: (a) aceita uma matriz de dissimilaridade; (b) é mais robusto, pois minimiza a soma das dissimilaridades ao invés da soma do quadrado das distâncias euclidianas; (c) fornece uma 
função gráfica chamada impressão de silhueta (silhouette plot), a qual exibe a silhueta dos dados;

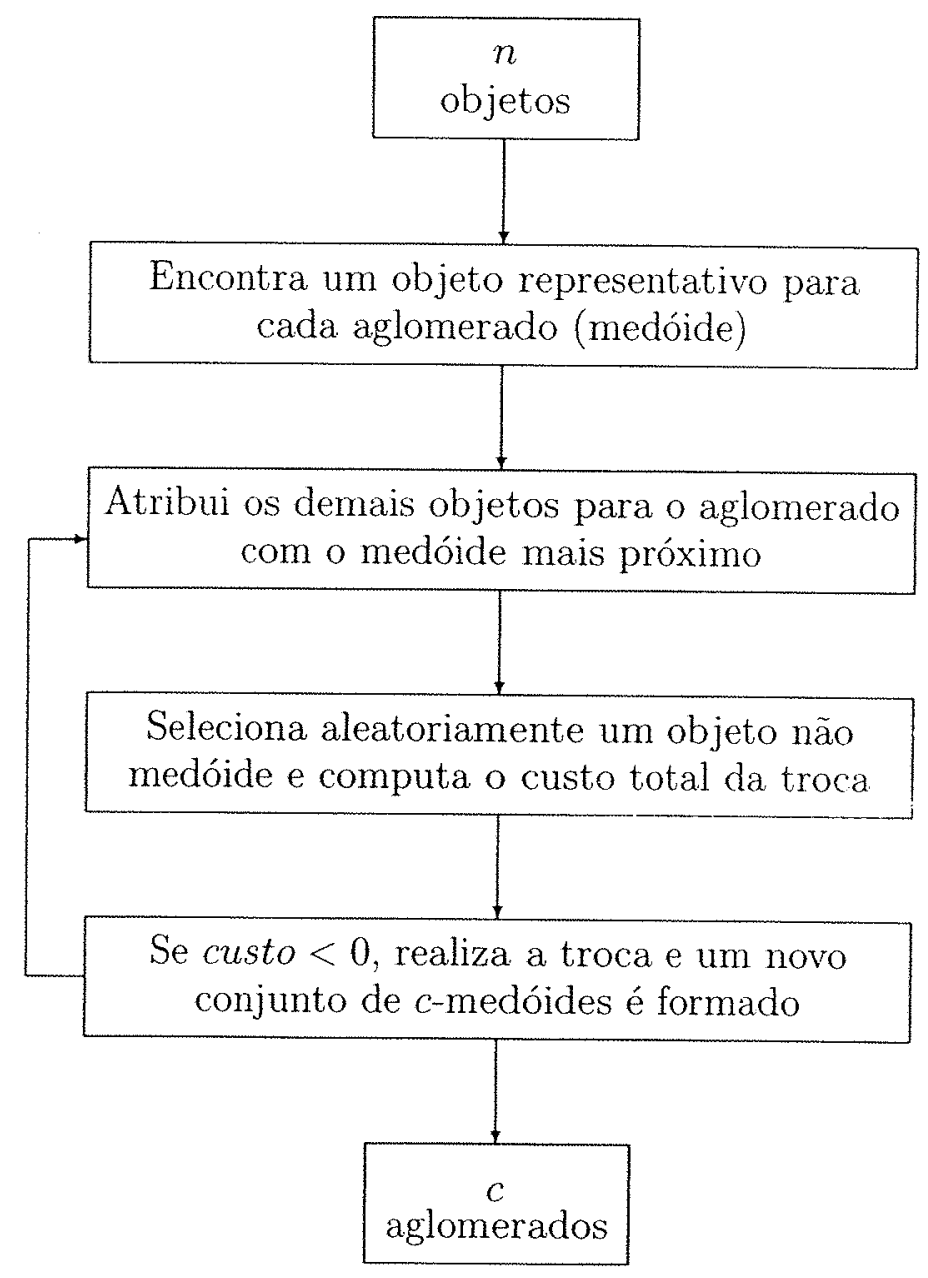

Figura A.1: Representação visual do algoritmo PAM

\section{A.2 CLARA}

Comparado ao algoritmo PAM, CLARA (Clustering LARge Applications) lida com conjuntos maiores de dados. $\mathrm{O}$ algoritmo também tenta encontrar $c$ objetos representativos que estão centralmente localizados nas aglomerações. Internamente, isso é alcançado considerando-se subconjuntos de dados de tamanho fixo, tornando linear o tempo de execução e armazenamento (espaço em memória) no número de objetos e não quadrático como acontece em PAM. 
O algoritmo é extensamente descrito no capítulo 3 de [KR90]. No PAM implementado por [MSH06], a coleção de todas as distâncias entre objetos é armazenada em memória, consumindo $O\left(n^{2}\right)$. Ao invés disso, CLARA trabalha apenas com as medidas atuais, ou seja, uma matriz $n \times p$ onde $n$ é o número de observações e $p$ é o número de elementos analisados em determinado instante.

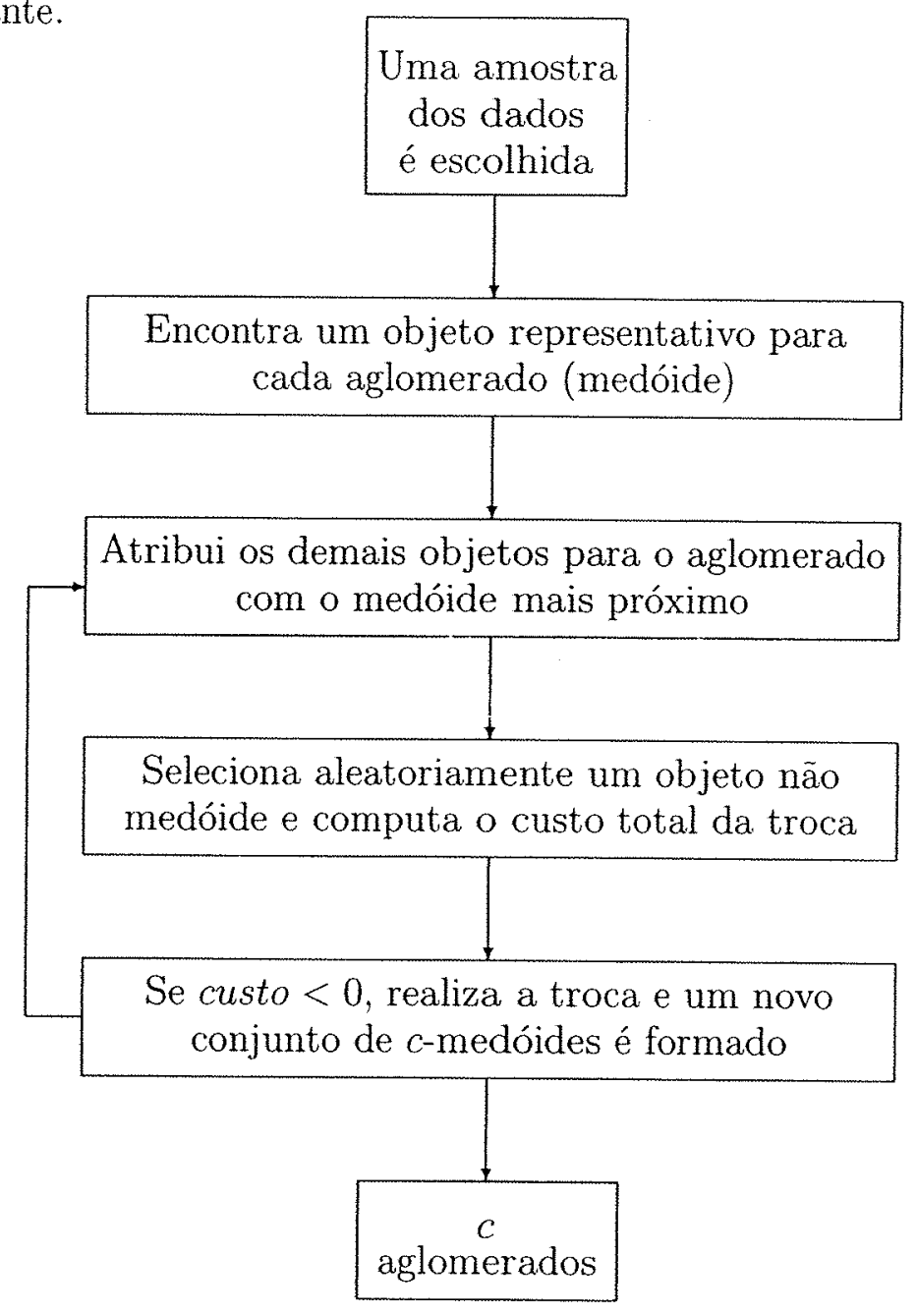

Figura A.2: Representação visual do algoritmo CLARA (Note que a única diferença com relação ao PAM, é que o algoritmo CLARA inicialmente não verifica todos os $n$ objetos de uma só vez)

O trabalho inicial de aglomeração divide-se em dois passos: primeiro uma escolha é feita no conjunto de objetos, dividindo-os em $c$ aglomerações, utilizando o mesmo método de PAM. O algoritmo consiste também de duas etapas: construção e troca. Na fase de construção, sucessivos medóides são escolhidos com o propósito de obter a menor distância média possível 
entre os objetos e seus respectivos representantes. Na fase de troca, tenta-se decrementar a distância média através da troca dos representantes. Então, cada objeto que não pertence à amostra, é atribuído ao medóide mais próximo, levando todos os objetos a pertencer a algum agrupamento.

A qualidade da aglomeração é definida como a distância média entre cada objeto e seu respectivo medóide. Este procedimento é repetido cinco vezes e o agrupamento com a menor distância é retido para análise futura.

A distância média final, média e maior distância para cada medóide é calculada do mesmo modo que PAM para todos os objetos. Também é calculada a taxa da máxima distância de um elemento do medóide com a menor distância de um elemento que não pertence a este medóide com relação ao mesmo. Esta taxa dá uma idéia do quanto um agrupamento é conexo. Um valor baixo (0.20) indica um agrupamento bem coeso, não disperso, enquanto que um valor maior que 1.00 indica um agrupamento com observações bem dispersas.

A silhueta do resultado de uma aglomeração utiliza apenas o melhor subconjunto de dados, para o qual o algoritmo terminou sua fase de trocas. Na figura A.3 temos um exemplo de uma silhueta.

A impressão de silhueta do resultado de um processo de aglomeração não hierárquico é descrita em descrito no capítulo 2 de [KR90]. Resumindo, para cada observação $i$, uma barra é desenhada, representando a largura de sua respectiva silhueta $s(i)$. As observações são agrupadas por aglomerados, com o aglomerado de número 1 no topo. Observações com valores de silhueta grande $(s(i) \approx 1)$ são bem aglomeradas, ao passo que valores pequenos de silhueta $(s(i) \approx 0)$ indicam que a observação está entre um aglomerado e outro. Valores negativos de silhueta indicam que a observação provavelmente está no aglomerado errado. 


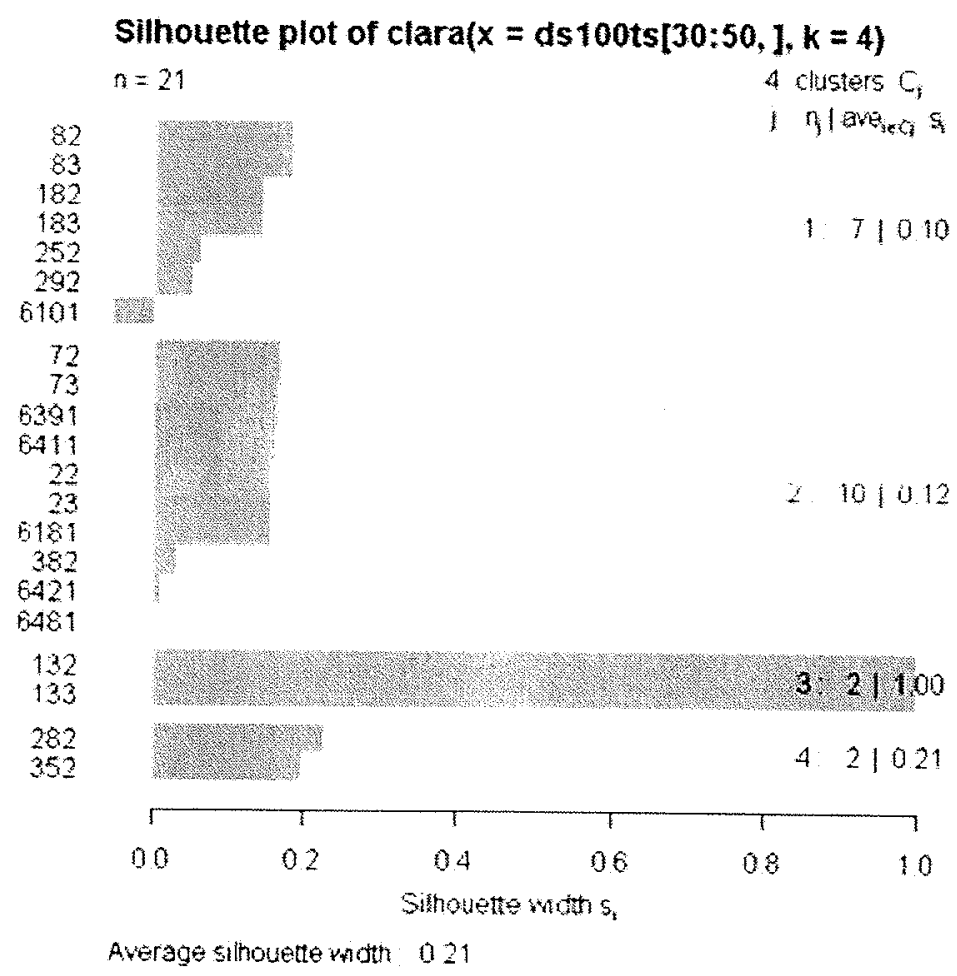

Figura A.3: Silhueta de 4 agrupamentos utilizando CLARA

(Resultado de uma aglomeração de 21 séries temporais em 4 agrupamentos utilizando algoritmo CLARA no sistema R. À esquerda o nome de cada observação. Observe o agrupamento 3, cujas duas observações são "100\%" similares) 


\section{Apêndice B}

\section{Implementação}

Nesta seção detalharemos as implementações dos algoritmos em português estruturado ${ }^{1}$.

Toda função criada possui sistemas de validação dos parâmetros de entrada. O código de ValidaçõesIniciais() é reponsável por isso e não será colocado aqui. Tratam-se de validações das entradas dos algoritmos, como receber $m$ negativo (número de pontos em uma série temporal reduzida), validar se $m$ é maior que o tamanho da série a ser reduzida, validar se o número $k$-NN é positivo, validar se $c$ aglomerados podem ser criados, etc.

Muitos pacotes do $\mathrm{R}$ foram testados e estudados. Os pacotes mais interessantes que achamos necessário mencionar são:

- RODC: Provém acesso ao SQL Server e outros Sistemas Gerenciadores de Banco de Dados (SGBD), escrito e mantido por [Rip06].

- tseries: Análise e impressão de séries temporais regulares, escrito por [Tra06].

- its: Análise e impressão de séries temporais irregulares, escrito por [GS05].

Para efetuarmos as combinações em IPA, utilizamos a função de combinação do pacote gregmisc, escrito por [War].

O algoritmo de redução de dimensionalidade DFT utiliza a transformação rápida de Fourier (função Fast Fourier Transform - FFT) que faz parte da instalação base do R. A mesma função calcula a transformada inversa de Fourier. A utilização de fft para reduzir uma série $\vec{x}$ de tamanho $n$ a uma série $\vec{X}$ de tamanho $N$ é dada abaixo:

\footnotetext{
${ }^{1}$ Alguns autores referem-se a pseudo-código ou portugol
} 


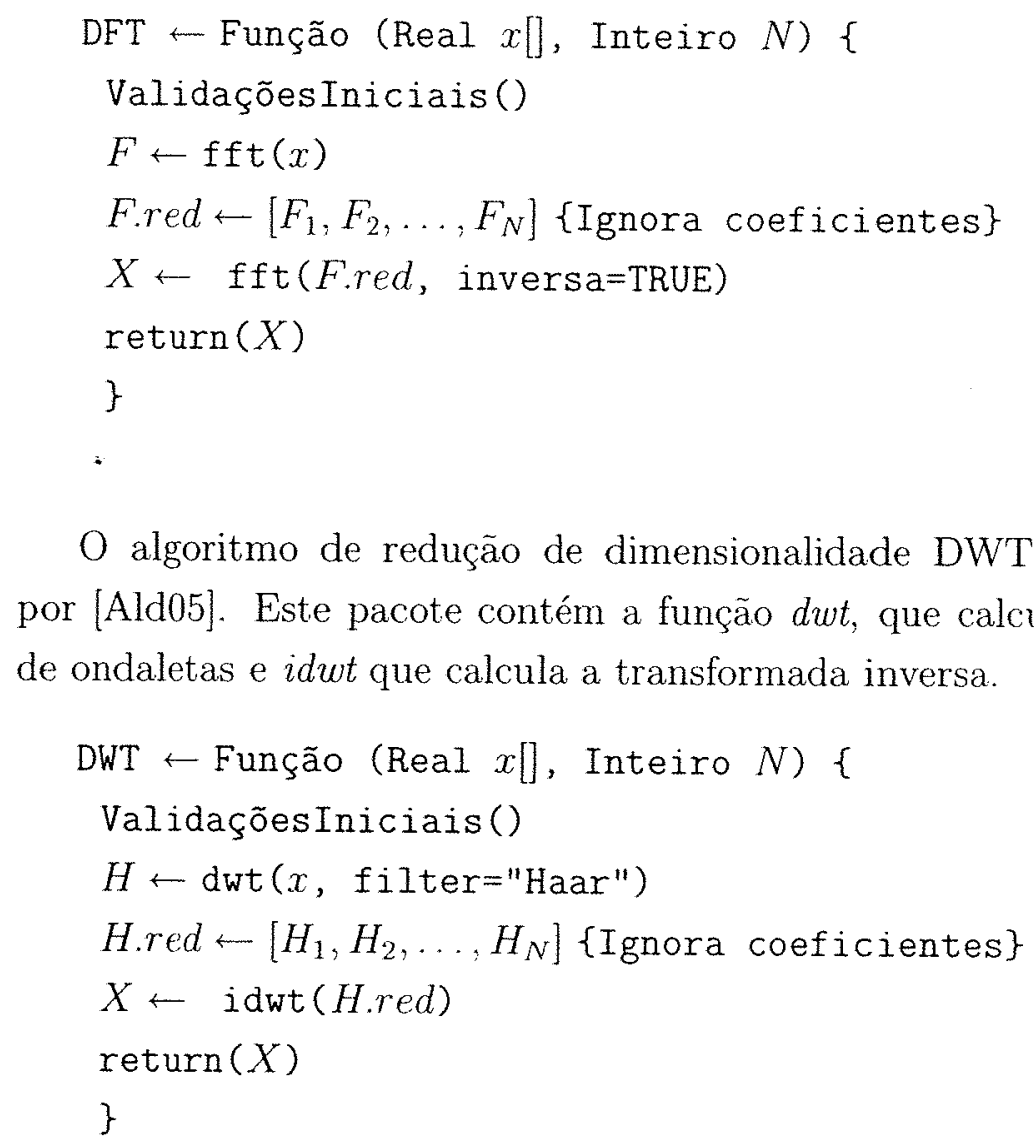
de ondaletas e $i d w t$ que calcula a transformada inversa.

O algoritmo de redução de dimensionalidade DWT utiliza o pacote wavelets escrito por [Ald05]. Este pacote contém a função dwt, que calcula os coeficientes da transformação

O algoritmo de redução de dimensionalidade PAA é bem simples de implementar, como segue abaixo:

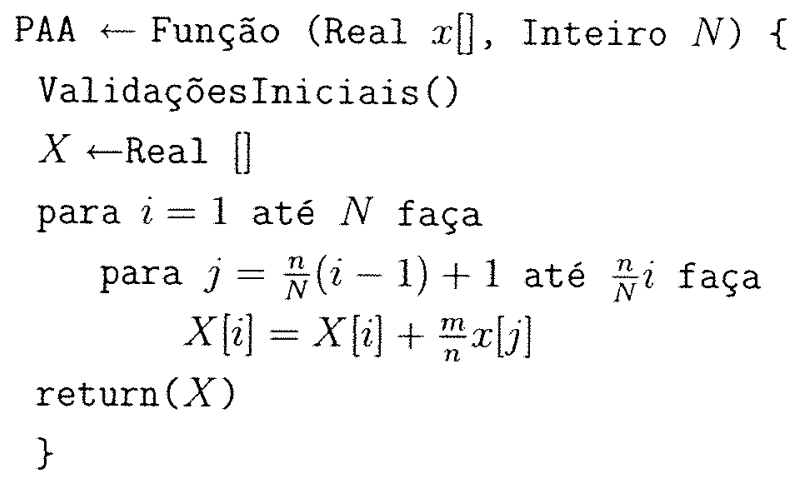

O algoritmo de redução de dimensionalidade PIP utiliza o conceito de distância vertical para a escolha dos pontos. Dados três pontos $A=\left(x_{A}, y_{A}\right), B=\left(x_{B}, y_{B}\right)$ e $C=\left(x_{C}, y_{C}\right)$ no plano 2-dimensional, a distância vertical entre a reta formada pelo segmento $\overline{A B}$ e o ponto $C$ é definida como:

$$
D(A, B, C)=\left|y_{A}+\left(y_{B}-y_{A}\right) \frac{\left(x_{C}-x_{A}\right)}{\left(x_{B}-x_{A}\right)}-y_{C}\right|
$$




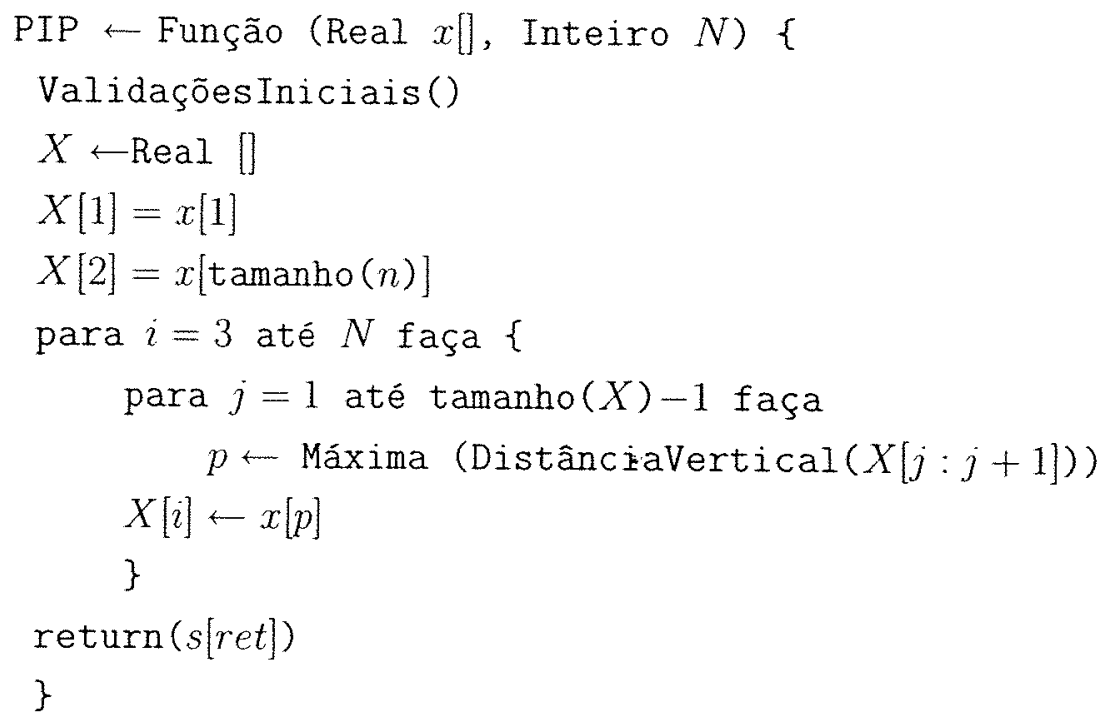




\section{Bibliografia}

[AFS93] Rakesh Agrawal, Christos Faloutsos, and Arun N. Swami. Efficient Similarity Search In Sequence Databases. In D. Lomet, editor, Proceedings of the 4th International Conference of Foundations of Data Organization and Algorithms (FODO), pages 69-84, Chicago, Illinois, 1993. Springer Verlag.

[Alc99] Robert Alcock. Synthetic control chart time series, Junho, 08 1999. This dataset contains 600 examples of control charts synthetically generated by the process in Alcock and Manolopoulos (1999).

[Ald05] Eric Aldrich. wavelets: A package of funtions for computing wavelet filters, wavelet tran. GPL version 2 or newer, Novembro, 02 2005. Versão 0.2-1.

[ALSS95] Rakesh Agrawal, King-Ip Lin, Harpreet S. Sawhney, and Kyuseok Shim. Fast similarity search in the presence of noise, scaling, and translation in time-series databases. In Twenty-First International Conference on Very Large Data Bases, pages 490-501, Zurich, Switzerland, 1995. Morgan Kaufmann.

[And73] Michael R. Anderberg. Cluster analysis for applications (Probability and mathematical statistics). Academic Press, Inc., Dezembro 1973.

[APWZ95] Rakesh Agrawal, Giuseppe Psaila, Edward L. Wimmers, and Mohamed Zaït. Querying shapes of histories. In $V L D B$ '95: Proceedings of the 21th International Conference on Very Large Data Bases, pages 502-514, San Francisco, CA, USA, 1995. Morgan Kaufmann Publishers Inc.

[BKSS90] Norbert Beckmann, Hans-Peter Kriegel, Ralf Schneider, and Bernhard Seeger. The $\mathrm{r}^{*}$-tree: an efficient and robust access method for points and rectangles. In SIGMOD '90: Proceedings of the 1990 ACM SIGMOD international conference on Management of data, pages 322-331, New York, NY, USA, 1990. ACM Press.

[CF99] Kin-pong Chan and Ada Wai-chee Fu. Efficient time series matching by wavelets. In Proceedings of the 15th IEEE International Conference on Data Engineering, pages 126-133, March 1999.

[CFNL04] Fu-Lai Chung, Tak-Chung Fu, Vincent Ng, and Robert W. P. Luk. An evolutionary approach to pattern-based time series segmentation. In IEEE Transactions on Evolutionary Computation, volume 8, pages 471-489, October 2004. 
[CN04] Yuhan Cai and Raymond Ng. Indexing spatio-temporal trajectories with chebyshev polynomials. In SIGMOD '04: Proceedings of the 2004 ACM SIGMOD international conference on Management of data, pages 599-610, New York, NY, USA, 2004. ACM Press.

[DGM97] Gautam Das, Dimitrios Gunopulos, and Heikki Mannila. Finding similar time series. In PKDD '97: Proceedings of the First European Symposium on Principles of Data Mining and Knowledge Discovery, pages 88-100, London, UK, 1997. Springer-Verlag.

[DLM+98] Gautam Das, King-Ip Lin, Heikki Mannila, Gopal Renganathan, and Padhraic Smyth. Rule discovery from time series. In KDD, pages 16-22, 1998.

[FCLN04] Tak-chung Fu, Fu-lai Chung, Robert Luk, and Chak-man Ng. Financial Time Series Indexing Based on Low Resolution Clustering. In The 4th IEEE International Conference on Data Mining (ICDM-2004) Workshop on Temporal Data Mining: Algorithms, Theory and Applications, pages 5-14, 1 november 2004.

[Fei] Matthew J. Feist. Summary of clustering techniques for data mining - a review of methods in jiawei han's book.

[FRM94] Christos Faloutsos, M. Ranganathan, and Yannis Manolopoulos. Fast subsequence matching in time-series databases. In SIGMOD '94: Proceedings of the 1994 ACM SIGMOD international conference on Management of data, pages 419-429, New York, NY, USA, 1994. ACM Press.

[GLT01] C. Lee Giles, Steve Lawrence, and Ah Chung Tsoi. Noisy time series prediction using recurrent neural networks and grammatical inference. Machine Learning, 44(1/2):161-183, 2001.

[Gon04] G. Z. Gondal. On the use of pdl, for domain independent and extensible pattern recognition. In 2nd International IEEE Conference, volume 3, pages 5-10, Junho 2004.

[Gra95] Amara Graps. An introduction to wavelets. IEEE Comput. Sci. Eng., 2(2):50-61, 1995.

[GS99] Valery Guralnik and Jaideep Srivastava. Event detection from time series data. In KDD '99: Proceedings of the fifth ACM SIGKDD international conference on Knowledge discovery and data mining, pages 33-42, New York, NY, USA, 1999. ACM Press.

[GS05] Portfolio Risk Advisory Group and Commerzbank Securities. its: Irregular time series. GPL Version 2, Maio, 26 2005. Versão 1.1.1.

[Gui00] Gabriela Guimarães. The induction of temporal grammatical rules from multivariate time series. In ICGI '00: Proceedings of the 5th International Colloquium on Grammatical Inference, pages 127-140, London, UK, 2000. Springer-Verlag. 
[HY99] Yun-Wu Huang and Philip S. Yu. Adaptive query processing for time-series data. In KDD '99: Proceedings of the fifth ACM SIGKDD international conference on Knowledge discovery and data mining, pages 282-286, New York, NY, USA, 1999. ACM Press.

[JLS] Xiaoming Jin, Yuchang Lu, and Chunyi Shi. Similarity measure based on partial information of time series.

[JMF99] Anil K. Jain, M. N. Murty, and Patrick J. Flynn. Data clustering: A review. ACM Computing Surveys, 31(3):264-323, Setembro 1999.

[KCMP01a] Eamonn J. Keogh, Kaushik Chakrabarti, Sharad Mehrotra, and Michael J. Pazzani. Dimensionality reduction for fast similarity search in large time series databases. Knowledge and Information Systems, 3(3):263-286, 2001.

[KCMP01b] Eamonn J. Keogh, Kaushik Chakrabarti, Sharad Mehrotra, and Michael J. Pazzani. Locally adaptive dimensionality reduction for indexing large time series databases. In SIGMOD Conference, 2001.

[Keo01] Eamonn J. Keogh. A tutorial on indexing and mining time series data, November, 292001.

[KJF97] Flip Korn, H. V. Jagadish, and Christos Faloutsos. Efficiently supporting ad hoc queries in large datasets of time sequences. In SIGMOD '97: Proceedings of the 1997 ACM SIGMOD international conference on Management of data, pages 289-300, New York, NY, USA, 1997. ACM Press.

[KP98] Eamonn J. Keogh and Michael J. Pazzani. An enhanced representation of time series which allows fast and accurate classification, clustering and relevance feedback. In Rakesh Agrawal, P. Stolorz, and G. Piatetsky-Shapiro, editors, Fourth International Conference on Knowledge Discovery and Data Mining (KDD'98), pages 239-241, New York City, NY, 1998. ACM Press.

[KP00] Eamonn J. Keogh and Michael J. Pazzani. A simple dimensionality reduction technique for fast similarity search in large time series databases. In T. Terano, H. Liu, and A. Chen, editors, Knowledge Discovery and Data Mining, Current Issues and New Applications, 4th Pacific-Asia Conference, PAKDD 2000, volume 1805, pages 122-133, Kyoto, Japan, 2000. Springer.

[KP01] E. Keogh and M. Pazzani. Derivative dynamic time warping, 2001.

[KR90] Leonard Kaufman and Peter J. Rousseeuw. Finding Groups in Data: An Introduction to Cluster Analysis. Wiley Series in Probability and Statistics. WileyInterscience, New York, 2rev ed edition (march 25, 2005) edition, 1990.

[KS97] Eamonn J. Keogh and Padhraic Smyth. A probabilistic approach to fast pattern matching in time series databases. In D. Heckerman, H. Mannila, D. Pregibon, 
and R. Uthurusamy, editors, Third International Conference on Knowledge Discovery and Data Mining, pages 24-30, Newport Beach, CA, USA, 1997. AAAI Press, Menlo Park, California.

[LKLC03] Jessica Lin, Eamonn Keogh, Stefano Lonardi, and Bill Chiu. A symbolic representation of time series, with implications for streaming algorithms. In $D M K D$ '03: Proceedings of the 8th ACM SIGMOD workshop on Research issues in data mining and knowledge discovery, pages 2-11, New York, NY, USA, 2003. ACM Press.

[LR98] Ling Lin and Tore Risch. Querying continuous time sequences. In Proc. 24th Int. Conf. Very Large Data Bases, VLDB, pages 170-181, 24-27 1998.

[Mei02] Marina Meilă. Comparing clusterings, Outubro, 202002.

[MH01] Marina Meilă and David Heckerman. An experimental comparison of modelbased clustering methods. Machine Learning, 42(1-2):9-29, 2001.

[Mor99] Pedro Alberto Morettin. Ondas e Ondaletas : Da Análise de Fourier à Análise de Ondaletas. Séries Temporais. EdUSP, 1 edition, 1999.

[Mör03] F. Mörchen. Time series feature extraction for data mining using dwt and dft, 2003.

[MSH06] Martin Maechler, Anja Struyf, and Mia Hubert. cluster: Cluster analysis extended rousseeuw et al. GPL version 2 or newer, Maio, 03 2006. Versão 1.11.0.

[PLC99] Sanghyun Park, Dongwon Lee, and Wesley W. Chu. Fast retrieval of similar subsequences in long sequence databases. In KDEX'99: Proceedings of the 1999 Workshop on Knowledge and Data Engineering Exchange, page 60, Washington, DC, USA, 1999. IEEE Computer Society.

[PW00] Donald B. Percival and Andrew T. Walden. Wavelet Methods for Time Series Analysis. Number 4 in Cambridge Series in Statistical and Probabilistic Mathematics. Cambridge University Press, Janeiro 2000.

[Ran71] William M. Rand. Objective criteria for evaluation of clustering methods. Journal of the American Statistical Association, 66(336):846-850, Dezembro 1971.

[Rip06] B. D. Ripley. Rodbc: Odbc database access. GPL2, Maio, 24 2006. Versão 1.1-7.

[SS99] Zbigniew R. Struzik and Arno Siebes. The haar wavelet transform in the time series similarity paradigm. In PKDD '99: Proceedings of the Third European Conference on Principles of Data Mining and Knowledge Discovery, pages 1222, London, UK, 1999. Springer-Verlag.

[SW90] Dennis Shasha and Tsong-Li Wang. New techniques for best-match retrieval. ACM Transactions on Information Systems, 8(2):140-158, Abril 1990. 
[Tea05] The R Development Core Team. The $\mathrm{r}$ project for statistical computing - a languagem and environment, 2005.

[TK06] S. Theodorids and K. Koutroumbas. Pattern Recognition. Academic Press, third edition, 2006.

[Tra06] Adrian Trapletti. tseries: Time series analysis and computational finance. GPL, Junho, 26 2006. Versão 0.10-3.

[WAA00a] Yi-Leh Wu, Divyakant Agrawal, and Amr El Abbadi. A comparison of dft and dwt based similarity search in time-series databases. In $\dot{C} I K M$ '00: Proceedings of the ninth international conference on Information and knowledge management, pages 488-495, New York, NY, USA, 2000. ACM Press.

[WAA00b] Yi-Leh Wu, Divyakant Agrawal, and Amr El Abbadi. A comparison of DFT and DWT based similarity search in time-series databases. In CIKM, pages 488-495, 2000 .

[War] Gregory R. Warnes. gregmisc: Backword compatibility package for gregmisc bundle. GPL (version 2 or later). Versão 2.0.8.

[WSA+96] Daniel Wu, Ambuj Singh, Divyakant Agrawal, Amr El Abbadi, and Terence R. Smith. Efficient retrieval for browsing large image databases. In CIKM '96: Proceedings of the fifth international conference on Information and knowledge management, pages 11-18, New York, NY, USA, 1996. ACM Press.

[WSHA04] Xiaozhe Wang, Kate A. Smith, Rob J. Hyndman, and Damminda Alahakoon. A scalable method for time series clustering. In Tech. Report Department of Econometrics and Business Statistics at Monash University, Victoria, Australia, 2004.

[XW05] R. Xu and D. Wunsch II. Survey of clustering algorithms. IEEE Transactions on Neural Networks, 16(3):645-678, 2005. 


\section{Índice}

Índices

IMP, 32

IPA, 35

IVI, 40

Aglomeração, 62

CLARA, 64

PAM, 63

Aglomerados

cálculo, 33

Algoritmos de redução

DFT, 16

DWT, 18

Lista de, 27

PAA, 24

PIP, 21

SOM, 11

Central de atendimento, 42

\section{DFT}

Portugol, 68

DWT

Portugol, 69

Fourier, 16

IMP, 32

IPA, 35

Limite, 39

IVI, 40

$K D D, 2$

Massa de dados, 43

Ondaleta(s), 18

\author{
Portugol, 69 \\ PIP \\ Portugol, 70 \\ Plataforma R, 44 \\ Portugol \\ DFT, 68 \\ DWT, 69 \\ PAA, 69 \\ PIP, 70
}

$\mathrm{R}, 44$

Range query, 13

Representações de séries, 8

Discretização, 10

Domínios contínuos, 8

Transformaçōes, 9

Resultados

IMP, 46

IPA, 51, 55

Séries temporais, 6

Similaridade, 11

Similaridade

busca, 31

Time Series, 6

PAA 


\section{Biografia do autor}

- Professor, Faculdade Sumaré, de 2005 a atual

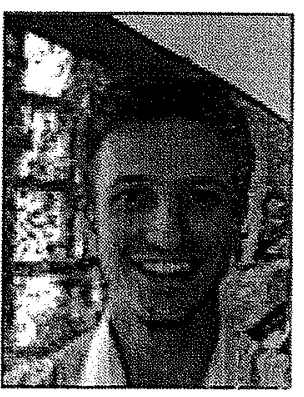

- Professor, Faculdade Impacta, de 2006 a atual

- Consultor de desenvolvimento de sistemas, de 1998 a atual

- Bacharel em Ciência da Computação, IME-USP em 2002

- Monitor de disciplina, IME-USP, de 2000 a 2002

Experiència de 8 anos em Tecnologia de Informação

Andre R. Sanches

- E-mail: andre@sanchesweb.com 